Universidad de Lima

Facultad de Ciencias Empresariales y Económicas

Carrera de Administración

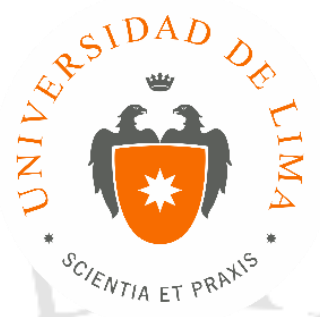

\title{
TALLERES MINDFULNESS Y SU IMPACTO SIGNIFICATIVO EN LA SATISFACCIÓN LABORAL EN LA EMPRESA RENTA 4
}

Trabajo de investigación para optar el Título Profesional de Licenciado en Administración

\section{Diana Luz Estacio Valverde}

Código 20090370

\author{
Asesor \\ Aldo Motta Ferreccio \\ Lima - Perú \\ Diciembre del 2018
}




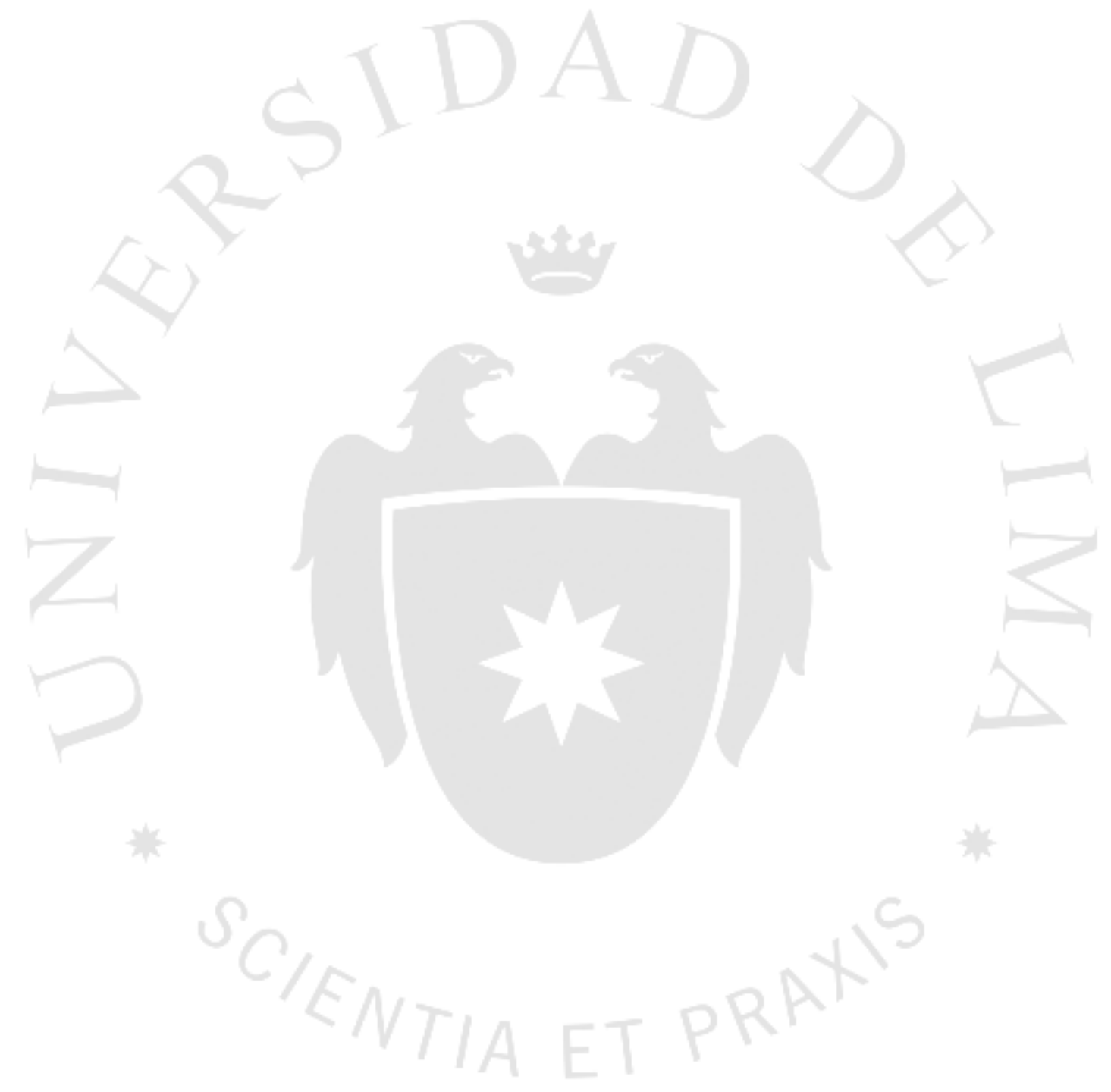


TALLERES MINDFULNESS Y SU IMPACTO SIGNIFICATIVO EN LA SATISFACCIÓN LABORAL EN LA EMPRESA RENTA 4 


\section{TABLA DE CONTENIDO}

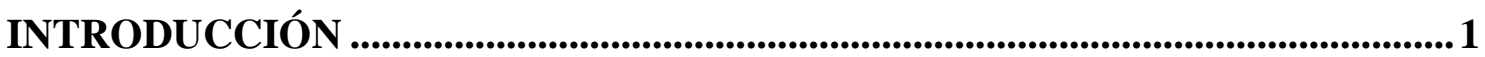

CAPÍTULO I. PLANTEAMIENTO DEL PROBLEMA.............................................. 3

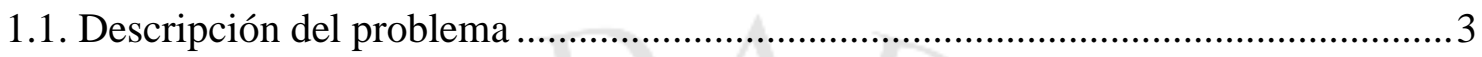

1.2. Formulación del problema ...........................................................................

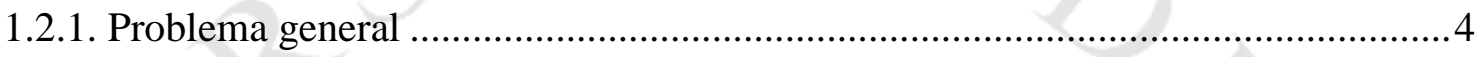

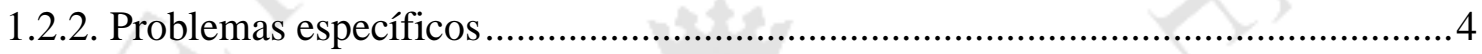

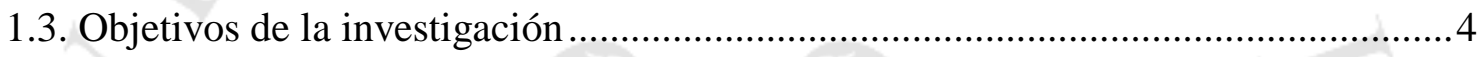

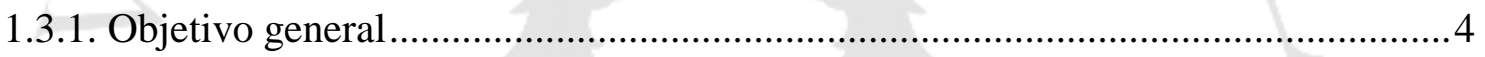

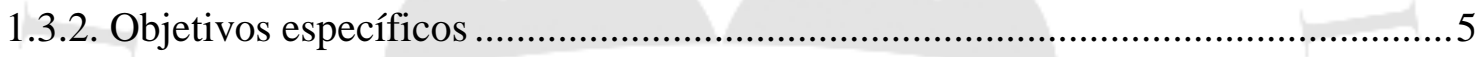

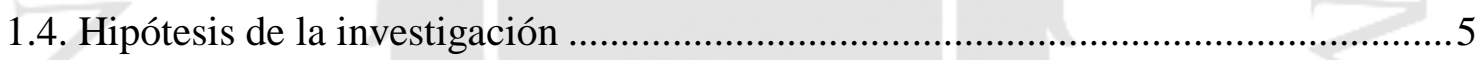

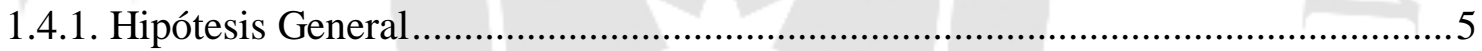

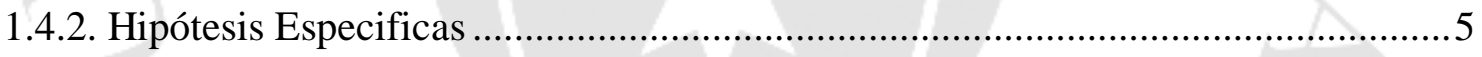

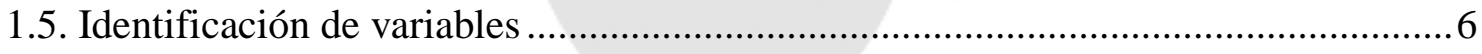

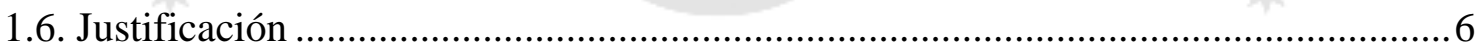

CAPÍTULO II. MARCO TEÓRICO .............................................................................. 7

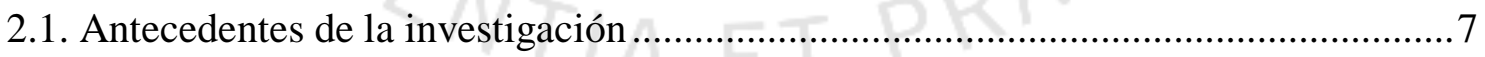

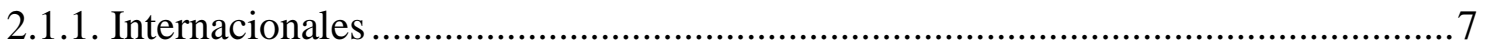

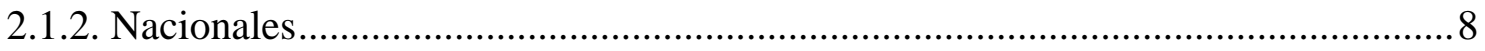

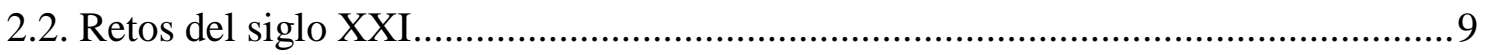

2.3. Impacto de la globalización y conexión en los empleados..................................... 10

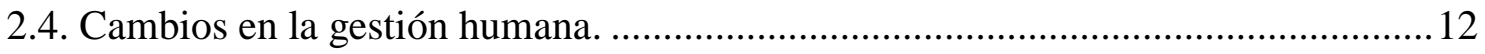


2.5.2. Origen e historia.

2.5.3. Beneficios generales del mindfulness

2.5.4. Beneficios del mindfulness en las organizaciones.

2.5.5. Talleres mindfulness

2.5.6. Programa de reducción de estrés en base a técnicas de mindfulness - MBSR.....29

2.5.7. Satisfacción Laboral .30

2.5.7.1. Definición 30

2.5.7.2. Factores que influyen en la satisfacción laboral. .31

2.5.8. Descripción de la empresa: Renta 4 SAB . .34

CAPÍTULO III. MARCO METODOLÓGICO .36

3.1. Tipo de investigación .36

3.2. Diseño de investigación .36

3.3. Población .37

3.4. Muestra .37

3.5. Técnicas e instrumentos de recolección de datos .38

3.5.1. Talleres mindfulness .38

3.5.2. Cuestionario de Satisfacción General - "Overall Job Satisfaction Scale". .39

3.5.3. Cuestionario operativo: mindfulness - Satisfacción laboral. .40

3.6. Técnicas de procedimiento y análisis de datos 41

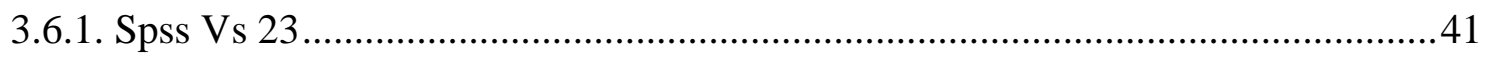

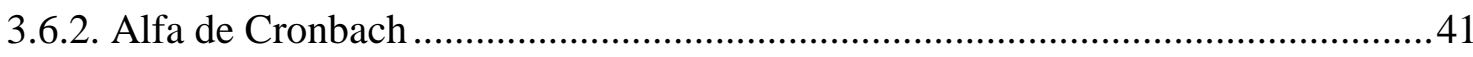

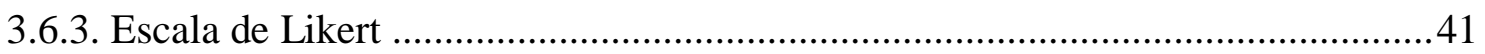

3.6.4. Coeficiente de Correlación Pearson..................................................................... 42 
CAPÍTULO IV. RESULTADOS............................................................................................43

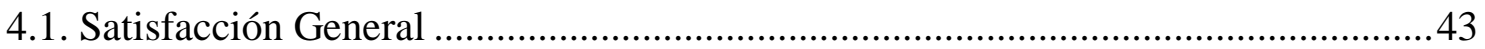

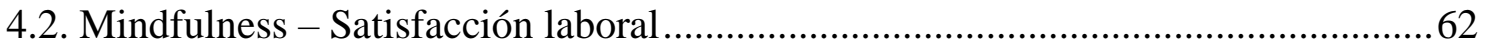

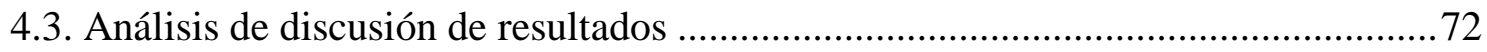

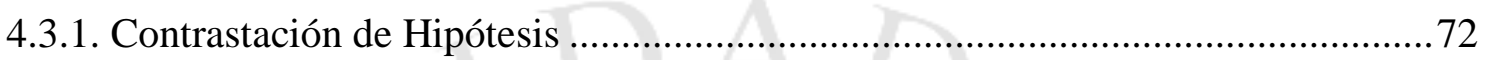

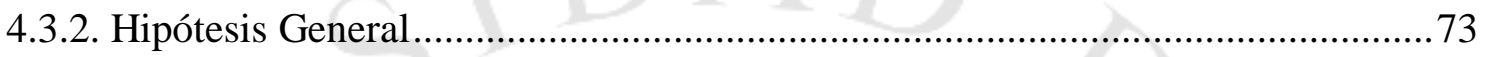

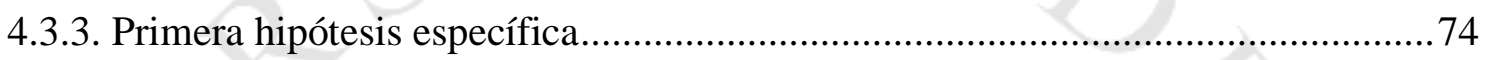

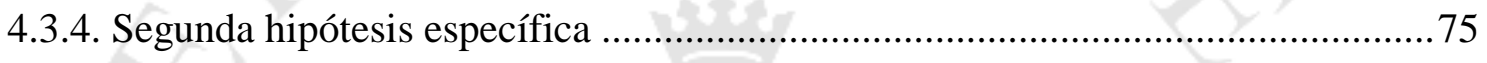

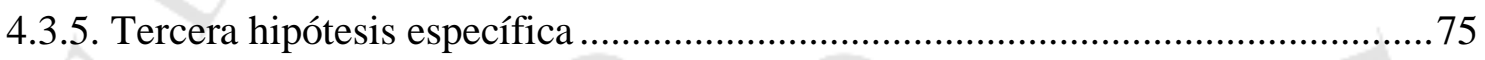

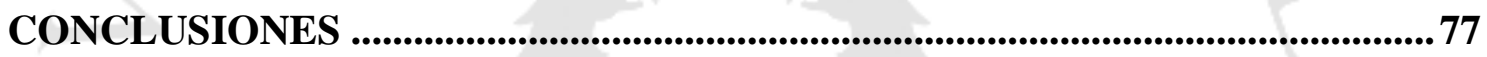

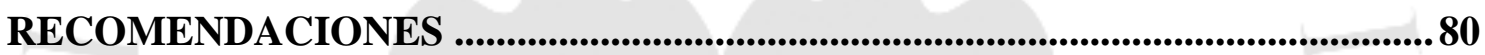

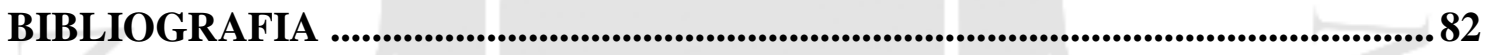

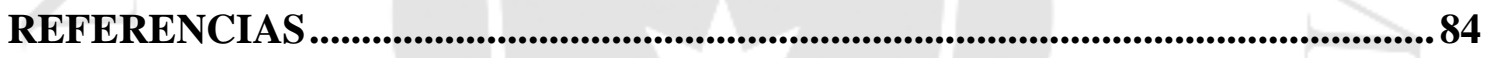

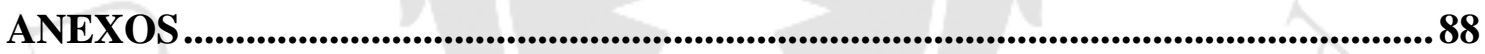




\section{ÍNDICE DE TABLAS}

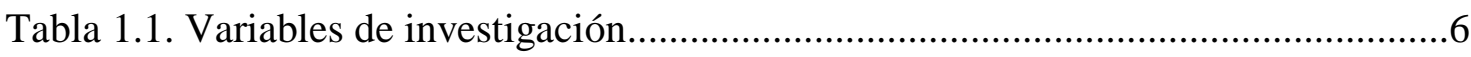

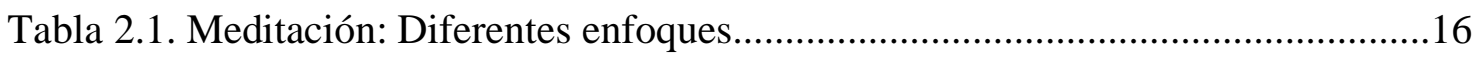

Tabla 3.1. Población de análisis en la investigación........................................................... 37

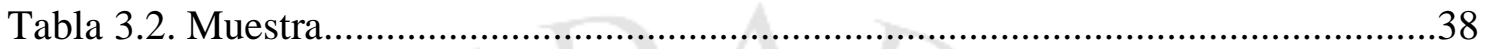

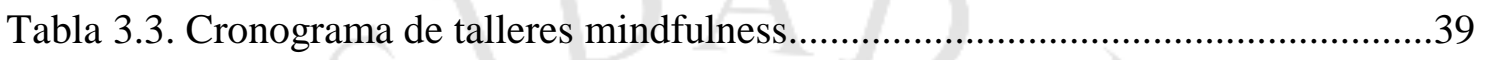

Tabla 3.4. Ficha técnica: Cuestionario de satisfacción general.....................................40

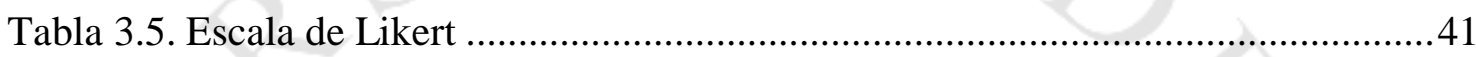

Tabla 3.6. Coeficiente de Correlación Pearson............................................................. 42

Tabla 4.1. Encuesta de Satisfacción General: Puntuación ................................................43

Tabla 4.2. Encuesta de Satisfacción General: Escala de satisfacción ...............................43

Tabla 4.3. Resultado de Satisfacción General en el trabajo...........................................44

Tabla 4.4. Encuesta de Satisfacción General: Preguntas intrínsecas.............................45

Tabla 4.5. Encuesta de Satisfacción General: Preguntas Extrínsecas............................46

Tabla 4.6. Resultados de la encuesta de Satisfacción General: Condiciones físicas de

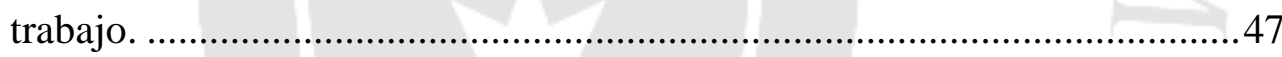

Tabla 4.7. Resultados de la encuesta de Satisfacción General: libertad para elegir

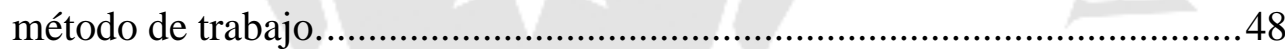

Tabla 4.8. Resultados de la encuesta de Satisfacción General: compañeros de trabajo. 49

Tabla 4.9. Resultados de la encuesta de Satisfacción General: reconocimiento por buen trabajo.

Tabla 4.10. Resultados de la encuesta de Satisfacción General: superior inmediato.....51

Tabla 4.11. Resultados de la encuesta de Satisfacción General: Responsabilidad

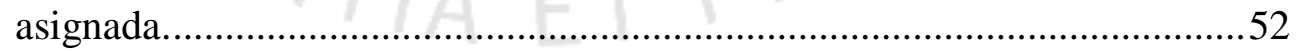

Tabla 4.12. Resultados de la encuesta de Satisfacción General: Salario ........................53

Tabla 4.13. Resultados de la encuesta de Satisfacción General: La posibilidad de utilizar sus capacidades.

Tabla 4.14. Resultados de la encuesta de Satisfacción General: Relación entre la dirección y los trabajadores

Tabla 4.15. Resultados de la encuesta de Satisfacción General: Posibilidad de promoción. 
Tabla 4.16. Resultados de la encuesta de Satisfacción General: Modo de gestión de la empresa.

Tabla 4.17. Resultados de la encuesta de Satisfacción General: La atención que se presta a las sugerencias que hace. .58

Tabla 4.18. Resultados de la encuesta de Satisfacción General: Horario de trabajo......59

Tabla 4.19. Resultados de la encuesta de Satisfacción General: Variedad de tareas asignadas.

Tabla 4.20. Resultados de la encuesta de Satisfacción General: Estabilidad en el empleo

Tabla 4.21. Análisis del Coeficiente de Cronbach 62

Tabla 4.22. Resultados del cuestionario operativo: pregunta 1.

Tabla 4.23. Resultados del cuestionario operativo: pregunta 2.

Tabla 4.24. Resultados del cuestionario operativo: pregunta 3.

Tabla 4.25. Resultados del cuestionario operativo: pregunta 4 ...................................65

Tabla 4.26. Resultados del cuestionario operativo: pregunta 5 ..................................66

Tabla 4.27. Resultados del cuestionario operativo: pregunta 6 ..................................67

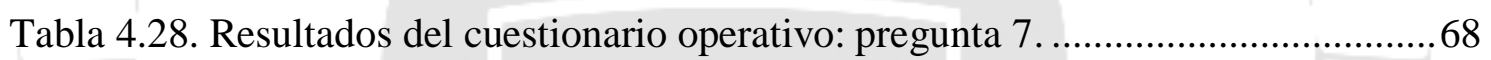

Tabla 4.29. Resultados del cuestionario operativo: pregunta 8 ..................................69

Tabla 4.30. Resultados del cuestionario operativo: pregunta 9 .................................. 70

Tabla 4.31. Resultados del cuestionario operativo: pregunta 10 ................................. 71

Tabla 4.32. Rangos de correlación Pearson................................................................... 73

Tabla 4.33. Resultados de la correlación de talleres mindfulness y la satisfacción laboral.

Tabla 4.34. Resultados de la correlación entre el MBSR y la Satisfacción laboral.........74

Tabla 4.35. Resultados de correlación entre las técnicas mindfulness y la satisfacción laboral.

Tabla 4.36. Resultados de la correlación entre los talleres mindfulness y la satisfacción laboral. .76 


\section{INDÍCE DE FIGURAS}

Figura 2.1. Impacto de la globalización en los puestos de trabajo. .............................. 10

Figura 2.2. Cuatro características que valoran las personas en una organización.........12

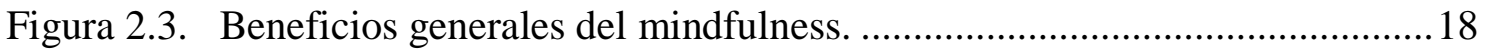

Figura 2.4. Beneficios del mindfulness en los empleados y las organizaciones...........22

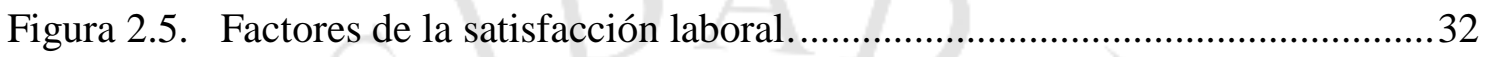

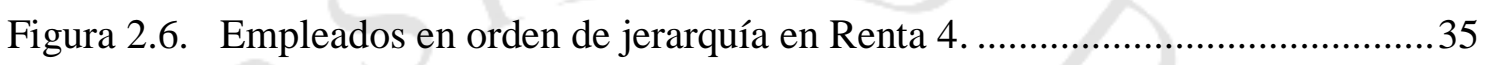

Figura 4.1. Resultado de Satisfacción General en el Trabajo......................................44

Figura 4.2. Resultados de la encuesta de Satisfacción General: Factores

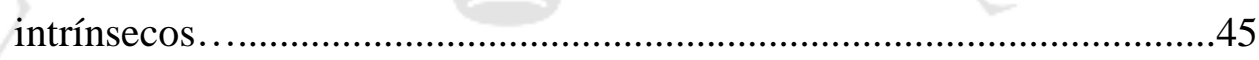

Figura 4.3. Resultado de la encuesta de Satisfacción General: factores extrínsecos.

Figura 4.4. Resultados de la encuesta de Satisfacción General: condiciones físicas de trabajo

Figura 4.5. Resultados de la encuesta de Satisfacción General: libertad para elegir método de trabajo.

Figura 4.6. Resultados de la encuesta de Satisfacción General: compañeros de trabajo.

Figura 4.7. Resultado de la encuesta de Satisfacción General: reconocimiento por buen trabajo. .50

Figura 4.8. Resultados de la encuesta de Satisfacción General: superior inmediato....51

Figura 4.9. Resultados de la encuesta de Satisfacción General: Responsabilidad asignada .52

Figura 4.10. Resultados de la encuesta de Satisfacción General: Salario .53

Figura 4.11. Resultados de la encuesta de Satisfacción General: La posibilidad de utilizar sus capacidades.

Figura 4.12. Resultado de la encuesta de Satisfacción General: Relación entre la dirección y los trabajadores.

Figura 4.13. Resultados de la encuesta de Satisfacción General: Posibilidad de promoción 
Figura 4.14. Resultado de la encuesta de Satisfacción General: Modo de gestión de la empresa.

Figura 4.15. Resultado de la encuesta de Satisfacción General: La atención que se le presta a las sugerencias que hace

Figura 4.16. Resultados de la encuesta de Satisfacción General: Horario de trabajo.....59

Figura 4.17. Resultados de la encuesta de Satisfacción General: Variedad de tareas asignadas

Figura 4.18. Resultados de la encuesta de Satisfacción General: Estabilidad en el empleo 61

Figura 4.19. Resultados del cuestionario operativo: pregunta 1. .63

Figura 4.20. Resultados del cuestionario operativo: pregunta 2 .................................64

Figura 4.21. Resultados del cuestionario operativo: pregunta 3...............................65

Figura 4.22. Resultados del cuestionario operativo: pregunta 4.................................66

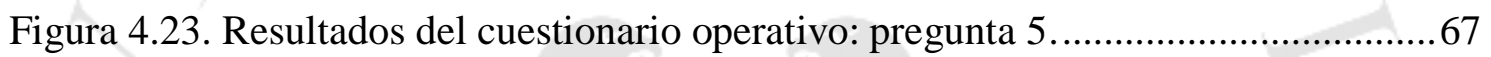

Figura 4.24. Resultados del cuestionario operativo: pregunta 6 .................................6 68

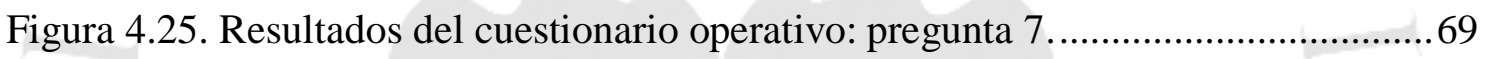

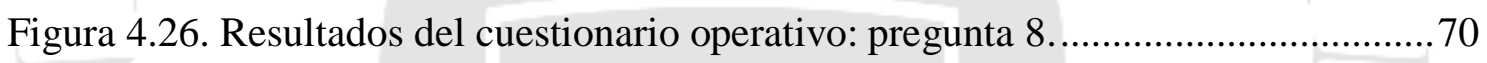

Figura 4.27. Resultados del cuestionario operativo: pregunta 9 .................................. 71

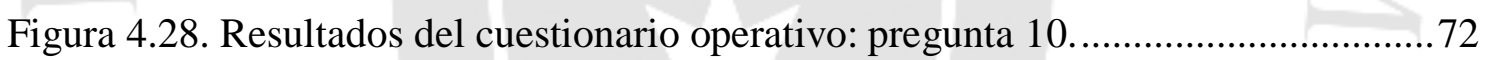




\section{ÍNDICE DE ANEXOS}

ANEXO 1: Encuesta de Satisfacción General - Adaptación de la "Overall Job

Satisfaction Scale" de Warr, Cook y Wall (1979).

ANEXO 2: Encuesta Operacional: mindfulness - Satisfacción Laboral .........................90

ANEXO 3: Contenido y herramientas de los talleres mindfulness. .............................. 91

ANEXO 4. Objetivos de los talleres mindfulness...................................................92 


\section{INTRODUCCIÓN}

Las organizaciones están expuestas a macro y micro entornos, con factores que impactan y generan cambios en su estructura, procesos, gestión, entre otros. En este siglo, los macro factores con mayor protagonismo son la globalización, la tecnología y la influencia social. Esto ha generado tendencias de impactos globales en las organizaciones, y como consecuencia de ello, el capital humano se ha convertido en uno de los factores más importantes como parte estratégica de la gestión de cambio.

Enfocada en el capital humano, esta investigación analiza los impactos que tienen los factores del macro entorno en las personas y sus tareas en el trabajo. La literatura especializada en recursos humanos muestra que, algunas veces los impactos en los empleados son negativos, influyendo en sus conductas, emociones y rendimiento laboral. Así mismo, se investiga los factores positivos que impactan en la satisfacción laboral, del cual se obtuvo como los más importantes: las emociones, los beneficios que te otorga la empresa y el equilibrio psicológico que el centro de trabajo les otorgue. Es así, que el contexto mencionado afecta en la satisfacción de los trabajadores.

En la actualidad, el mindfulness se encuentra en un momento de gran interés social, considerada una herramienta eficaz en la meditación y el bienestar. Siendo clasificado como un método que enseña a gestionar las emociones, actitudes y pensamientos con los que afrontamos la realidad. El mindfulness persigue encontrar el equilibrio en el conocimiento interno, gestionando las propias emociones para interactuar con el medio de la forma más eficaz posible. Esto abre un creciente campo de aplicaciones en ámbitos no solo médicos y psicológicos, como se ha profundizado en la actualidad, sino también en educación, productividad laboral y búsqueda del incremento del bienestar incluso en la población sana (Alberts, H., \& Hülsheger, U., 2015).

En esta investigación se propone al mindfulness como una herramienta para mejorar la satisfacción laboral. Principalmente busca comprobar el impacto positivo que 
tienen los talleres mindfulness en la satisfacción laboral. Por tal objetivo, se aplicaron los talleres en una empresa, Renta 4, para observar el impacto de los talleres mindfulness en los empleados.

Las herramientas que se utilizaron para la investigación fueron: tres tipos de talleres de mindfulness (yoga, meditación y mentalismo) y dos encuestas (satisfacción general y operacional), estas herramientas permitieron medir el impacto en los empleados y así mismo, hallar la relación entre las variables en estudio.

Finalmente, la investigación concluye con resultados positivos, por lo cual, se valida la hipótesis planteada, fortaleciendo la propuesta de utilizar los talleres mindfulness como una herramienta para mejorar la satisfacción laboral en una organización.

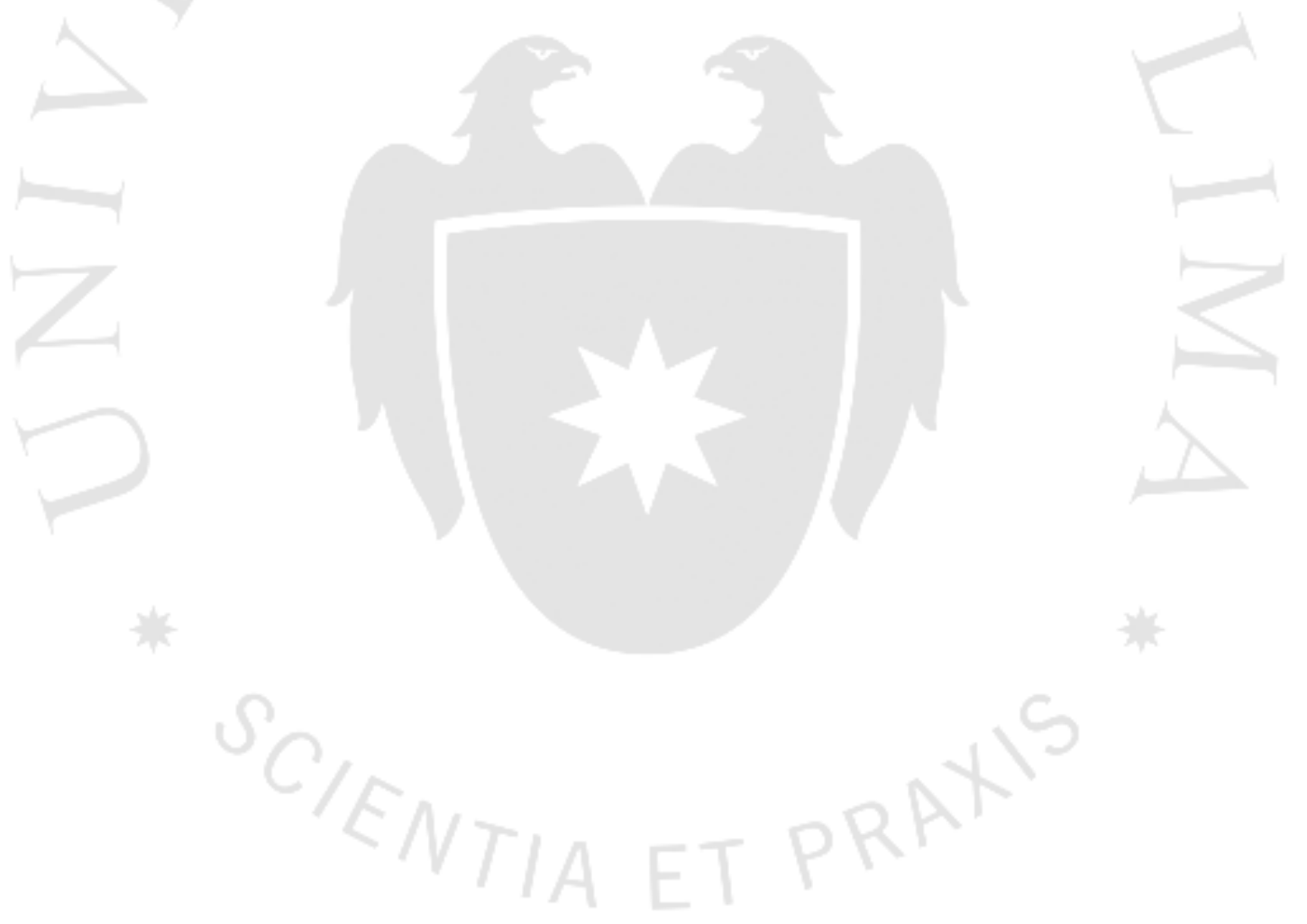




\section{CAPÍTUlo I. PLANTEAMIENTO DEL PROBLEMA}

\subsection{Descripción del problema}

La continua y acelerada trasformación de las organizaciones, las personas y la sociedad es evidente, sin embargo, la forma de afrontar o gestionar estos cambios no suele ser eficiente, porque olvidan el principal agente de cambio: las personas.

Los cambios en el macro entorno, tienen un impacto directo en el micro entorno de las organizaciones y este, un impacto directo en la gestión humana, porque los requerimientos de los colaboradores también cambian. Una de las características importantes contemporáneas, para los colaboradores, es sentirse bien en el lugar de trabajo que elijan, ya que es el lugar dónde las personas se desarrollan y sociabilizan la mayor parte de su día, y se podría decir, que la mayor parte de su vida, por lo cual, la satisfacción laboral del trabajador es un indicador contemporáneo vital para las organizaciones.

El reto más importante de la gestión humana es encontrar una herramienta que, ante un escenario en continuo cambio, mantenga el equilibrio, entre la calidad y el bienestar de sus colaboradores, debido a que el recurso humano es el mejor aliado para llevar a cabo estrategias que ayuden a conseguir objetivos, metas y/o resultados deseados en una organización.

Los talleres mindfulness son una herramienta contemporánea que optimiza los recursos mentales y el bienestar a la vez; te enseñan a tener una perspectiva positiva y constructiva de los escenarios que se presentan en el entorno, impactando de manera positiva en la interrelación con las personas; así mismo, mejoran la creatividad, la productividad y la estabilidad emocional en las personas.

En la empresa Renta 4, sociedad agente de bolsa, sujeto a nuestra investigación, en un primer momento se detectó insatisfacción laboral, siendo la causa principal la poca comunicación con los jefes y la mala relación e interacción entre compañeros de trabajo. Por ello, se tomó como caso de análisis, con el fin de mejorar la satisfacción laboral a través de los talleres mindfulness. 


\subsection{Formulación del problema}

\subsubsection{Problema general}

- ¿En qué medida los tallares de mindfulness impactan en la satisfacción laboral de todos los empleados de la empresa Renta 4 ?

\subsubsection{Problemas específicos}

- ¿Cuáles son los beneficios de la aplicación del mindfulness y cómo influye en la satisfacción laboral de los empleados de la empresa Renta 4, en el 2017?

- ¿Cómo influye el programa mindfulness Based Stress Reduction (MBSR) en la satisfacción laboral en los empleados de la empresa Renta 4, en el 2017?

- ¿Cómo influye las técnicas mindfulness en la satisfacción laboral de los empleados de la empresa Renta 4, en el 2017 ?

- ¿En qué medida la aplicación de talleres de mindfulness influye en el cuestionario de satisfacción general en los empleados de la empresa Renta 4, en el 2017?

\subsection{Objetivos de la investigación}

Los objetivos que buscamos en este estudio son de dos tipos:

\subsubsection{Objetivo general}

- Determinar en qué medida los talleres de mindfulness impactan en la satisfacción laboral de los trabajadores de la empresa Renta 4 Sociedad Agente de Bolsa S.A. 


\subsubsection{Objetivos específicos}

- Determinar en qué medida el programa de mindfulness Based Stress Reduction (MBSR) influye en la satisfacción laboral en los trabajadores de la empresa Renta 4, durante 2017.

- Determinar en qué medida el Técnicas de mindfulness influyen en la satisfacción laboral en los trabajadores de la empresa Renta 4, periodo 2017.

- Determinar cuáles son los beneficios de la aplicación de los talleres mindfulness y cómo influye en la satisfacción laboral en los trabajadores de la empresa Renta 4, periodo 2017.

- Determinar en qué medida la aplicación de talleres de mindfulness influye en el cuestionario de satisfacción general en los trabajadores de la empresa Renta 4, periodo 2017 .

\subsection{Hipótesis de la investigación}

Las hipótesis en este estudio son de dos tipos:

\subsubsection{Hipótesis General}

- Los talleres de mindfulness impactan positivamente en la satisfacción laboral de los trabajadores de la empresa Renta 4, periodo 2017.

\subsubsection{Hipótesis Especificas}

- El Programa de Mindfulness Based Stress Reduction (MBSR) influye significativamente en la satisfacción laboral en los trabajadores de la empresa Renta 4, periodo 2017.

- Las técnicas de mindfulness influyen significativamente en la satisfacción laboral en los trabajadores de la empresa Renta 4, periodo 2017.

- Los beneficios de la aplicación del mindfulness influyen significativamente en la satisfacción laboral en los trabajadores de la empresa Renta 4, periodo 2017. 
- La aplicación de los talleres de mindfulness influye significativamente en el cuestionario de satisfacción general de los trabajadores de la empresa Renta 4 , periodo 2017 .

\subsection{Identificación de variables}

Tabla 1.1

Variables de investigación.

Elaboración propia (2018).

\section{TIPOS DE VARIABLES}

\subsection{Justificación}

El problema de esta investigación se justifica porque los talleres mindfulness son herramientas que sirven de base para cualquier mejora o implementación de procesos en las organizaciones, siendo una herramienta eficiente para la mejora de la comunicación e interrelación de los trabajadores; y estos beneficios también mejoran la satisfacción laboral de la empresa.

Además, Renta 4 mejorará indirectamente su clima laboral, en base a la mejora de satisfacción laboral; los talleres mindfulness mejorarán la comunicación e interrelación entre compañeros del trabajo, impactando en la productividad y creatividad. 


\section{CAPÍTULO II. MARCO TEÓRICO}

\subsection{Antecedentes de la investigación}

\subsubsection{Internacionales}

- La compañía Google, desde el 2007 ha implementado un curso de mindfulness titulado "Search inside yourself", este programa se basó en enseñar a relacionarse de una mejor manera con ellos mismos y con los demás, así mismo, buscan reducir el estrés y calmar la mente. Como resultado, Google se posicionó el 2014 como la mejor empresa para trabajar. Esto fue resultado de los cursos, ya que, como resultado de ellos, se obtuvo que los empleados mejoraron su productividad, optimizaron sus tiempos en las tareas, mejoraron de sus decisiones, su capacidad de escuchar, tienen un enfoque positivo de las situaciones, aumentaron su creatividad y mejoró la interrelación entre compañeros (Baer,2014).

- Aetna, una compañía de seguros estadounidense, es otra de las empresas que implementó un programa de mindfulness en el adiestramiento de sus trabajadores. Desde la implementación de este nuevo hábito, ahorraron 2000 dólares por empleado en costos de atención médica y ganaron 3000 dólares por empleado en productividad. Los resultados del programa de atención plena se ven reflejados en los empleados, ya que reportó que eran más conscientes, más sanos, razonaban con mayor facilidad y estaban más enfocados (Atlantic, 2017).

- La universidad de Maastricht realizó una investigación para comprobar los beneficios del mindfulness en la satisfacción laboral; los resultados revelaron que la atención plena se enlaza de una manera positiva con la satisfacción laboral (Revista de psicología aplicada de la universidad de Maastricht, 2012).

- En la revista de psicología de la Pontificia Universidad Católica de Argentina, en un trabajo de investigación de los conceptos actuales de la satisfacción 
laboral, se afirmó que el concepto de satisfacción laboral se basa en emociones que percibe el trabajador o empleado. Además, se concluye que existe relación directa entre el bienestar percibido de cada uno, la vida personal de un empleado y la satisfacción laboral (Salessi, 2014).

\subsubsection{Nacionales}

- La entonces ministra de salud, Patricia García, afirmó, en el evento del Día internacional del yoga 2017, que esta práctica oriental es beneficiosa para la salud física y mental, libera tensiones y estrés. Así mismo, manifestó que implementaría esta práctica para los empleados y los pacientes en los hospitales con el objetivo de ayudar no solo en la recuperación de los enfermos si no también, en el bienestar del personal. (Minsa, 2017)

- En Lima, no existen estadísticas de empresas que hayan implementado los talleres mindfulness como herramienta para la satisfacción laboral. Sin embargo, Mercer, especialista en estudios estadísticos organizacionales, realizó un estudio de las tendencias de gestión de talento 2017 a nivel Latinoamérica, en dónde participaron las empresas más importantes para la economía peruana, la cual concluyó que la satisfacción laboral es un factor importante para dos de las tendencias de gestión del talento. Determinando que hoy en día los empleadores buscan un lugar de trabajo en donde se sientan bien y que esté compuesto por diferentes factores que van más allá de lo económico (Mercer, 2017).

- En una tesis de titulación, Universidad de Lima, en referencia del vínculo entre el feedback y la satisfacción laboral, se concluyó que uno de los factores más importantes en la satisfacción laboral es la relación entre jefe y subordinados, así como, la relación entre compañeros de trabajo (Ortiz, 2017).

- Así mismo, empresas consultoras, enfocadas en el capital humano, una de ellas: "ACH Consultoría y Activación del capital humano", han implementado conceptos y técnicas mindfulness en sus asesorías y actividades para capacitar y asesorar a sus clientes. De esta forma se ve 
insertada la herramienta de técnicas de mindfulness en las organizaciones en Perú.

\subsection{Retos del siglo XXI}

El mundo se ha transformado, explica Fernández (2017), es más volátil, globalizado e híper conectado. Estudios e investigaciones muestran un nuevo escenario de trabajo, conformado principalmente por distracciones sociodemográficas y tecnológicas, impactando en las organizaciones y los empleados, generando nuevos retos para ellos. (p.46).

Kotter (2007) afirma que actualmente nos enfrentamos a retos nuevos que los del siglo pasado. La mundialización está dirigida por un amplio y potente conjunto de fuerzas asociadas con los cambios tecnológicos y la integración económica internacional. Esto obliga a las organizaciones a llevar a cabo mejoras dramáticas no sólo para competir y prosperar, sino también simplemente para sobrevivir.

Shimon (2007) señalan que todos los fenómenos globales de desarrollo tecnológico y de aumento de las fronteras competitivas, representan una serie de retos para las empresas, centrados en incrementar la competitividad. Y esta, solo se puede obtener utilizando los recursos de una empresa de manera correcta y estratégica.

La velocidad de transformación del mundo, impacta en los modelos de gestión en las empresas; requiere agilidad, creatividad e innovación. Según Fernández (2017), esto genera nuevos requerimientos en las competencias y habilidades de las personas. La mayor conexión e información que existe en el entorno; la atención es el elemento clave del rendimiento. La complejidad del entorno requiere que los empleados tengan competencias tales como: trabajo en equipo, colaboración, adaptabilidad, pensamiento crítico, y flexibilidad cognitiva. Además, construir relaciones, conectar y comunicarse en distintas culturas, tener mesura en medio de una crisis, sobresalir de la adversidad y tener paciencia y tranquilidad ante la incertidumbre y la ambigüedad, son competencias que requiere el contexto de hoy. Así mismo, las organizaciones necesitan ser más flexibles, empáticas y ser más sensibles con su capital humano (p.47).

Así mismo, dentro de las empresas, explica Fernández (2017), en cada área y en los puestos de trabajo, la sobrecarga de información y la presión han aumentado, por restructuras en las organizaciones o un aumento en las tareas y responsabilidades, además 
estas se acumulan a diario y se superponen, generando una sobrecarga de información, la cual tienes que revisar (p.46).

\subsection{Impacto de la globalización y conexión en los empleados.}

Fernández (2017), describe el impacto que tiene la globalización en las personas y las consecuencias de ellas en su puesto de trabajo. Los clasifica en cuatro:

Figura 2.1

Impacto de la globalización en los puestos de trabajo.

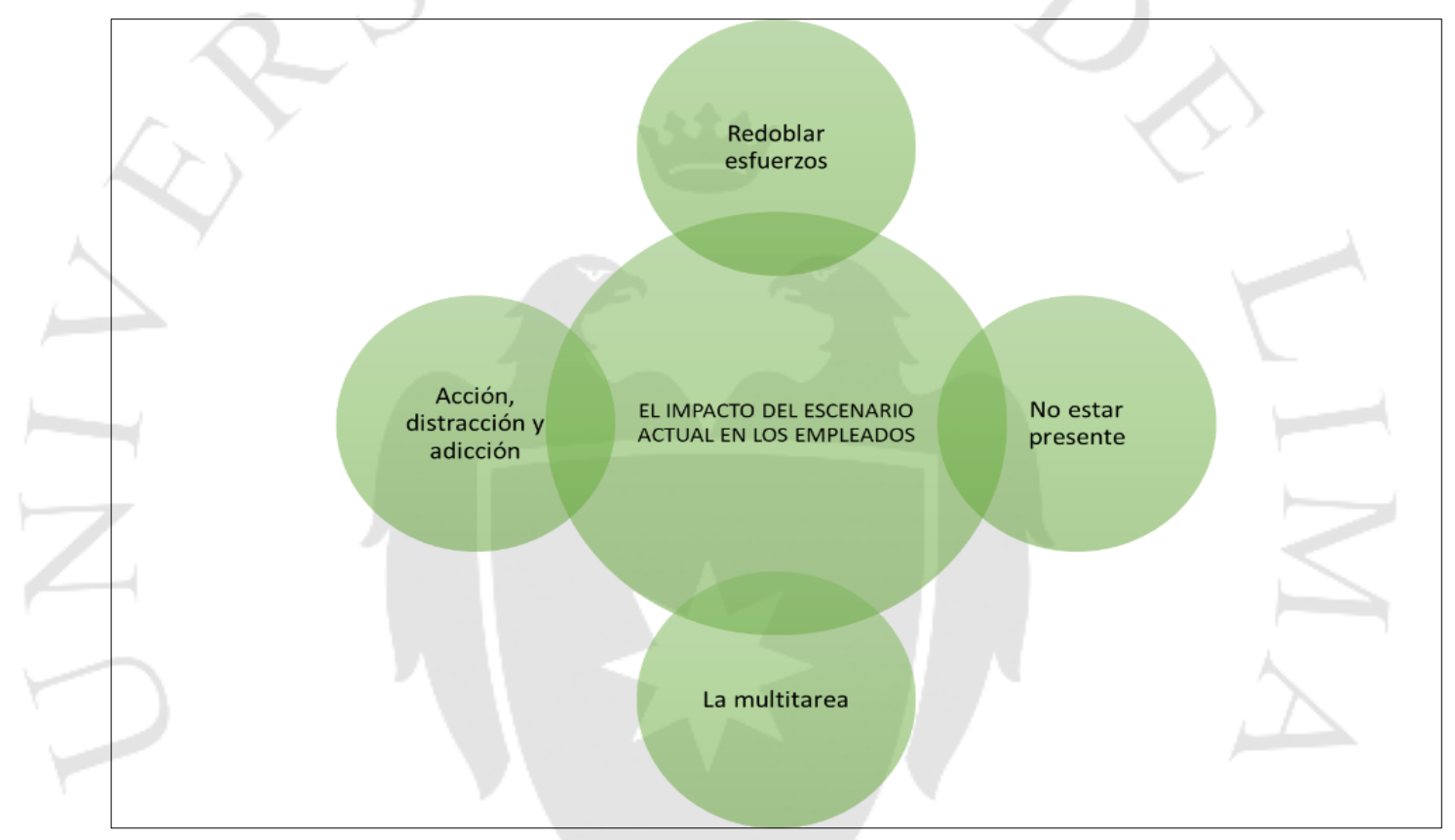

Fuente: Fernández, Estrella (2017).

Elaboración propia.

- Redoblar esfuerzos. Debido a la sobrecarga, de información y trabajo, empuja a los empleados a duplicar esfuerzos para reducir la inevitable sensación de falta de control e incumplimiento. Este esfuerzo adicional, implica prescindir de las cosas que le gustan a una persona, fuera de la oficina, para centrarse en el trabajo (aficiones, amigos, deporte, etc.). Esto, reduce el tiempo para la vida personal, y con ello, tu tiempo de descanso y tiempo personal, que son los generadores de energía que el cerebro requiere. Y si este no se gestiona, conduce a la desmotivación y al agotamiento (p.46). 
- No estar presenta, atención dividida. Cuando el tiempo y el esfuerzo aumentan, la presencia, disminuye. Nuestra mente se distrae regresando al pasado o en el futuro, generando una lista grande de pendientes, conformada por problemas y tareas que al momento no le corresponden. Esta acción de vivir y recordar los pendientes en los momentos que no le corresponde, es la causa principal de la ansiedad y estrés (p.46).

- Multitarea. Es una reacción natural a los excesos de tareas, pendientes y trabajo, forzando al cerebro atender a todas a la vez, y creando una esperanza en la mente de poder solucionar todo al mismo tiempo y de manera rápida; sin embargo, fisiológicamente, nuestro cerebro no está diseñado para ello; por lo tanto, la multitarea, no existe. Lo que realmente las personas hacen es modificar la atención de una tarea a otra, minimizando la productividad, ya que se generan más errores, por lo tanto, necesitas más tiempo, y te vuelves menos productivo. Así mismo, tiene un impacto negativo en el bienestar personal, ya que el llevar nuestra atención de un lado a otro, estimula el estrés, generando más hormonas que generan esta. Y, también se ve afectada la creatividad, debido a un aumento del estrés. Esto se resume en que la multitarea y las distracciones hacen a las personas ineficaces (p.47).

Acción, distracción y adicción. A diferencia del entorno que pueden afectar a una persona, existen razones biológicas que generan la distracción de forma automática y adictiva. Un ejemplo de ello, es estar constantemente pendiente de un chat o mensaje mientras realizas alguna tarea; al hacerlo, esto produce una gratificación automática. La dopamina, que se genera en el centro de recompensa cerebral, sustancia química que genera bienestar, sensación de logro o placer, amortigua la insatisfacción que se puede sentir. Como toda adicción, mientras más se repite la conducta, se refuerza la adicción. Por ello, se puede concluir que estamos diseñados para distraernos. Así mismo, si se quiere terminar con una adicción, se requiere determinación, autoconsciencia y habilidad para dirigir la atención, y enfocarla en los objetivos que se quiere alcanzar (p.47). 


\subsection{Cambios en la gestión humana.}

El contexto de cambio continuo en el que se desenvuelven las organizaciones, ha modificado la forma de gestionar a las personas, debido a que tenemos más conciencia de cómo impacta en ellas el desempeñar un puesto de trabajo, como explica Fernández (2017).

Un contexto globalizado también impacta en las necesidades de las personas y en lo que ellas quieren en su centro de trabajo. En un estudio realizado por Mercer (Mercer, 2017), acerca de las tendencias globales de gestión de talento en Latinoamérica, identificó cuatro características que las personas valoran en una organización. Analicemos:

Figura 2.2

Cuatro características que valoran las personas en una organización
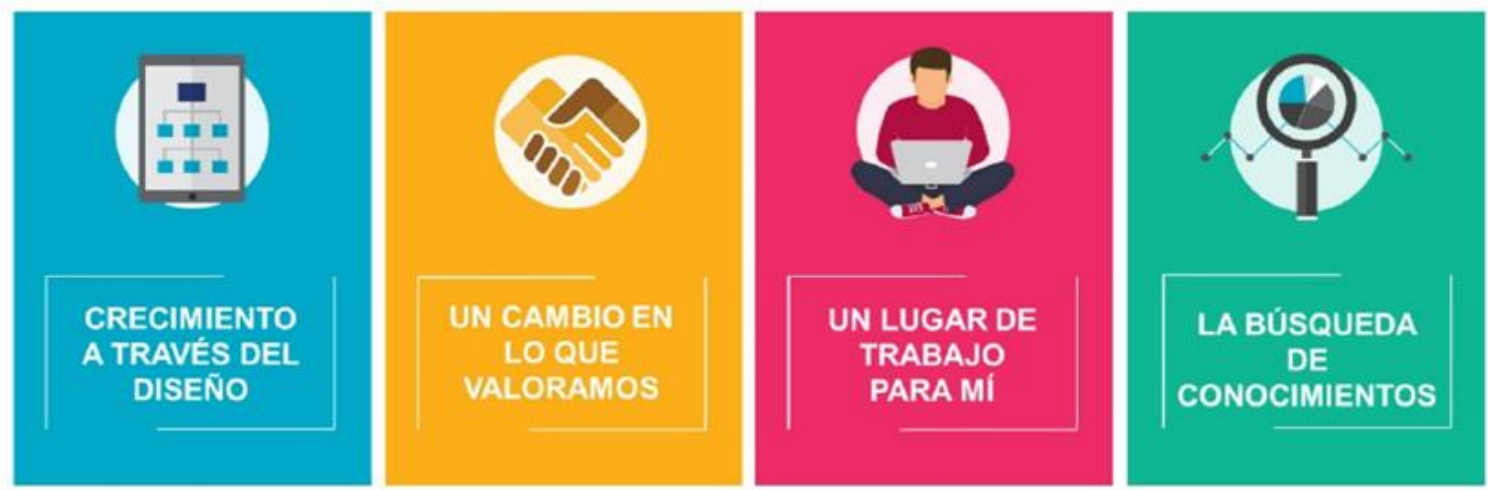

Fuente: Mercer (2017).

1) El crecimiento a través del diseño. Se refiere a la importancia de la estructura organizacional, ya que esta muestra información a los colaboradores acerca del gobierno corporativo de la empresa. Una buena estructura organizacional es el reflejo de rentabilidad y competitividad; muestra una organización sin problemas de recortes de personal o indicadores alta rotación de personal. Y esto les permite a los colaboradores ver las probabilidades de un crecimiento laboral a corto o largo plazo en un puesto de trabajo.

2) Un cambio en lo que valoramos. Se refiere a lo que hoy las personas valoran en una organización: buen gobierno corporativo. Haciendo énfasis en la transparencia, valores y ética que demuestran las empresas. Siendo muy importante la claridad en sus procesos, y explicación de los pagos y beneficios que recibe cada uno de los colaboradores. 
3) Un lugar de trabajo para mí. Se refiere a los beneficios que la empresa le ofrece al colaborador. Teniendo como prioridad aquellos que le permitan tener ese punto de equilibrio entre lo laboral y lo personal, que respeten sus tiempos y espacio personal.

4) La búsqueda de conocimientos. Se refiere a los beneficios que las empresas ofrezcan según el perfil de sus necesidades e interés tanto laborales como personales. A esto se le denomina en las empresas: inteligencia del negocio. Es una forma de decirle a los colaboradores, por parte de la empresa, que se interesan realmente por sus necesidades y en general, por su capital humano.

El estudio realizado por Mercer, muestra cambios en los requerimientos de las personas, así como las expectativas que tienen de las organizaciones. Por el lado, las organizaciones requieren de colaboradores con competencias, antes mencionadas, que generen valor en un contexto globalizado.

\subsection{Mindfulness}

\subsubsection{Definición}

El término mindfulness es una palabra de origen anglosajón que tiene difícil traducción al castellano. Aunque no existe una definición exacta, se le conoce como "atención plena" o "conciencia plena".

Kabat-Zinn (2012), referente mundial del mindfulness, define el mindfulness como atención plena, que significa prestar atención al momento presente sin prejuicios, en la vida cotidiana.

Para Bishop y su equipo (2004), el mindfulness está compuesto por la autorregulación y la actitud ante la experiencia. Definiendo autorregulación como la capacidad que desarrolla una persona para mantener la atención exclusivamente en la experiencia que está viviendo en ese momento, lo que le permite una mayor percepción de la misma. Y, por otro lado, se entiende por actitud su capacidad de observación sin centrarla en el yo, sino focalizada en lo que está sucediendo. Esta actitud también involucra la apertura, la curiosidad y la tolerancia de la experiencia vivida. 
Sánchez (2011), define al mindfulness como algo difícil de definir, ya que es un proceso de estar presente y genera en las personas: una a) gran sensibilidad por nuestro entorno, b) mayor apertura y c) conciencia para resolución de conflictos.

Para Alberts (2017), mindfulness implica prestar toda su atención de una manera consciente a lo que uno está haciendo o experimentando en un momento dado, siendo consciente de las sensaciones corporales, los pensamientos y las emociones, para relacionarse con una actitud abierta y sin prejuicios.

Siegel (2010) plantea el mindfulness como herramienta eficaz para mejorar las funciones cognitivas y las relaciones interpersonales. Según este autor, el mindfulness es prestar atención con conciencia plena a los momentos vividos, mediante una presencia activa y reflexiva.

Desde un enfoque organizacional, Steve Jobs, quién es uno de los referentes a dar a conocer la práctica del mindfulness en el ámbito empresarial, definió al mindfulness como una disciplina transformadora que te ayuda a calmar la mente y es ahí donde la intuición empieza a florecer; entonces se empieza a ver las cosas con mayor claridad, a estar presente en el presente. Te da una perspectiva diferente, ves mucho más de lo que podías ver antes (Isaccson, 2015).

Con un enfoque organizacional, Hugo Alberts (2017), define el mindfulness como un facilitador del afecto que regula las emociones, esto ayuda a los empleados a lidiar con altas demandas emocionales del día a día en el trabajo; así mismo, los ayuda a cultivar una reacción positiva frente a situaciones estresantes, mejora la productividad y la satisfacción laboral.

\subsubsection{Origen e historia}

La palabra mindfulness se basa, en conceptos de meditación, ya que, en cualquier actividad de mindfulness interviene la meditación, definiéndolo como el espacio entre un pensamiento y otro, en donde te permite sintonizar con todo (Chopra, 2012).

Sánchez (2011) explica el origen e historia de la meditación:

La meditación tiene origen antes de la llegada de Jesús a la tierra. Según la historia oficial de la meditación, desde un enfoque oriente-occidente, esta tiene origen en las sociedades orientales. 
En el Siglo VI a.C., las culturas védicas se enfocaban en la enseñanza de los principios de la vida, a nivel espiritualidad. Como ejemplo, tenían figuras prototipo que les mostraba el camino correcto que debían seguir para ser un humano ideal, que trasciendan y superen los valores limitantes en la existencia cotidiana. En base a las sociedades y sus características correspondientes, existieron varios caminos de crecimiento espiritual a través de la meditación, con características en común, pero diferentes objetivos. (p.225).

McIntosh y equipo (como se cita en Sánchez, 2011), explican el origen e historia del budismo:

El budismo zen proviene del sánscrito, que surge de la filosofía hindú, cuyo significado es meditación. Esto es lo que enseña Siddartha Gotama, Buda, el cual su apodo tiene el significado de "el que sabe", el cual ha logrado un nivel de madurez y comprensión que por lo tanto lo hace un humano ideal inspirado por alguna de las divinidades. El budismo ha llegado a diseminarse por historias de maestros y discípulos, y luego por recolección de los antiguos textos sagrados. Lo más importante de un budista es la iluminación, la liberación espiritual de las posesiones del ego, las comodidades, la familia. Esto implica llegar al ascenso espiritual, también liberándose de toda pasión y las ataduras que con llevan a la misma, reconociendo y admitiendo que el sufrimiento es inevitable. Las empatías extremas llegan a distraer a las personas de vivir y disfrutar plenamente el presente. Si se plasma en la geografía el budismo zen se inicia en la India y emigra hacia Nepal, Japón, China, Vietnam (p.226).

Sánchez (2011), señala en su investigación el origen e historia del yoga:

El yoga, palabra originaria de la lengua sánscrita, significa unión. El yoga se basa en la unificación de un conjunto de actividades: la meditación, la disciplina corporal, los cánticos e himnos religiosos. El origen y las bases del yoga proviene del libro sagrado "Los Yoga Sutras de Patanjali”. Sutra significa hilo o también conocido como: el cordón sagrado. Este libro fue escrito por el sabio Patanjali en el año 150 a.C. En el libro sagrado se muestra un código de conducta, meditando cada aspecto de la vida, con el objetivo de vivir en paz, equilibrio y armonía mental. Para Patanjali, el purusha o espíritu viene siendo la conciencia pura, y la meditación unifica la mente con el cuerpo. Y la iluminación 
es un estado donde la unión se desvanece y queda solo presente el significado del objeto por el cual la atención se fija (p.226).

Fadigan y Frager (como cita Sánchez, 2011, p.227) en su investigación muestran el origen e historia del sufismo:

El sufismo El sufismo significa espiritualidad. Se utilizó este término para referirse a la parte mística y espiritual del islam. El término también hace referencia a un tipo de psicología islámica cuyo objetivo era conocer y purificar el alma, consiguiendo la nobleza del carácter. En su generalidad se conoce al sufismo como el camino de la auto realización, basados en el conocimiento y el amor. Sus actividades principales son la cuestión de todo lo que sucede y la meditación de cada uno de ellos. Teniendo como centro la aproximación de sus enseñanzas con Dios (p.227).

Tabla 2.1

Meditación: Diferentes enfoques.

\begin{tabular}{|c|c|c|c|}
\hline & EL BUDISMO ZEN & EL YOGA & EL SUFISMO \\
\hline Concepto & El que sabe & $\begin{array}{c}\text { Unión de la mente y el } \\
\text { cuerpo }\end{array}$ & Seguir la senda o camino \\
\hline Personajes & $\begin{array}{c}\text { Siddhartha Gotama (Buda) } \\
\text { Monges tibetanos } \\
\text { Dalai Lama }\end{array}$ & $\begin{array}{l}\text { Sutras de Patanjali } \\
\text { Bhagavad Gita }\end{array}$ & $\begin{array}{c}\text { El Profeta Mahoma Abu } \\
\text { Hamid Al Ghazzali }\end{array}$ \\
\hline Países y Culturas & $\begin{array}{c}\text { China } \\
\text { Japón } \\
\text { Oriente Medio }\end{array}$ & $\begin{array}{l}\text { Cultura Vedíca } \\
\text { Ascetismo hindú }\end{array}$ & $\begin{array}{l}\text { Islamismo Difundido por } \\
\text { todo el mundo }\end{array}$ \\
\hline Palabra clave & Moderación & lluminación & Autorrealización \\
\hline Descripción & $\begin{array}{l}\text { Las } 8 \text { sendas: palabra verdadera, } \\
\text { acción correcta, vida correcta, } \\
\text { esfuerzo correcto, atención } \\
\text { correcta, concentración correcta, } \\
\text { pensamiento correcto, comprensión } \\
\text { correcta. }\end{array}$ & $\begin{array}{l}\text { Los } 8 \text { pasos: abstenciones, } \\
\text { observancias, postura, } \\
\text { control energía vital, } \\
\text { interiorización, } \\
\text { concentración, meditación, }\end{array}$ & $\begin{array}{l}\text { Crítica a la lógica, la } \\
\text { filosofía, la academia } \\
\text { Prioriza la experiencia } \\
\text { directa, conocimiento } \\
\text { directo, comprensión } \\
\text { intuitiva, certeza. }\end{array}$ \\
\hline
\end{tabular}

Fuente: Revista electrónica de psicología de la Universidad Autónoma de México (2011).

En síntesis, Sánchez (2011), define a la meditación como:

El integral proceso de la conciencia, guiado a mejorar el desarrollo de la psique y sus funciones, el cual incluye la parte espiritual y moral que mide el comportamiento de las personas y su estilo de vida (p.228). 
Proulx, describe que en las Universidades de Massachusetts y Harvard en los años setenta se comenzaron las investigaciones sobre mindfulness y su relevancia en asuntos de negocios, salud y educación (como se citó en Salessi, 2011, p.228).

Además Proulx (citado en Salessi, 2011), también menciona que:

El área de salud, se empiezan a estudiar los beneficios del mindfulness en las poblaciones de adultos mayores, investigando el impacto en el estrés. Luego de varias investigaciones, se obtuvo que la práctica del mindfulness tiene impactos positivos en los tratamientos médicos, disminuyendo los dolores físicos, generados por artritis, o vinculado al alcoholismo. En los negocios, el mindfulness impacta de manera positiva, aumentando la creatividad, disminuyendo el burnout y evitando accidentes causados por la tecnología (como se citó en Salessi, 2011, p.229).

En los años ochenta, según Langer y Moldoveanu, en el área educativa se implementa el tema de una educación mindfull teniendo como objetivo la atención y el aprendizaje, dirigido a estudiantes escolares, universitarios y adultos mayores (como se citó en Salessi, 2011, p.229).

Según Mason y Hargreaves:

En los noventa, la meditación y el yoga para el fortalecimiento de la atención-concentración, y la conciencia en la salud física y mental se desarrolló significativamente, siendo Kabat - Zinn, del centro médico de la universidad de Massachusetts, el creador del programa conocido como “mindfulness Based Stress Reduction”, en español, programa de reducción del estrés basado en técnicas mindfulness. (como se citó en Salessi, 2011, p.229).

\subsubsection{Beneficios generales del mindfulness}

Martín (2015) en su trabajo de investigación, describe ocho beneficios de la práctica del mindfulness. Analicemos: 
Figura 2.3

Beneficios generales del mindfulness.

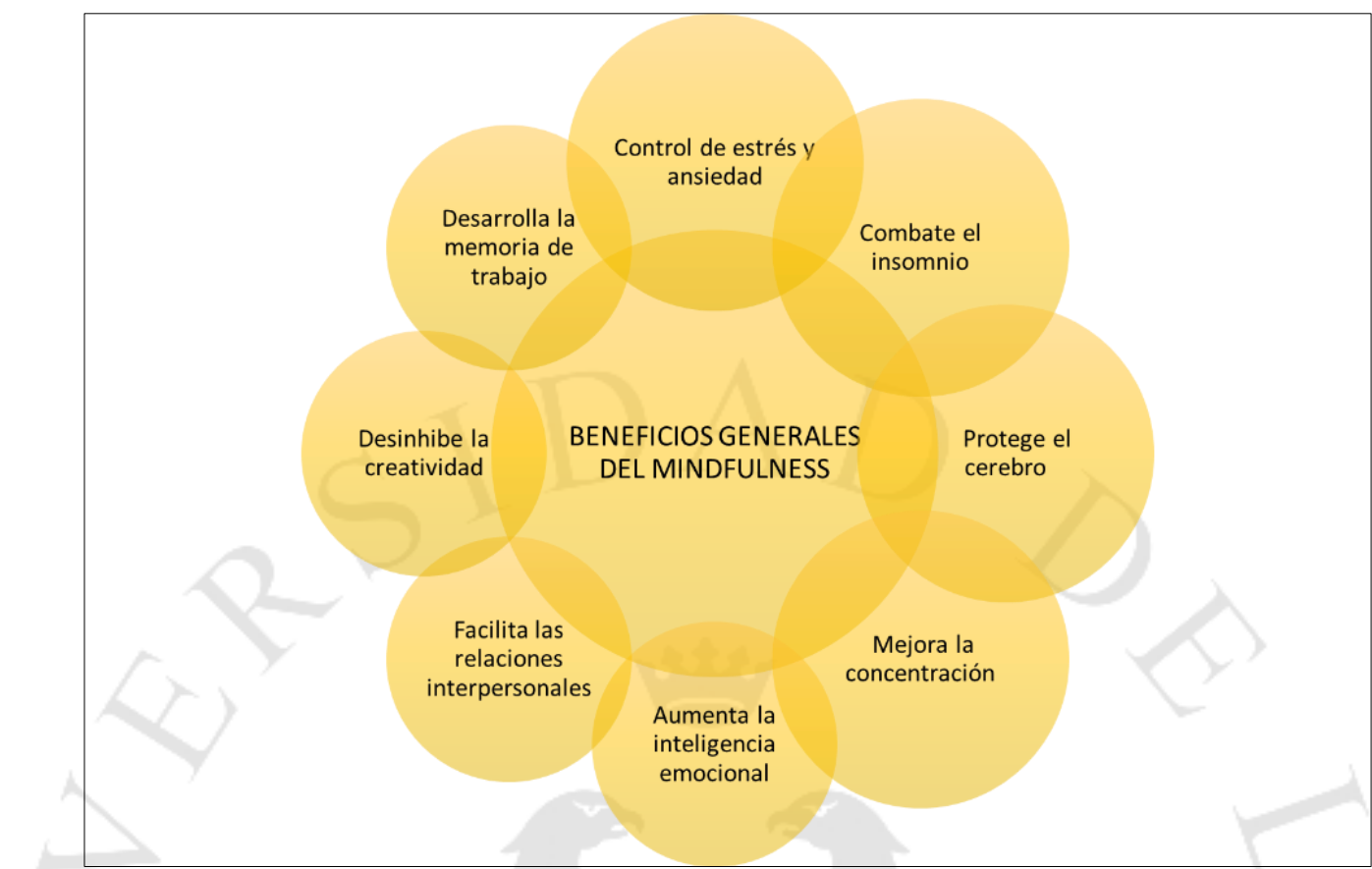

Fuente: Martín, Rosa (2015).

Elaboración propia.

- Control del estrés y la ansiedad. El estrés está muy presente en la sociedad occidental, produciendo problemas de salud como: depresión y ansiedad. Se ha comprobado que el mindfulness reduce los niveles de cortisol, que son las hormonas que aparecen para combatir el estrés cuando nuestro cuerpo está estresado, regulando y movilizando la energía en situaciones estresantes. El exceso de cortisol en nuestro organismo tiene efectos secundarios. En este sentido, la serenidad que aporta el mindfulness beneficia a la salud física y emocional, pues reduce los niveles de cortisol y regula la presión arterial (p.38).

En un estudio de Zeidan, F., Martucci, K., Keaft, R., McHaffie, J. y Coghill, R. (2011) acerca de los efectos de la práctica del mindfulness, comprobaron que la práctica de mindfulness ayuda a las personas que sufren cuadros de ansiedad o algún tipo de fobias. Se comprobó que las emociones negativas y los síntomas generados por la ansiedad, disminuyeron. Al mismo tiempo, la respuesta de la corteza parietal, referente de atención, aumentaban, ayudando a la regulación emocional. Fortaleciendo las zonas del cerebro que hacen 
posible la autorregulación y, en consecuencia, también ejerce una influencia positiva en las personas que sufren adicciones.

- Combate el insomnio. La práctica del mindfulness puede mejora las posturas y manera para descansar, Martín (2015) afirma que las personas que practican mindfulness en su vida diaria tienen un mejor control sobre sus emociones y comportamientos. Además, estas personas presentan baja activación cortical, que les ayuda a dormir mejor (p.38).

- Protege el cerebro. El envejecimiento y la aparición de patologías asociadas a la vejez guardan una estrecha relación con el estado de conservación de nuestros telómeros, que son los extremos de los cromosomas, estructuras semejantes al remate de los cordones de los zapatos. Investigaciones de la Escuela de Medicina de Harvard y del Hospital General de Massachusetts demostraron que la práctica del mindfulness aumenta el tamaño de los telómeros. Por su parte, una investigación de la Universidad de Oregón afirma que la práctica habitual de la Atención Plena está relacionada al aumento de la densidad y de la mielina axial, partes muy importantes de nuestras neuronas (Martín, 2015, p.38).

Diversos estudios científicos han justificado que con la práctica del mindfulness existen evidencias de cambios en los circuitos neuronales. En una investigación realizado por el neuro científico Davidson y el doctor KabatZinn (2003), confirmaron que las personas que realizaron el programa de entrenamiento MBSR (Reducción de Estrés basado en el mindfulness) presentaban un mayor índice de activación del hipocampo. Esta región cerebral está relacionada con la autoconciencia, la empatía, la memoria y el estrés (como se citó en Martín, 2015, p.40).

La doctora Lazar y su equipo (2011), en una investigación que realizaron, observaron que, a practicar mindfulness, este produce un cambio en el tamaño y volumen del cerebro. Se observó un aumento del hipocampo en el cerebro y otras áreas las cuales están encargadas de ordenar las emociones y el proceso auto-referencial. Además, se comprobó el descrecimiento del tamaño de la amígdala, parte del cerebro que es la encargada de la ansiedad, el estrés y el miedo. En esta investigación también, se descubrió la correlación que 
existe entre las modificaciones estructurales del cerebro y el bienestar subjetivo percibido por los participantes, debido a la disminución de los niveles de estrés. Es decir, junto con los cambios neuronales se pudo apreciar el bienestar emocional (como se citó en Martín, 2015, p.42).

- Mejora la concentración. En una investigación de Walsh y Shapiro, concluyeron que la práctica del mindfulness es beneficioso para nuestra capacidad de concentración. Además, en un estudio de Moore y Malinowski (2009) se comprobó que la práctica del mindfulness aumenta la flexibilidad cognitiva y la atención (como se citó en Martín, 2015, p.39).

La Universidad de California realizó un estudio dirigido por el equipo Mrazek, M., Franklin, M., Tarchin, D., Baird, B y Scooler (2012), este demostró que con pocas sesiones de entrenamiento mindfulness, la capacidad de atención y concentración mejoran. Según pruebas neuropsicológicas se apreció un incremento en la capacidad de atención y memoria de los participantes (como se citó en Martín, 2015, p.42).

- Aumenta la inteligencia emocional. Un estudio de la Universidad de Toronto, concluyó que las personas que practican habitualmente el mindfulness poseen un mayor autocontrol emocional que las que no lo practican (Martín, 2015, p.39).

Chan y otros (2008), de la Universidad China de Hong Kong por el uso del método Triarchic body-pathway relaxation (TBRT) (meditación proveniente de la cultura ancestral China y basada en mindfulness) plantean que las emociones positivas y el estado de conciencia se dan cuando no existe tensión o preocupación internalizada por una persona. El estudio evaluó el patrón EEG producido en el desarrollo de ejercicios de mindfulness y se comparó con escuchar música el cual se ha probado que produce emociones positivas, los dos tratamientos suministrados a diecinueve estudiantes universitarios (1922 años). Se mostró en los resultados, que la activación del lado izquierdo anterior se produjo con las dos técnicas, no obstante, sólo con la TBRT se vio una mayor actividad theta frontal media, patrón que es asociado a la atención internalizada (como se citó en Sánchez, 2011, p.238). 
- Facilita las relaciones interpersonales. La habilidad adquirida en la práctica del mindfulness puede predecir la satisfacción de las relaciones personales, según afirman Watchs y Córdova (2007), ya que mejora la capacidad de comunicación de las propias emociones y el autocontrol de las mismas. También Barnes, de la Universidad de Rochester, concluye que la propia filosofía de la compasión y la aceptación presentes en el mindfulness facilita las relaciones interpersonales (como se citó en Martín, 2015, p,39).

- Desinhibe la creatividad. Martín (2015) explica que necesitamos calma y paz para generar nuevas ideas. Con la mente en calma, la creatividad se encuentra desinhibida para explorar nuevas soluciones. Se constata el aumento de la creatividad en personas que practican habitualmente el mindfulness, según un estudio el Instituto del Cerebro y de la Cognición de la Universidad de Leiden, Holanda (p.39).

- Desarrolla la memoria de trabajo. En un estudio comparativo realizado por Jah (2010), se comprobó que los individuos que habían realizado un programa de entrenamiento en mindfulness obtuvieron mejores resultados en memoria de trabajo que los que no lo habían hecho (como se citó en Martín, 2015, p.39).

\subsubsection{Beneficios del mindfulness en las organizaciones.}

El contexto en el que se desarrollan las organizaciones impacta directamente, también, a los empleados. Es importante recordar, que los pensamientos y emociones, no son actividades separadas en la mente, por eso, en el momento en que alguna cosa daña el estado emocional de las personas, puede ser algún contratiempo o un cambio significante, la racionalidad se ve interrumpida. Las emociones positivas ayudan a lograr metas, y él estado de ánimo negativo tiene una consecuencia contraria, fomenta actitudes y conductas de evitación, apartamiento y de simplificación. Por lo cual, el bienestar observado por los empleados, tiene un papel importante, y esto viene siendo un reto para el área de RRHH: hallar métodos confiables que refuercen el gestionar del capital humano, en un contexto con globalizado e híper conectado (Fernández, 2017, p.48). 
Fernández (2017) explica que la herramienta que ayudará a las organizaciones y sus empleados, es la práctica del mindfulness, por los beneficios que este tiene:

Figura 2.4

Beneficios del mindfulness en los empleados y las organizaciones.

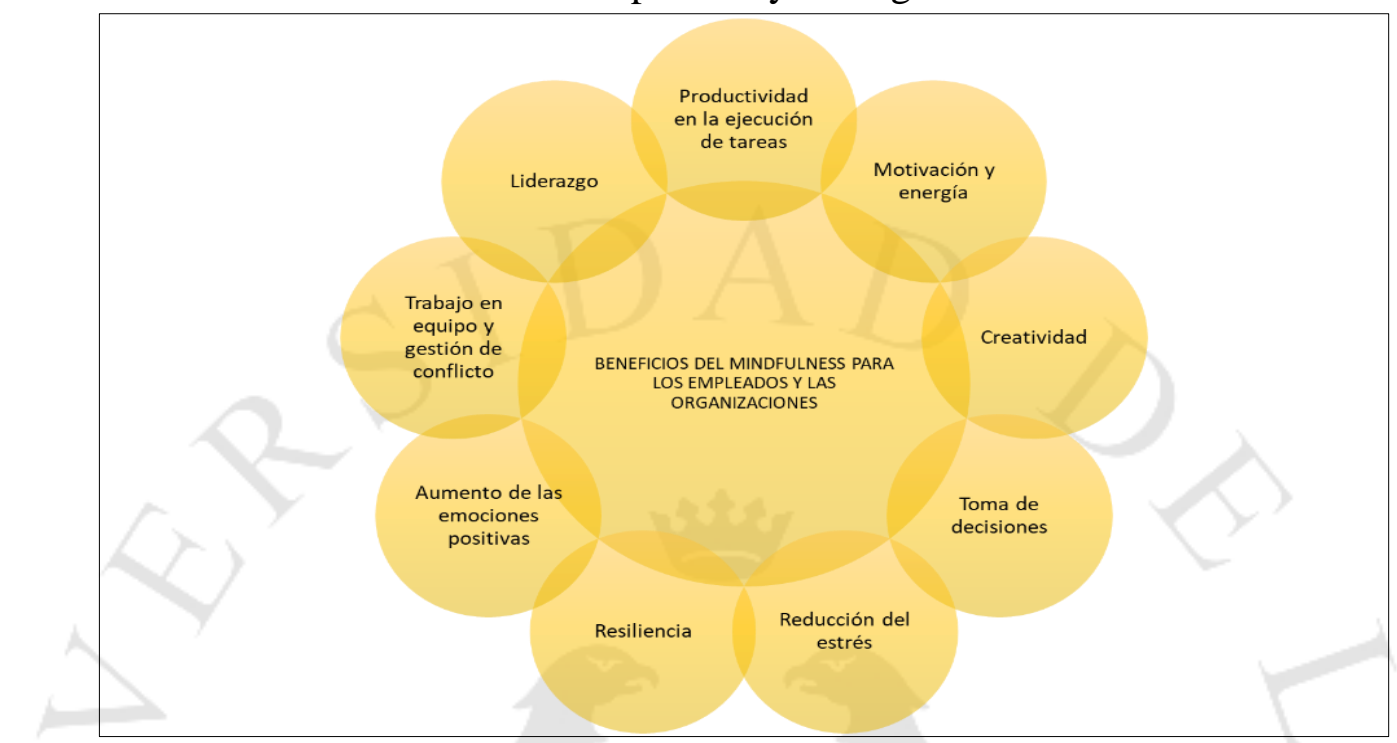

Fuente: Fernández, Estrella (2017)

Elaboración propia.

- Productividad en la ejecución de tareas. La suficiencia de poder dirigir la atención, ayuda en concentrarse en el enfoque de aquello que se elija y también evitando los descuidos, ya sean internos (pensamientos) como también externos, o desprenderse de ellas. La mente mientras esté más enfocada será objetiva, principalmente es útil en etapas de bastante intensidad emocional o en ambientes relativos, para que pueda permanecer el rendimiento estable. También se dice, que el trámite de la atención compromete de todas maneras la flexibilidad, la competencia de reconocer y comprender el momento que es imprescindible renovar o extender el foco para introducir los elementos cambiantes que podrían ser importantes en el desarrollo de los trabajos más complejos o en las situaciones que son muy demandantes (p.49).

- Motivación y energía. La energía que nos mueve es la motivación, es lo que está por detrás del comportamiento y que nos ayuda al cumplimiento de los objetivos. La motivación viene siendo intrínseca, es decir que no es dependiente del resultado, de tal manera que, en el tiempo que algunas cosas 
van por buen camino, existe un descrecimiento reactivo a las críticas y al error inminente, se conserva la determinación y se aprende de los errores. Luego se retoma el camino deseado. Extrapolar esta competencia al ambiente laboral representa clarificar los objetivos, establecer de buena manera las condiciones y el camino para el éxito, y luego de liberar la posibilidad de ganar y el miedo a fracasar, y centrarse en los requisitos del momento actual. Practicar mindfulness compromete constancia, accionar para poder cumplir los objetivos y propósitos formados con valores. Pero la perspectiva se conduce hacia el proceso, a la dirección y no hacia la meta atrasada (p.49).

- Creatividad. La práctica en mindfulness asiste en la inventiva de formatos diferentes e interrelacionados: al aumentar la autoconsciencia, se puede notar las interpretaciones que realizamos del mundo y soltarlas, expandiendo nuestra visión para nuevas formas de ver la realidad. Dominando la atención, estamos dando apertura a más información, sentimos y vemos más ángulos en las situaciones dadas. Aumentando el espacio de la memoria de trabajo, se extiende el espacio de generar, conservar y operar de forma paralela distintas ideas, realizar nuevas asociaciones, integrarlas y organizarlas. Indirectamente la creatividad se incrementa, al disminuir el estrés y aumentar los estados de ánimo positivos y la constancia ante fracasos (p.49).

- Toma de decisiones. De otro lado, el mindfulness ayuda a la mejora de la toma de decisiones, aportando una perspectiva necesaria para apartarnos de los sesgos y preferencias propias, y partir automatismos y condicionamientos. Realiza una pausa, un pequeño lugar para escoger; y ayuda a las soluciones más sensatas, las que reconcilian y componen intuición y análisis (son los dos elementos del buen juicio y raciocinio). Esta conciencia, panorama, franqueza y la disposición de control ayuda al proceso antes, durante y después del proceso de decidir (p.50).

- Reducción del estrés. El estrés es algo totalmente natural que lo notamos como una sobrecarga en la manera automática de una activación fisiológica, que nos pone en un estado de alerta. Esta situación se terminar al momento que la situación es resuelta. Si es que el estado de alerta es grave, las consecuencias en el organismo son profundos y peligroso, y dañan a todas las áreas del funcionamiento cognitivo, emocional y físico. El mindfulness ayuda 
a identificar los factores estresores, calmando la mente y manteniéndola en el presente, no en el pasado ni en el futuro. Proporciona claridad y habilidad para influir en el entorno que existe (p.50).

- Resiliencia. Es el talento de confrontar el tropiezo y los fracasos, recobrando y hasta saliendo airosos de ellos. En el ambiente laboral, es crucial mantenerse resiliente para permanecer en la búsqueda del cumplimiento de los objetivos. El mindfulness refuerza la capacidad de desviar, es decir de establecer una segregación entre uno mismo, las experiencias y las emociones. Así mismo, te da la competencia de admitir las emociones negativas sin pretender eludirlas ni reaccionar ante ellas, buscando lo que realmente se quiere (p.51).

- Aumento de las emociones positivas. La regulación emocional no depende solo de la reducción de los factores estresores o problemas, sino asimismo de la concepción y conservación de emociones positivas, que son un fundamento importante para el crecimiento del potencial humano. El entrenamiento del mindfulness impulsa emociones positivas al variar la estrategia de negación o evitación por la aceptación (p.51).

- Trabajo en equipo y gestión de conflicto. Fijar y conservar relaciones positivas es importante para un buen performance de un equipo de trabajo. Las relaciones personales buenas incrementan los recursos para protegernos del estrés, creando equipos más productivos y eficientes. El mindfulness favorece al trabajo en equipo desde dos perspectivas: incrementa la autoconciencia, la conciencia del otro y se desarrolla la empatía, ya que estudios han comprobado que para tener buenas relaciones con otros hay que tener conocimiento de nuestros propios estados mentales. El entendimiento de los demás te da la capacidad de escuchar y comprender la perspectiva de otro. Así mismo, el mindfulness te ayuda a tener mayor orden emocional y flexibilidad de solución; realizar la competencia de comprender las emociones negativas sin reaccionar y ayuda a reducir los patrones habituales de reacción (p.51).

- Liderazgo. Liderazgo comprende lograr los objetivos de empresa influyendo de manera motivadora en los integrantes del equipo. Este curso requiere 
precisión y enfoque central en los objetivos, capacidad para coordinar y crear determinación. La práctica mindfulness mejora la disposición de tomar perspectiva y apartarse de la experiencia, generando una visión más clara, sin sesgos, tomando mejores decisiones. El enfoque de objetivos se practica en el mindfulness, enfocando tu atención en un estímulo y volver a él cuando nos distraemos; esto es muy útil para los lideres porque deben enfocarse en los objetivos organizacionales aun persistan las distracciones y obstáculos. El entendimiento de uno mismo y la regulación de tus emociones ayuda una buena relación con los demás, generando confianza en ellos, porque entiendes su perspectiva y se sienten participes de algo (p.51).

\subsubsection{Talleres mindfulness}

Según Alberts y Hülsheger (2015), los talleres mindfulness son ejercicios que se realizar en un lugar específico o en casa de manera personal, no tiene limitaciones. Explican de qué manera se desarrollan los talleres en forma grupal y personal. Dividiendo estos en ejercicios durante los talleres y después de los talleres.

\subsubsection{Ejercicios durante los talleres mindfulness}

Los talleres de mindfulness se realizan durante sesiones grupales, guiadas por un entrenador, haciendo uso de herramientas que ayudan en estas (anexo 3), explican Alberts y Hülsheger. La función principal del entrenador es explicarles y mostrarles a los participantes a través de las técnicas de mindfulness, el propósito de estas: cultivar una mentalidad que se caracteriza por abrir la conciencia y la capacidad de observación, y lograr un cambio general en la relación de pensamientos, emociones y sensaciones. Ya que la atención plena implica la conciencia continua y automática de procesos, se trata de mantener una conciencia abierta y enfocada, en todo tipo de situaciones, tanto fáciles como difíciles, sea en la vida diaria como en la vida laboral (p.102).

Los talleres mindfulness están compuestos por actividades principales:

- Conciencia o apertura. Los participantes deben dejar la mentalidad de la automatización, y cuestionarse por qué hacen lo que hacen y en que les ayuda. Esa es una forma de tomar conciencia del "aquí y 
ahora", no solo hacer por hacer sino pensar que lo que haces, esto suma en pensamientos e ideas acerca de las cosas que realmente deseas en tu vida. De esa manera se capta la atención del participante hacia el objetivo de las prácticas mindfulness. Es importante que los participantes sientan entusiasmo de aprender nuevas herramientas para mejorar ciertos aspectos que desean, ya que, sin esta apertura, no se obtendrá el máximo beneficio de los talleres (p.103).

- Escáner corporal. El escáner corporal, como su nombre indica, es una técnica que implica tomar conciencia de cada parte del propio cuerpo. Los participantes son instruidos para prestar atención a su postura y luego dirigir la atención a su respiración. Durante el ejercicio, los participantes prestan atención a las diferentes sensaciones físicas presentes en un área específica del cuerpo. Muchos se encuentran fácilmente distraídos por pensamientos, sensaciones corporales o sonidos. Cuando ocurre la distracción, el participante es instruido para devolver suavemente la atención y se alienta a los participantes a hacerlo sin culpas o frustración. Además, al prestar atención al cuerpo, uno puede darse cuenta de sensaciones dolorosas o desagradables, en lugar de alterar, ignorar o suprimir estas sensaciones, se busca el entendimiento para hallar una solución (p.104).

- La respiración. El espacio de respiración es una meditación de atención plena muy breve que puede ayudar a integrar la atención plena en la vida cotidiana. Le permite a uno interrumpir los patrones automáticos de pensamiento y comportamiento y aumentar el afrontamiento basado en la aceptación. Por ejemplo, cuando un empleado experimenta estrés en el trabajo, puede respirar por un momento y usar el ejercicio para interrumpir el ciclo negativo de pensamientos relacionados con el estrés. Tomarse un tiempo para conectarse al cuerpo y tomar conciencia de las respuestas que produce el estrés corporal, lo que permite elegir las medidas apropiadas (p.104). 


\subsubsection{Ejercicios después de los talleres mindfulness}

Continuando con la explicación y descripción de Alberts y Hülsheger (2015), las intervenciones de atención plena también involucran ejercicios que apuntan a mejorar la conciencia consciente durante las actividades diarias. Requieren un solo foco de atención y la capacidad de regresar suavemente al objeto de atención. El objeto de atención puede ser cualquier cosa, desde una conversación con un colega para almorzar. Predecimos que estos ejercicios son particularmente útiles cuando se trata de integrar la atención plena en el lugar de trabajo, porque no requieren necesariamente tiempo adicional o cambios ambientales. Hay ejemplos prácticamente infinitos, lo que hace imposible enumerarlos y describirlos a todos. Algunos de los ejercicios informales más importantes en el contexto del trabajo son:

- Conciencia de las actividades de rutina. Las actividades de rutina son actividades realizadas regularmente, a menudo sobre una base diaria. La mayoría de las actividades requieren poca atención consciente, porque están altamente automatizados. Los ejemplos incluyen tomar una ducha, conducir o caminar al lugar de trabajo, o almorzando. La idea es enfocar la atención completamente en la actividad; los movimientos del cuerpo, la vista, las sensaciones. Cuando los pensamientos tienen distracciones, uno las nota y devuelve la atención a la tarea en cuestión. Por ejemplo, cuando come con atención, uno come lentamente y la atención se dirige principalmente a la experiencia en el momento presente, que incluye movimientos físicos y el sabor y olor de la comida. Por lo tanto, en lugar de hacer varias cosas al mismo tiempo (como leer mientras come, hablar por teléfono mientras conduce a casa, pensando en el trabajo mientras toma una ducha), uno adopta un solo enfoque de atención (p.105).

- Como parte de los programas de entrenamiento de mindfulness, los participantes se les anima a elegir algunas de estas actividades de rutina y para practicar realizarlos de una manera consciente. Dado que no consume mucho tiempo e involucra actividades que se realizan a diario, este ejercicio puede implementarse fácilmente en el día a día del trabajo. Los participantes pueden elegir 
actividades tales como ser consciente mientras almuerza, atento mientras camina hacia la copiadora, o estar atento mientras va conduciendo a casa (p.105).

- Conciencia corporal. La conciencia del cuerpo que se cultiva a través de el escaneo corporal se puede implementar en la vida diaria prestando atención al cuerpo durante todo el día en diversas circunstancias. Uno puede prestar atención a la postura y darse cuenta de la presencia física, sensaciones como dolor o tensión. Trabajos que requieren levantamiento, monótono tareas de trabajo, posturas de trabajo incómodas, movimientos repetitivos, y por períodos prolongados, como estar en la computadora, son asociados con problemas físicos tales como dolor de cuello, espalda y lesiones ocupacionales por esfuerzo repetitivo. Consciente de estas sensaciones es probable una detección temprana y prevención de quejas físicas. Por ejemplo, implementar momentos diarios de conciencia consciente mediante una alarma con el fin de interrumpir los movimientos repetitivos o tomar conciencia de nuestra postura (p.106).

- Conciencia de patrones impulsivos y reactivos. Patrones diarios de pensamiento y comportamiento son reacciones habituales (inconscientes) a las experiencias o eventos. Si no se desempeña bien en el trabajo puede inmediatamente desencadenar pensamientos y juicios autocríticos negativos. La tristeza puede resultar en un intento directo de alejar la sensación no deseada. Recibir un comentario sarcástico de un colega puede hacernos decir cosas que luego lamentamos. En todos estos ejemplos, el comportamiento está guiado por patrones automáticos. La atención plena requiere conocimiento de estos patrones a medida que surgen durante el día. Mientras que a veces puede ser difícil de tomar conciencia antes de la aparición de una impulsiva reacción, tomar conciencia después también puede ser beneficioso porque puede mejorar la detección de patrones similares en el futuro (p.106). 
- Conciencia durante la interacción social. En el contexto social implica el uso de la interacción con las otras personas como un único punto de enfoque. En lugar de multitarea durante una conversación con un colega o pensando qué decir, la atención es dirigida a la conversación actual. La atención requiere una actitud abierta y sin prejuicios previos ni durante la conversación, escuchando profundamente, tomando perspectiva y dejando espacio para una respuesta de la otra persona. Además, la atención plena durante la interacción social puede implicar hablar con conciencia. Los ejemplos incluyen pausar mientras entablas una conversación, monitoreando los pensamientos y considerando el impacto, así como el tono de voz. La mayoría de los trabajos requieren interacción social y comunicación con clientes, colegas y supervisores. Practicando la conciencia durante la interacción social es por lo tanto otro ejercicio que puede implementarse fácilmente en la vida laboral (p.106).

\subsubsection{Programa de reducción de estrés en base a técnicas de mindfulness - MBSR.}

Según Baer, Carmody y Hunsinger (2012):

El MBSR es un programa con el propósito de reducir del estrés mediante la práctica sistemática y formación de la atención plena. Se trata del programa pionero en esta disciplina y constituye el principal referente en la elaboración de nuevos programas basados en el mindfulness (p.755).

Este programa fue desarrollado en un entorno de medicina del comportamiento para grupos heterogéneos de personas que sufren de una variedad de quejas relacionadas con el dolor y el estrés, y se ha adaptado para una amplia gama de poblaciones (p.755).

En su forma estándar, incluye ocho sesiones semanales de 2.5 horas, con una sesión de todo el día durante la semana 6, para grupos de hasta 30 participantes. Las sesiones incluyen la práctica intensiva de tres ejercicios de meditación primarios basados en la atención plena: escaneo corporal, meditación sentada y meditación suave, yoga, todo lo cual 
fomenta la observación sin juicios y la aceptación de las sensaciones corporales, cogniciones, estados emocionales, urgencias y estímulos ambientales a medida que surgen. Los participantes son animados a practicar estos ejercicios por hasta 45 minutos por día, 6 días por semana, usando grabaciones para orientación, e integrar las habilidades de atención plena en las actividades cotidianas de rutina, como comiendo y caminando.

En la revisión de literatura han concluido que la participación en MBSR proporciona importantes beneficios psicosociales para una variedad de poblaciones, incluidos los pacientes con cáncer y otras enfermedades crónicas (p.756).

En los beneficios del programa MBSR, se encontró que los aumentos en la atención plena mediaban la relación entre el grado de práctica de atención y mejoras en salud psicológica. Numerosas investigaciones corroboran su eficacia en el tratamiento de patologías psíquicas. Además, se encontró una correlación significativa entre el uso del mindfulness y la limitación de síntomas depresivos (p.756).

\subsubsection{Satisfacción Laboral}

\subsubsection{Definición}

Dalal (2012) define: "El regocijo constituye un estado emocional positivo resultante de la evaluación de las prácticas laborales" (como se citó en Salessi, 2014, p.69).

Yukl (2008) puntualiza que: "El buen clima laboral nace del hecho de hacer un trabajo interesante, dentro del ámbito de una organización que resulta atractiva, y por el que se recibe una sucesión de beneficios de acorde con las expectativas" (como se citó en Salessi, 2014, p.69).

Morris y Venkatesh (2010) señalan que: "En tanto respuesta emocional, la satisfacción laboral es producto de la congruencia entre el puesto y los valores personales del empleado" (como se citó en Salessi, 2014, p.69). 
Para Robbins \& Judge (2013), "la satisfacción laboral debe entenderse como una actitud general hacia el propio trabajo viendo diversos aspectos del mismo y de la organización" (como se citó en Salessi, 2014, p.69).

Reforzando este último, Judge et al. (2012), adiciona que:

Existen más factores que influyen en la satisfacción laboral, ya sean causas relativas a la labor realizada (significatividad e identidad, capacidad para la toma de decisiones inherentes a la planificación y distribución de recursos, retroalimentación sobre el cumplimiento, entre otras), como características relacionados a la organización, así como la estructura de recompensas, salarios y beneficios; las oportunidades de desarrollo de carrera y promoción; el clima laboral, y los estados y medioambiente de trabajo (como se citó en Salessi, 2014, p.70).

Dalal, Bashshur y Credé (2011) han analizado la satisfacción desde un enfoque en la alta y media gerencia, aspecto referido a la evaluación y visión por el lado de los colaboradores de aspectos, así como la comunicación, confianza, justicia, apoyo, compromiso y competencia de los jefes directos. (como se citó en Salessi, 2014, p.70). En relación con esta tendencia, Rogelberg, Allen, Shanock, Scott y Shuffler (2010) han introducido a el concepto de satisfacción laboral las reuniones de trabajo, enlazadas al modo cómo éstas se desarrollan en términos de frecuencia, duración, modalidad, cantidad de asistentes, cumplimiento de la agenda definida, posibilidades de participación y debate (como se citó en Salessi, 2014, p.70).

\subsubsection{Factores que influyen en la satisfacción laboral.}

Según Salessi (2014), son ocho los principales factores que configuran la satisfacción laboral: 
Figura 2.5

Factores de la satisfacción laboral.

Fuente: Salessi, Solana (2014).

Elaboración propia.

- Diseño del puesto. Los principales requerimientos para el diseño del puesto, son la responsabilidad otorgada en la ejecución de las tareas y actividades diversas, se han determinado como influencias directas de la satisfacción laboral (p.73).

- Beneficios del puesto. Los puestos cuya oferta son la libertad, autonomía y reserva para programar el trabajo, tener decisión en los procedimientos; autonomía para la toma de decisiones; y emplear las oportunidades y mejorar las habilidades y el mismo desarrollo personal, son fundamentos que influyen de una manera positiva en la satisfacción laboral (p.73).

- El clima organizacional. Es muy importante el clima organizacional donde el colaborador se desenvuelve. En este sentido, la seguridad en el líder organizacional tiene un impacto positivo en la satisfacción laboral de un equipo de trabajo, ya que en el momento en que los empleados sienten a su supervisor o jefe directo como una persona líder transformadora y carismático, que da valor a sus contribuciones, recompensa su conducta y atiende directamente sus necesidades, los niveles de satisfacción laboral aumentan (p.73). 
- La justicia. Tiene un papel muy importante en las relaciones empleado-empleador. En consecuencia, se ha demostrado que las satisfacciones con el salario están relacionadas de una manera muy directa con la apreciación de la justicia distributiva, mientras que la justicia procedimental se ve más afiliado a la satisfacción con otros beneficios, ya sean premios o comisiones (p.73).

- Reconocimiento social. Diferentes estudios de una muestra de profesionales asistenciales que han sido llevados a cabo, han indicado como resultado que lo que impacta positivamente sobre los niveles de satisfacción laboral de médicos y enfermeros es el reconocimiento público del trabajo (p.73).

- Salario y seguridad laboral. Estudios han determinado que la apreciación de salarios competitivos e incentivos monetario equilibrado, así como la seguridad laboral y la percepción de estabilidad impactan de una manera positiva en las actitudes y comportamientos de los trabajadores, teniendo como resultado el incremento de la satisfacción laboral. (p.73).

- Tercerización. La tercerización dentro de una organización puede tener efectos adversos sobre la satisfacción laboral. Se demostró que los empleados eventuales perciben una satisfacción menor que los trabajadores permanentes, ya que no reciben los mismos beneficios. Esto, puede generar un impacto en los demás empleados irrumpiendo en un buen clima laboral (p.73).

- Equilibrio trabajo - familia. Los menores niveles de conflicto se asocian con una cultura de apoyo trabajo-familia (originados por la intromisión laboral en las responsabilidades familiares o viceversa) y aumenta los niveles de satisfacción. En este sentido, las políticas organizacionales que promueven el equilibrio trabajo-familia, son asociadas a las positivas actitudes laborales, principalmente las intenciones de permanecer en la empresa y su satisfacción en la misma. Junto a las políticas, requerimientos como el apoyo emocional que proviene ya sea de la organización como de la familia propia, 
también constituyen importantes elementos al momento de hacer alguna gestión en las responsabilidades laborales y familiares. Desde este punto de vista, en el momento en el que el entorno del trabajo y la familia pueden ser manejados exitosamente son facilitados por el supervisor y son percibidos por los empleados se fomentan positivamente las actitudes laborales y mejora su productividad (p.74).

\subsubsection{Descripción de la empresa: Renta 4 SAB}

Renta 4 es una Sociedad Agente de Bolsa, autorizada a actuar como tal por la Superintendencia del Mercado de Valores desde el año 2014. La actividad principal de Renta 4 es la intermediación de valores y entre otras actividades y operaciones aprobadas por la Ley del Mercado de Valores.

Su casa matriz es Renta 4 Banco S.A., un banco español de inversión que tiene más de 28 años de trayectoria en los mercados financieros de una manera exitosa. Desde 2011, Renta 4 Banco S.A. empezó su expansión internacional por el mercado latinoamericano, enfocándose en la zona MILA. Actualmente tiene presencia en Chile, Perú y Colombia.

En Perú, Renta 4 tiene una estructura organizacional funcional, siendo sus áreas core: el Área Comercial, la de Trade y la de Research. Cabe mencionar que cuenta con un promedio de 15 trabajadores (número total de la planilla) con una estrategia de tercerización de sus áreas de apoyo. 
Figura 2.6

Empleados en orden de jerarquía en Renta 4.

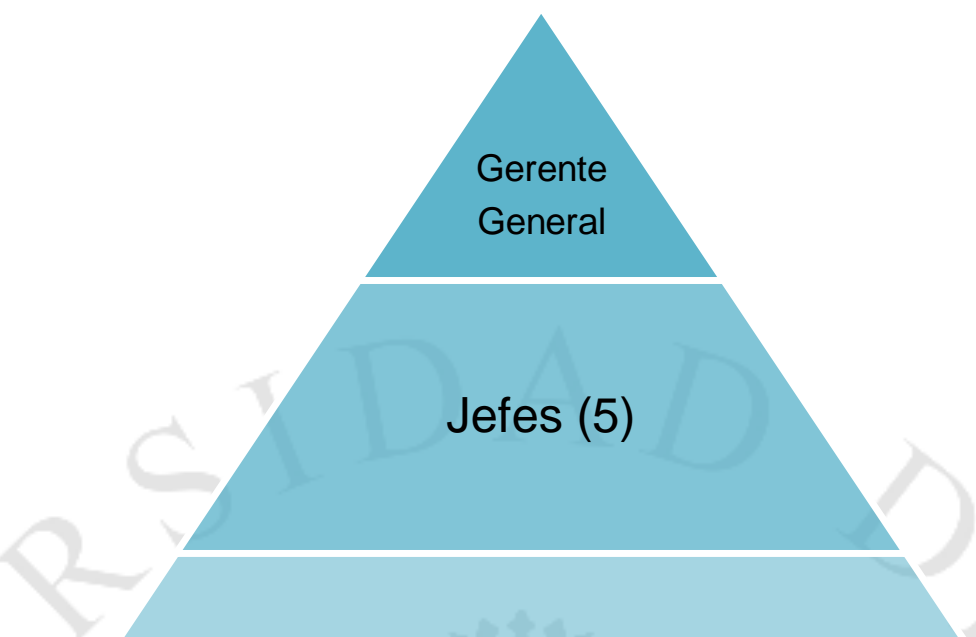

\section{Asistentes (9)}

Fuente: Datos brindados por la empresa Renta 4 (2017).

Elaboración propia.

\section{Misión}

Gestionar de forma eficiente las inversiones de sus clientes, mediante una asesoría personalizada y cercana brindada por su staff de especialistas en inversiones; con los más altos estándares de calidad en cada operación.

\section{Visión}

Ser la Sociedad Agente de Bolsa más importante en los países presentes, con los estándares más altos de calidad y excelencia. 


\section{CAPÍTULO III. MARCO METODOLÓGICO}

\subsection{Tipo de investigación}

La investigación se divide según los siguientes criterios:

- Por el tipo de conocimiento: Científica

- Por el objetivo del investigador: Aplicada

- Por el método de la investigación: Inductiva

- Por la cantidad de variables: Bi variado

- Por el ambiente en el que se realiza: De campo

- Por la obtención de datos: Primaria

- Por el análisis de las variables: Descriptiva

- Por el método de recolección de datos: Cuantitativa

\subsection{Diseño de investigación}

De acuerdo a las siguientes consideraciones, el diseño de la investigación es no experimental y es de corte transversal - correlacional, (Behar, 2008, p.19):

- Diseño es No Experimental, porque no se manipula adrede las variables, se enfoca principalmente en la observación en un entorno natural.

- Diseño Transversal - Correlacionadas, analiza un grupo determinado, y la relación de dos o una de las variables en una circunstancia dada te permite recolectar datos y describirlas.

En este diseño se observó la influencia de los talleres mindfulness y su efecto positivo en la satisfacción laboral de los trabajadores de la empresa Renta 4 Sociedad Agente De Bolsa S.A. 


\subsection{Población}

La población está compuesta por 15 trabajadores de la empresa Renta 4 Sociedad Agente de Bolsa S.A, que están distribuidos de la siguiente manera:

Tabla 3.1

Población de análisis en la investigación.

\begin{tabular}{|c|c|}
\hline ÁREA & PERSONAS \\
\hline $\begin{array}{l}\text { Administrativo y } \\
\text { Finanzas }\end{array}$ & 6 \\
\hline Research & 2 \\
\hline Comercial & 3 \\
\hline Sistemas y soporte & 4 \\
\hline TOTAL & 15 \\
\hline
\end{tabular}

Fuente: Datos brindados por la empresa Renta 4 (2017).

Elaboración propia.

\subsection{Muestra}

Se tomó una muestra, debido a que todos los empleados de la empresa, no contaban con la disponibilidad para participar en los talleres. Por ello, sacamos una muestra, para cumplir con los objetivos de la empresa.

Está constituida por 8 trabajadores de la empresa Renta 4 Sociedad Agente de Bolsa S.A. Para determinar la muestra óptima se empleó el muestreo aleatorio simple, para estimar proporciones cuando la población es conocida.

Dónde:

$$
\mathrm{n}=\frac{z^{2} \times p \times q \times N}{\varepsilon^{2} \times(N-1)+z^{2} \times p \times q}
$$

- $\quad \mathrm{Z}=$ Valor crítico del nivel de confianza 1,96 (para $\alpha=0,05)$ 
- $\quad \mathrm{E}=$ Margen de error de la muestra $5 \%(0.05)$

- $\mathrm{p}=$ Proporción poblacional de ocurrencia de un evento (se asume $\mathrm{p}=0,5$ ).

- $\quad \mathrm{q}=$ Proporción poblacional de no ocurrencia de un evento (se asume $\mathrm{q}=0,5$ ).

- $\quad \mathrm{N}=$ Valor de la población (15)

Entonces, con un nivel de confianza del 95\% y margen de error del 5\% (0.05) tenemos:

$$
\begin{gathered}
n=\frac{(0.50 * 0.50) * 1.96^{2 * 8}}{(0.05)^{2}(8-1)+(0.50 * 0.50) * 1.96^{2}} \\
\text { Muestra }=\mathrm{n}=8
\end{gathered}
$$

La muestra tiene la siguiente distribución dentro de la empresa Renta 4:

Tabla 3.2

Muestra.

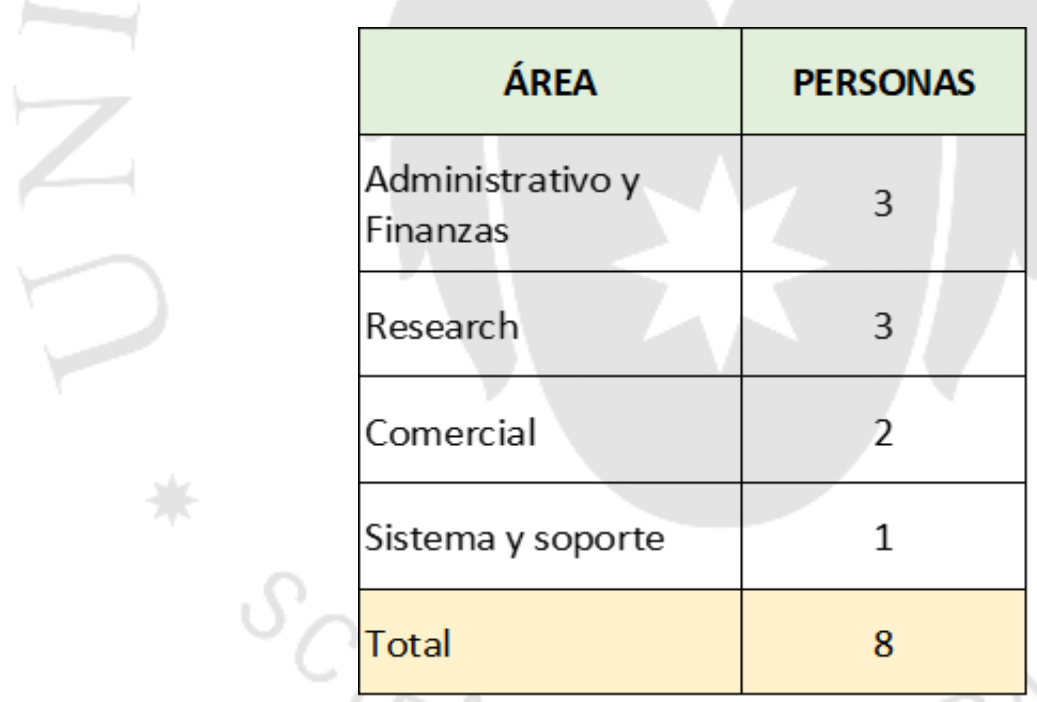

Fuente: Datos brindados por la empresa Renta 4 (2017).

Elaboración propia.

\subsection{Técnicas e instrumentos de recolección de datos}

\subsubsection{Talleres mindfulness}

Los talleres que se implementaron fueron teóricos y prácticos de las técnicas de mindfulness (Autoconocimiento y des aprendizaje / Yoga / Meditación), y se llevaron a cabo por el periodo de 4 semanas en 3 sesiones por semana, siendo un total de 12 sesiones. 
Estos talleres se llevaron a cabo en base al siguiente cronograma:

Tabla 3.3.

Cronograma de talleres mindfulness

\begin{tabular}{|c|c|c|c|c|c|c|c|c|c|c|c|c|c|c|c|c|c|c|c|c|c|}
\hline \multirow{3}{*}{ TIEMPO } & SEMANAS & \multicolumn{5}{|c|}{ SEMANA1 } & \multicolumn{5}{|c|}{ SEMANA2 } & \multicolumn{5}{|c|}{ SEMANA3 } & \multicolumn{5}{|c|}{ SEMANA4 } \\
\hline & DÍA & l & M & $\mathrm{Ml}$ & 」 & V & L & M & MI & J & V & l & M & MI & 」 & V & L & M & MI & J & V \\
\hline & TIEMPODE TALLER & 2HRS & & 2HRS & & 2 HRS & HRS & & 2HRS & & $2 H R S$ & HRS & & 2HRS & & & HRS & & $2 H R S$ & & 2HRS \\
\hline \multirow{3}{*}{$\begin{array}{l}\text { TALLERES } \\
\text { MINDFULNESS }\end{array}$} & AUTOC. YDESAPREND. & & & & & 2 & & 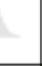 & 2 & & 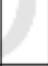 & & & & & & & & & & \\
\hline & YOGA & & & & & & & & & & & & & & & & & & & & \\
\hline & MEDITACIÓN & & & & & & & & & & & & & 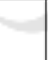 & & & & & & & \\
\hline
\end{tabular}

Elaboración propia (2017).

\subsubsection{Cuestionario de Satisfacción General - "Overall Job Satisfaction Scale".}

Se trata de un test que es una adaptación realizada por los psicólogos Manuel Fidalgo Vega y Jesús Pérez Bilbao de la "Overall Job Satisfaction Scale” de Warr, Cook y Wall que fue publicada en el año 1979. Es importante resaltar que el test se aplicó sin autorización del autor.

El cuestionario de satisfacción general se aplicó con el fin de medir la satisfacción en rasgos generales de los factores extrínseco e intrínsecos que motivan a los trabajadores en su puesto de trabajo.

La encuesta se aplicó dos veces a los participantes, antes de la implementación de los talleres mindfulness, lo que sirvió como un diagnóstico; y también se aplicó, luego de 4 semanas, 12 sesiones de talleres mindfulness, con el objetivo de ver el impacto de los talleres mindfulness en los resultados de esta encuesta (Anexo 1). 
Tabla 3.4.

Ficha técnica: Cuestionario de satisfacción general.

\begin{tabular}{|c|c|}
\hline Autor & Warr Cooky Wall \\
\hline Añode edición & 1979 \\
\hline Forma de administración & Individual y colectiva \\
\hline Duración & 5 a10minutos \\
\hline Fibililidad & El cuestionario de satisfacción general reporta un alfa entre 0,88. Ylas dimensiones reportan de un 0,74 a 0,88 \\
\hline Campo de aplicación & Personal \\
\hline Caracteristicas de la escala & 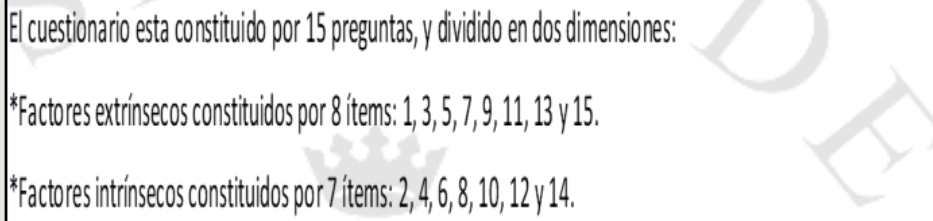 \\
\hline
\end{tabular}

Fuente: José Pérez Bilbao y Manuel Fidalgo Vega (2013).

La escala cuenta con dos factores específicos, los cuales se definen por grupos de preguntas, en el dónde se puede identificar cual de esos factores es más importante para cada trabajador y de qué manera impacta en ellos.

- Factores intrínsecos: Abarca aspectos como la observación obtenido por el trabajo, responsabilidades, aspectos relativos al contenido de la tarea, etc. Esta escala está conformada por siete ítems (números 2, 4, 6, 8, 10, 12 y 14).

- Factores extrínsecos: Trata sobre la satisfacción del trabajador con aspectos referente a la organización del trabajo como la remuneración, el horario, las condiciones físicas del trabajo, etc. Esta escala está conformada por ocho ítems (números 1, 3, 5, 7, 9, 11, 13 y 15).

\subsubsection{Cuestionario operativo: mindfulness - Satisfacción laboral}

Se elaboró un cuestionario de creación propia con el fin de medir el impacto de los talleres mindfulness en la satisfacción laboral, y la relación entre ellos, en la empresa Renta 4 (Anexo 2).

El cuestionario se aplicó al finalizar las 12 sesiones, 4 semanas, de los talleres mindfulness. La finalidad del cuestionario es validar la relación que existe entre la 
aplicación de los talleres mindfulness y la satisfacción laboral, basados en la experiencia, práctica y teórica, que obtuvieron los empleados en los talleres mindfulness.

\subsection{Técnicas de procedimiento y análisis de datos}

\subsubsection{Spss Vs 23}

El procesamiento y análisis de datos, se ejecutará con el software estadístico de mayor uso; Statistical Packagefor the Social Sciences, conocido por sus siglas SPSS, edición IBM® SPSS® Statistics 23, versión en español.

\subsubsection{Alfa de Cronbach}

Es un coeficiente que sirve para poder saber explícitamente la seguridad de una escala de medida, en este caso, medirá la fiabilidad del cuestionario que se diseñó para la investigación.

El coeficiente deberá fluctuar entre 0 y 1 ; un resultado de 1 indica que existe consistencia ideal de las preguntas para expresar la variable en análisis.

\subsubsection{Escala de Likert}

En el trabajo de investigación siguiente se utilizó la escala de Likert, la cual es una herramienta que determina la medición de actitudes y conocer el nivel de satisfacción del encuestado. Por ello se hizo la siguiente escala valorativa:

\section{Tabla 3.5}

Escala de Likert.

Elaboración propia.

\begin{tabular}{|l|}
\hline \multicolumn{1}{|c|}{ LIKERT - Escala valorativa } \\
\hline 1 = Muy en desacuerdo \\
\hline 2 = En desacuerdo \\
\hline 3 = Parcialmente de acuerdo \\
\hline 4 = De acuerdo \\
\hline 5 = Muy de acuerdo \\
\hline
\end{tabular}




\subsubsection{Coeficiente de Correlación Pearson}

Mide la relación de dos variables cuantitativas linealmente.

Tabla 3.6

Coeficiente de Correlación Pearson

\begin{tabular}{|c|l|}
\hline $\begin{array}{c}\text { Valor del coeficiente de } \\
\text { correlación de Pearson }(\boldsymbol{r})\end{array}$ & \multicolumn{1}{c|}{ Interpretación } \\
\hline$r=0$ & Ausencia de correlación lineal \\
\hline $0.10<r<0.19$ & Correlación lineal insignificante \\
\hline $0.20<r<0.39$ & Correlación lineal baja - leve \\
\hline $0.40<r<0.69$ & Correlación lineal moderada \\
\hline $0.70<r<0.99$ & Correlación alta muy alta \\
\hline$r=1$ & Función lineal perfecta \\
\hline
\end{tabular}

Elaboración Propia.

\subsubsection{Excel}

Se utilizará para comparar resultados del diagnóstico y luego de la implementación de los talleres mindfulness, de la encuesta General de Satisfacción. 


\section{CAPÍTULO IV. RESULTADOS}

\subsection{Satisfacción General}

\section{Medición}

Tabla 4.1

Encuesta de Satisfacción General: Puntuación

\begin{tabular}{|c|l|c|}
\hline ITEM & \multicolumn{1}{|c|}{ RESPUESTA } & PUNTOS \\
\hline 1 & Muy Insatisfecho & 1 \\
\hline 2 & Insatisfecho & 2 \\
\hline 3 & Moderadamente insatisfecho & 3 \\
\hline 4 & Ni Satisfecho ni insatisfecho & 4 \\
\hline 5 & Moderadamente Insatisfecho & 5 \\
\hline 6 & Satisfecho & 6 \\
\hline 7 & Muy satisfecho & 7 \\
\hline
\end{tabular}

Fuente: José Pérez Bilbao y Manuel Fidalgo Vega (2013).

Tabla 4.2

Encuesta de Satisfacción General: Escala de satisfacción.

\begin{tabular}{|c|c|c|c|}
\hline ITEM & DESCRIPCIÓN & INDICADOR & RESULTADO \\
\hline \multirow{2}{*}{1} & \multirow{2}{*}{ Satisfacción General } & Promedio $>0$ = 70.53 puntos & Satisfacción laboral \\
\hline & & Promedio $<70.53$ puntos & Insatisfacción laboral \\
\hline \multirow{2}{*}{2} & \multirow{2}{*}{ Factores intrínsecos } & Promedio $>0$ ó 32.74 puntos & Satisfacción intrínseca \\
\hline & & Promedio $<32.74$ puntos & Insatisfacción intrínseca \\
\hline \multirow{2}{*}{3} & \multirow{2}{*}{ Factores extrínsecos } & Promedio $>0$ o $=38.22$ puntos & Satisfacción extrínseca \\
\hline & & Promedio $<38.22$ puntos & Insatisfacción extrínseca \\
\hline
\end{tabular}

Fuente: José Perez Bilbao y Manuel Fidalgo Vega (2013). 


\section{Satisfacción General en el Trabajo}

Tabla 4.3

Resultado de Satisfacción General en el trabajo.

\begin{tabular}{|c|c|c|c|c|}
\hline RESULTADO & PERSONAS & INICIAL & PERSONAS & $\begin{array}{c}\text { DESPUÉS DE LOS } \\
\text { TALLERES MINDFULNESS }\end{array}$ \\
\hline Satisfechos & 1 & $12 \%$ & 5 & $62 \%$ \\
\hline Insatisfechos & 7 & $88 \%$ & 3 & $38 \%$ \\
\hline Total & $\mathbf{8}$ & $100 \%$ & 8 & $100 \%$ \\
\hline
\end{tabular}

Elaboración propia.

Figura 4.1.

Resultado de Satisfacción General en el Trabajo.

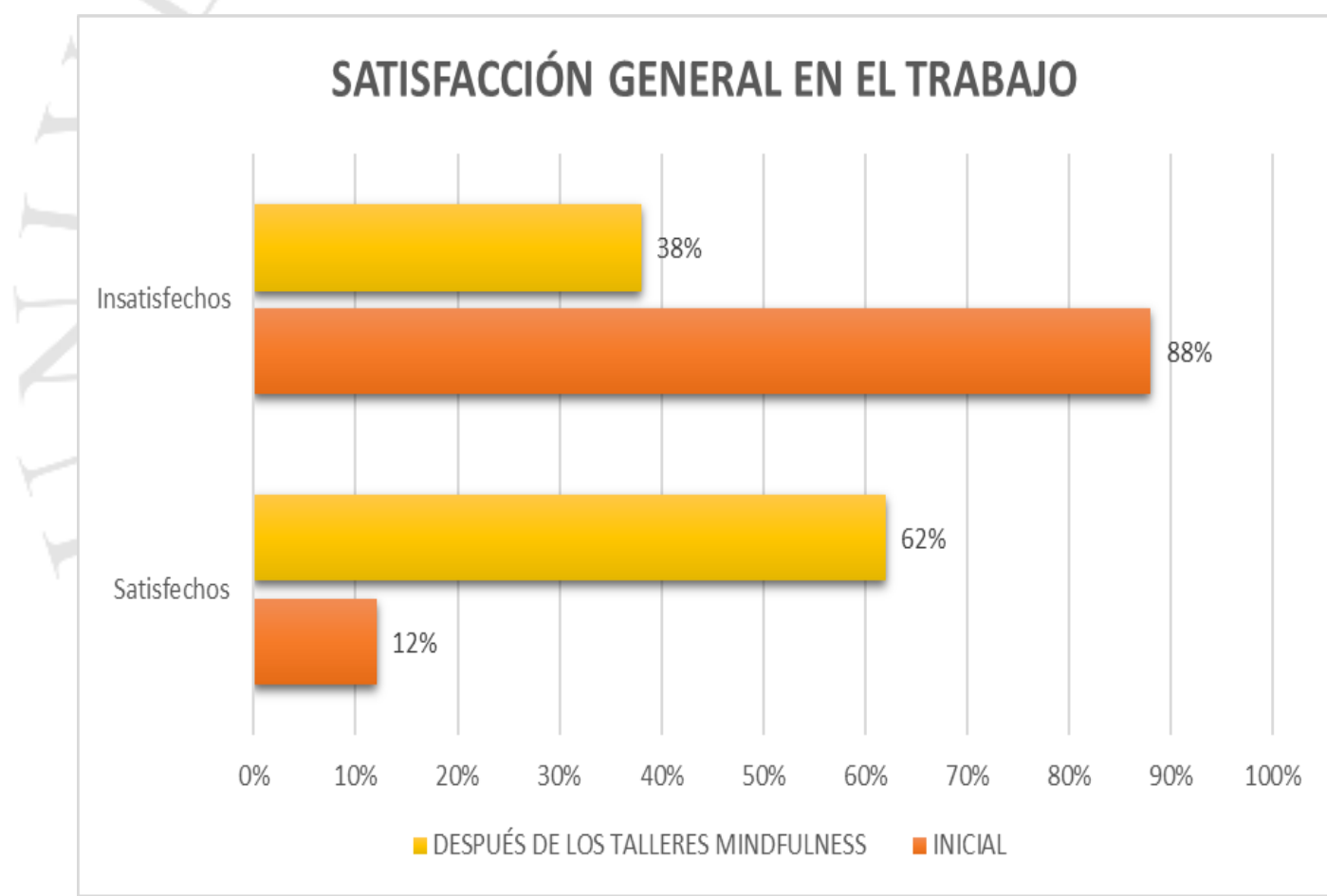

Elaboración propia

Interpretación: En la encuesta inicial de Satisfacción General en el trabajo, mostró que el $88 \%$ de los empleados de Renta 4 se encontraban insatisfechos; y el 12\%, satisfechos. Luego de la implementación de los talleres mindfulness en la empresa, se obtuvo que el $62 \%$ de los empleados, en Renta 4, se encontraban satisfechos; y el 38\%, insatisfechos. 


\section{Factores Intrínsecos}

Compuesto por las siguientes preguntas:

Tabla 4.4

Encuesta de Satisfacción General: Preguntas intrínsecas

\begin{tabular}{|c|l|}
\hline PREGUNTA & \multicolumn{1}{c|}{ DESCRIPCIÓN } \\
\hline 2 & Libertad para elegir su propio método de trabajo. \\
\hline 4 & Reconocimiento que obtiene por el trabajo bien hecho. \\
\hline 6 & Responsabilidad que usted tiene asignada. \\
\hline 10 & La posibilidad de utilizar sus capacidades. \\
\hline 12 & Sus posibilidades de promocionar. \\
\hline 14 & La atención que se presta a las sugerencias que usted hace. \\
\hline
\end{tabular}

Elaboración propia

Figura 4.2.

Resultados de la encuesta de Satisfacción General: Factores intrínsecos.

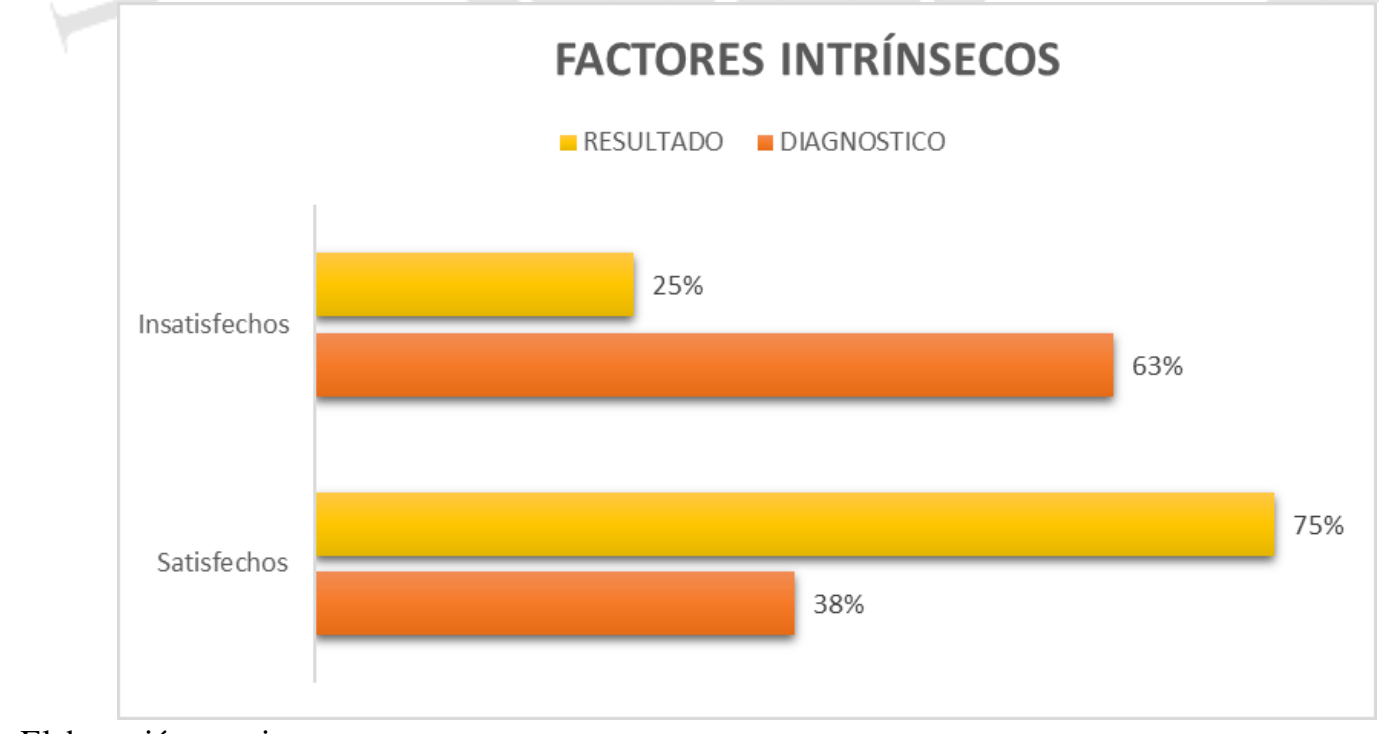

Elaboración propia

Interpretación: En el diagnóstico 25\% de los empleados de Renta 4 estaban insatisfechos y $25 \%$ satisfechos con los factores intrínsecos. Luego de la aplicación de 
los talleres mindfulness, el $25 \%$ de los empleados percibían insatisfacción y el $75 \%$ satisfacción intrínseca.

\section{Factores Extrínsecos}

Compuesto por las siguientes preguntas:

Tabla 4.5

Encuesta de Satisfacción General: Preguntas Extrínsecas

\begin{tabular}{|c|l|}
\hline PREGUNTA & \\
\hline 1 & Condiciones físicas de su trabajo. \\
\hline 3 & Sus compañeros de trabajo. \\
\hline 5 & Su superior inmediato. \\
\hline 7 & Su salario. \\
\hline 9 & Relación entre dirección y trabajadores en su empresa. \\
\hline 11 & El modo en que su empresa está gestionada. \\
\hline 13 & Su horario de trabajo. \\
\hline 15 & Su estabilidad en el empleo. \\
\hline
\end{tabular}

Elaboración propia.

Figura 4.3.

Resultado de la encuesta de Satisfacción General: factores extrínsecos.

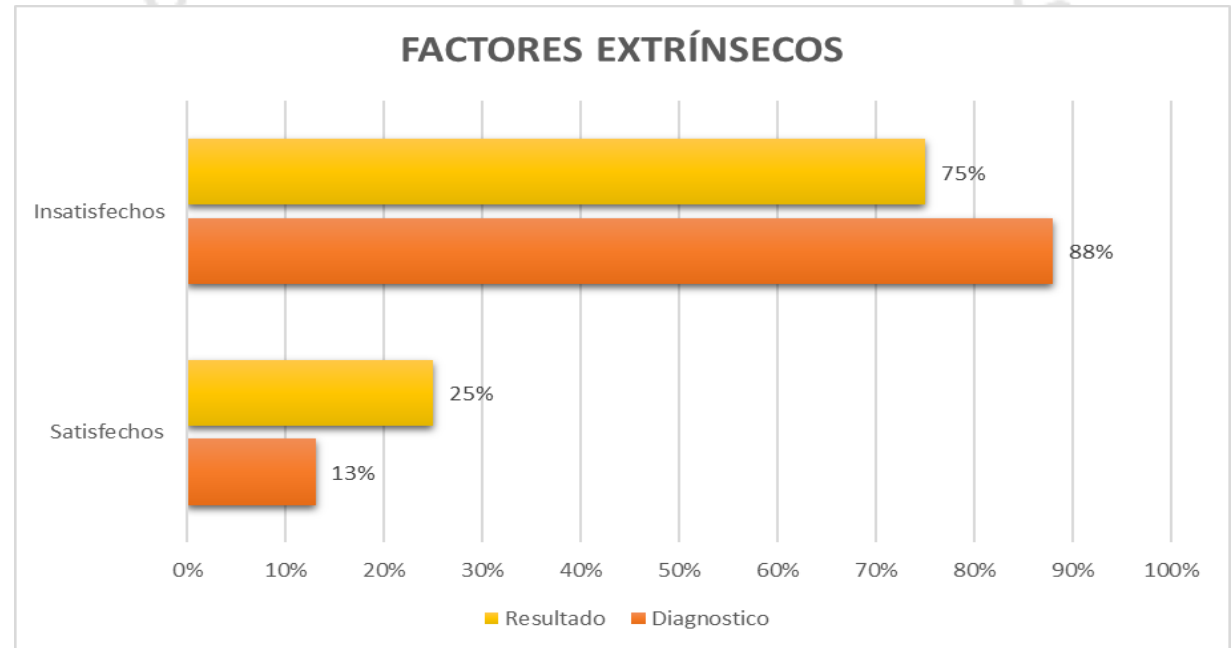

Elaboración propia. 
Interpretación: En el diagnóstico, el 88\% de los empleados de Renta 4 se encontraban insatisfechos; y 13\%, satisfechos con los factores intrínsecos. Luego de la aplicación de los talleres mindfulness, el $13 \%$ de los empleados se encontraban insatisfechos y el $25 \%$ satisfechos.

PREGUNTA 1. Condiciones físicas de trabajo

Tabla 4.6

Resultados de la encuesta de Satisfacción General: Condiciones físicas de trabajo.

\begin{tabular}{|l|c|c|c|c|}
\hline \multicolumn{1}{|c|}{ RESPUESTAS } & PERSONAS & $\begin{array}{c}\text { DIAGNÓSTICO } \\
\text { (\%) }\end{array}$ & PERSONAS & $\begin{array}{c}\text { DESPUÉS DE } \\
\text { TALERES } \\
\text { MINDFULNESS (\%) }\end{array}$ \\
\hline Muy Insatisfecho & 5 & $62.50 \%$ & 5 & $62.50 \%$ \\
\hline Insatisfecho & 1 & $12.50 \%$ & 1 & $12.50 \%$ \\
\hline Moderadamente insatisfecho & 0 & $0 \%$ & 0 & $0 \%$ \\
\hline Ni Satisfecho ni insatisfecho & 0 & $0 \%$ & 0 & $0 \%$ \\
\hline Moderadamente Insatisfecho & 0 & $0 \%$ & 0 & $25 \%$ \\
\hline Satisfecho & 2 & $25 \%$ & 0 & $0 \%$ \\
\hline Muy satisfecho & 0 & $0 \%$ & $\mathbf{8}$ & $\mathbf{1 0 0 \%}$ \\
\hline
\end{tabular}

Elaboración propia.

Figura 4.4.

Resultados de la encuesta de Satisfacción General: condiciones físicas de trabajo.
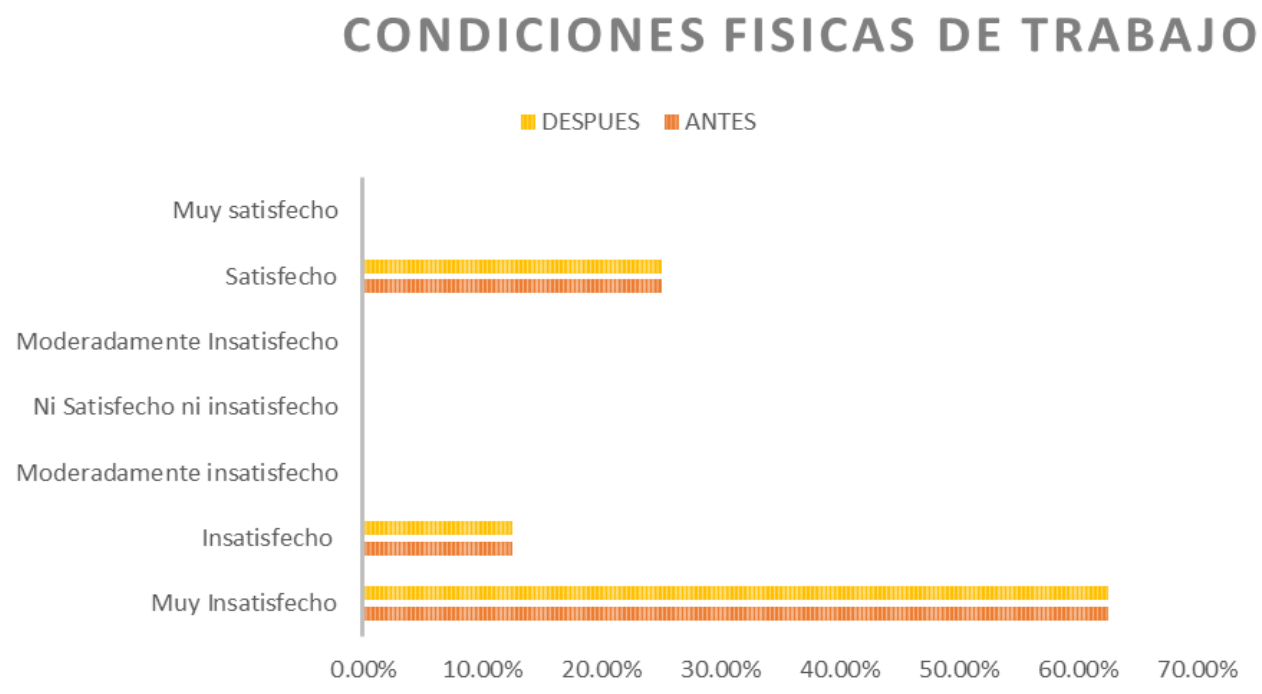

Elaboración propia.

Interpretación: El 100\% de los empleados en Renta 4, se encuentran insatisfechos con las condiciones físicas de trabajo. Luego de la implementación de los talleres mindfulness, no existió ninguna variación en los resultados. 
PREGUNTA 2. Libertad para elegir su método de trabajo.

Tabla 4.7

Resultados de la encuesta de Satisfacción General: libertad para elegir método de trabajo.

\begin{tabular}{|l|c|c|c|c|}
\hline \multicolumn{1}{|c|}{ RESPUESTAS } & PERSONAS & $\begin{array}{c}\text { DIAGNÓSTICO } \\
\text { (\%) }\end{array}$ & PERSONAS & $\begin{array}{c}\text { DESPUÉS DE } \\
\text { TALLERES } \\
\text { MINDFULNESS (\%) }\end{array}$ \\
\hline Muy Insatisfecho & 0 & $0 \%$ & 0 & $0 \%$ \\
\hline Insatisfecho & 0 & $0 \%$ & 0 & $0 \%$ \\
\hline Moderadamente insatisfecho & 0 & $0 \%$ & 0 & $0 \%$ \\
\hline Ni Satisfecho ni insatisfecho & 0 & $0 \%$ & 0 & $0 \%$ \\
\hline Moderadamente Insatisfecho & 0 & $0 \%$ & 0 & $0 \%$ \\
\hline Satisfecho & 2 & $25 \%$ & 1 & $13 \%$ \\
\hline Muy satisfecho & 6 & $75 \%$ & 7 & $88 \%$ \\
\hline \multicolumn{1}{c}{ Total } & $\mathbf{8}$ & $100 \%$ & $\mathbf{8}$ & $100 \%$ \\
\hline
\end{tabular}

Elaboración propia.

Figura 4.5.

Resultados de la encuesta de Satisfacción General: libertad para elegir método de trabajo.

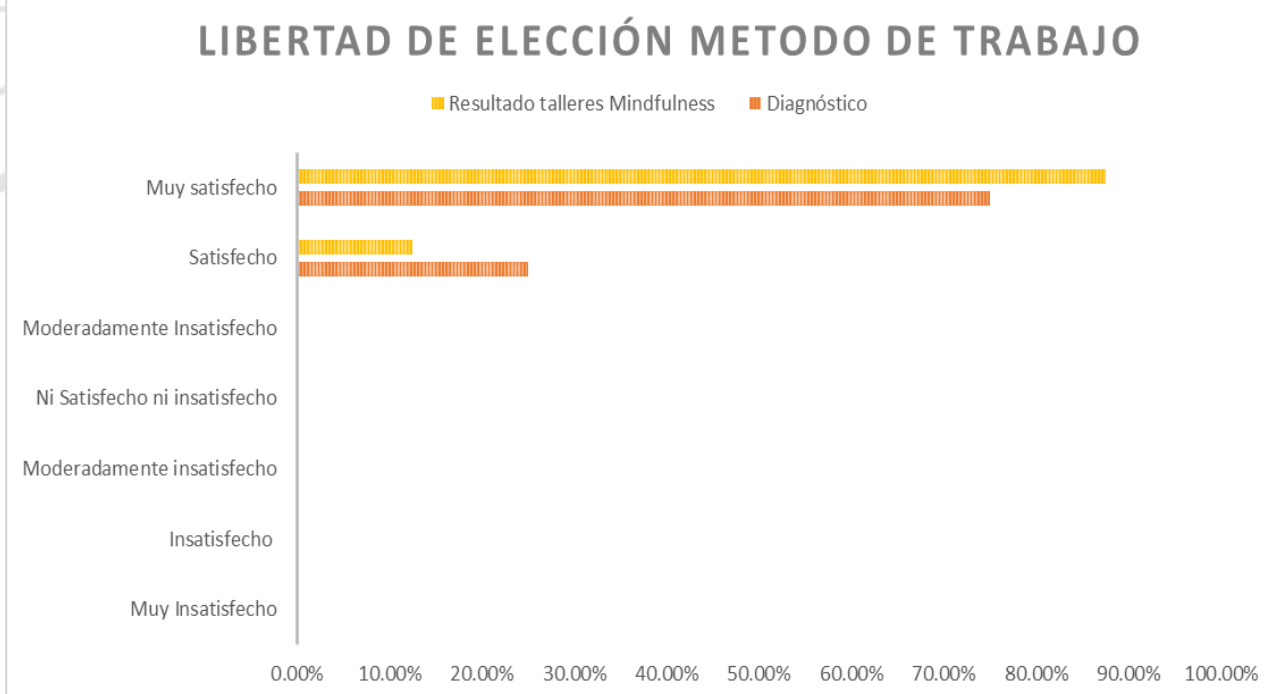

Elaboración propia.

Interpretación: En la encuesta de diagnóstico, el 75\% de los empleados de Renta 4 se encontraban muy satisfechos con la libertad para elegir su método de trabajo. Después de la implementación de los talleres mindfulness, el $88 \%$ de los empleados se encontraban muy satisfechos. 
PREGUNTA 3. Compañeros de trabajo

Tabla 4.8

Resultados de la encuesta de Satisfacción General: compañeros de trabajo.

\begin{tabular}{|l|c|c|c|c|}
\hline \multicolumn{1}{|c|}{ RESPUESTAS } & PERSONAS & $\begin{array}{c}\text { DIAGNÓSTICO } \\
(\%)\end{array}$ & PERSONAS & $\begin{array}{c}\text { DESPUÉS DE TALLERES } \\
\text { MINDFULNESS (\%) }\end{array}$ \\
\hline Muy Insatisfecho & 1 & $12.50 \%$ & 0 & $0.00 \%$ \\
\hline Insatisfecho & 5 & $62.50 \%$ & 0 & $0.00 \%$ \\
\hline Moderadamente insatisfecho & 0 & $0.00 \%$ & 0 & $0.00 \%$ \\
\hline Ni Satisfecho ni insatisfecho & 0 & $0.00 \%$ & 0 & $0.00 \%$ \\
\hline Moderadamente Insatisfecho & 0 & $0.00 \%$ & 0 & $0.00 \%$ \\
\hline Satisfecho & 2 & $25.00 \%$ & 8 & $100.00 \%$ \\
\hline Muy satisfecho & 0 & $0.00 \%$ & 0 & $0.00 \%$ \\
\hline \multicolumn{1}{|c|}{ Total } & 8 & $100 \%$ & 8 & $100 \%$ \\
\hline
\end{tabular}

Elaboración propia.

Figura 4.6.

Resultados de la encuesta de Satisfacción General: compañeros de trabajo.

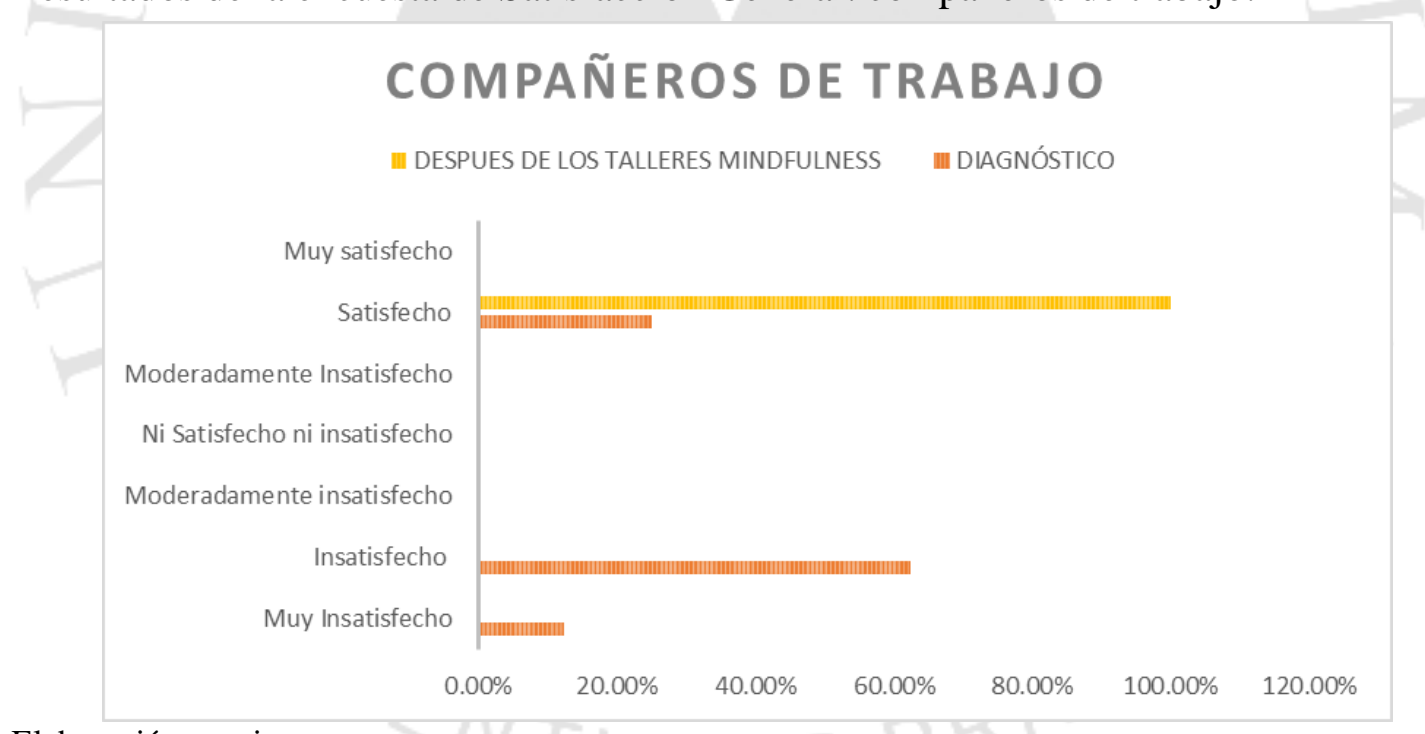

Elaboración propia.

Interpretación: En la encuesta de diagnóstico, el 12.5\% de los empleados en Renta 4, se encontraban muy insatisfechos con sus compañeros de trabajo; 62.5\%, insatisfechos; y $25 \%$, satisfechos. Después de la implementación de los talleres mindfulness, el 100\% de los empleados, estaban satisfechos.

PREGUNTA 4. Reconocimiento por el trabajo bien hecho. 
Tabla 4.9

Resultados de la encuesta de Satisfacción General: reconocimiento por buen trabajo.

\begin{tabular}{|l|c|c|c|c|}
\hline \multicolumn{1}{|c|}{ RESPUESTAS } & PERSONAS & $\begin{array}{c}\text { DIAGNÓSTICO } \\
\text { (\%) }\end{array}$ & PERSONAS & $\begin{array}{c}\text { DESPUÉS DE TALLERS } \\
\text { MINDFULNESS (\%) }\end{array}$ \\
\hline Muy Insatisfecho & 2 & $25.00 \%$ & 2 & $25.00 \%$ \\
\hline Insatisfecho & 5 & $62.50 \%$ & 2 & $25.00 \%$ \\
\hline Moderadamente insatisfecho & 0 & $0.00 \%$ & 0 & $0.00 \%$ \\
\hline Ni Satisfecho ni insatisfecho & 0 & $0.00 \%$ & 0 & $0.00 \%$ \\
\hline Moderadamente Insatisfecho & 0 & $0.00 \%$ & 0 & $0.00 \%$ \\
\hline Satisfecho & 1 & $12.50 \%$ & 4 & $50.00 \%$ \\
\hline Muy satisfecho & 0 & $0.00 \%$ & 0 & $0.00 \%$ \\
\hline \multicolumn{1}{|c|}{ Total } & $\mathbf{8}$ & $100 \%$ & $\mathbf{8}$ & $100 \%$ \\
\hline
\end{tabular}

Elaboración propia

Figura 4.7.

Resultado de la encuesta de Satisfacción General: reconocimiento por buen trabajo.

\section{RECONOCIMIENTO POR TRABAJO BIEN HECHO}

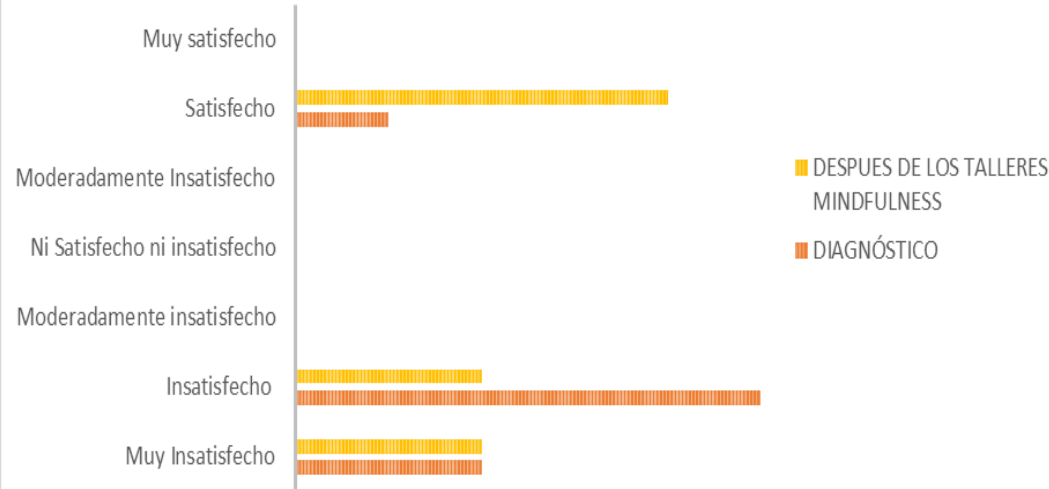

$0.00 \% 10.00 \% 20.00 \% 30.00 \% 40.00 \% 50.00 \% 60.00 \% 70.00 \%$

Elaboración propia.

Interpretación: En la encuesta de diagnóstico, el $87 \%$ de los empleados de Renta 4, se encontraban insatisfechos y el $12.5 \%$, satisfechos con el reconocimiento al trabajo bien hecho. Después de los talleres de mindfulness, el 50\% de los empleados, se encontraban satisfechos. 
PREGUNTA 5. Superior inmediato

Tabla 4.10

Resultados de la encuesta de Satisfacción General: superior inmediato.

\begin{tabular}{|l|c|c|c|c|}
\hline \multicolumn{1}{|c|}{ RESPUESTAS } & PERSONAS & $\begin{array}{c}\text { DIAGNÓSTICO } \\
(\%)\end{array}$ & PERSONAS & $\begin{array}{c}\text { DESPUÉS DE TALLERES } \\
\text { MINDFULNESS (\%) }\end{array}$ \\
\hline Muy Insatisfecho & 0 & $0.00 \%$ & 0 & $0.00 \%$ \\
\hline Insatisfecho & 4 & $50.00 \%$ & 2 & $25.00 \%$ \\
\hline Moderadamente insatisfecho & 0 & $0.00 \%$ & 0 & $0.00 \%$ \\
\hline Ni Satisfecho ni insatisfecho & 0 & $0.00 \%$ & 0 & $0.00 \%$ \\
\hline Moderadamente Insatisfecho & 0 & $0.00 \%$ & 0 & $0.00 \%$ \\
\hline Satisfecho & 4 & $50.00 \%$ & 6 & $75.00 \%$ \\
\hline Muy satisfecho & 0 & $0.00 \%$ & 0 & $0.00 \%$ \\
\hline Total & $\mathbf{8}$ & $100 \%$ & $\mathbf{8}$ & $100 \%$ \\
\hline
\end{tabular}

Elaboración propia.

Figura 4.8.

Resultados de la encuesta de Satisfacción General: superior inmediato.

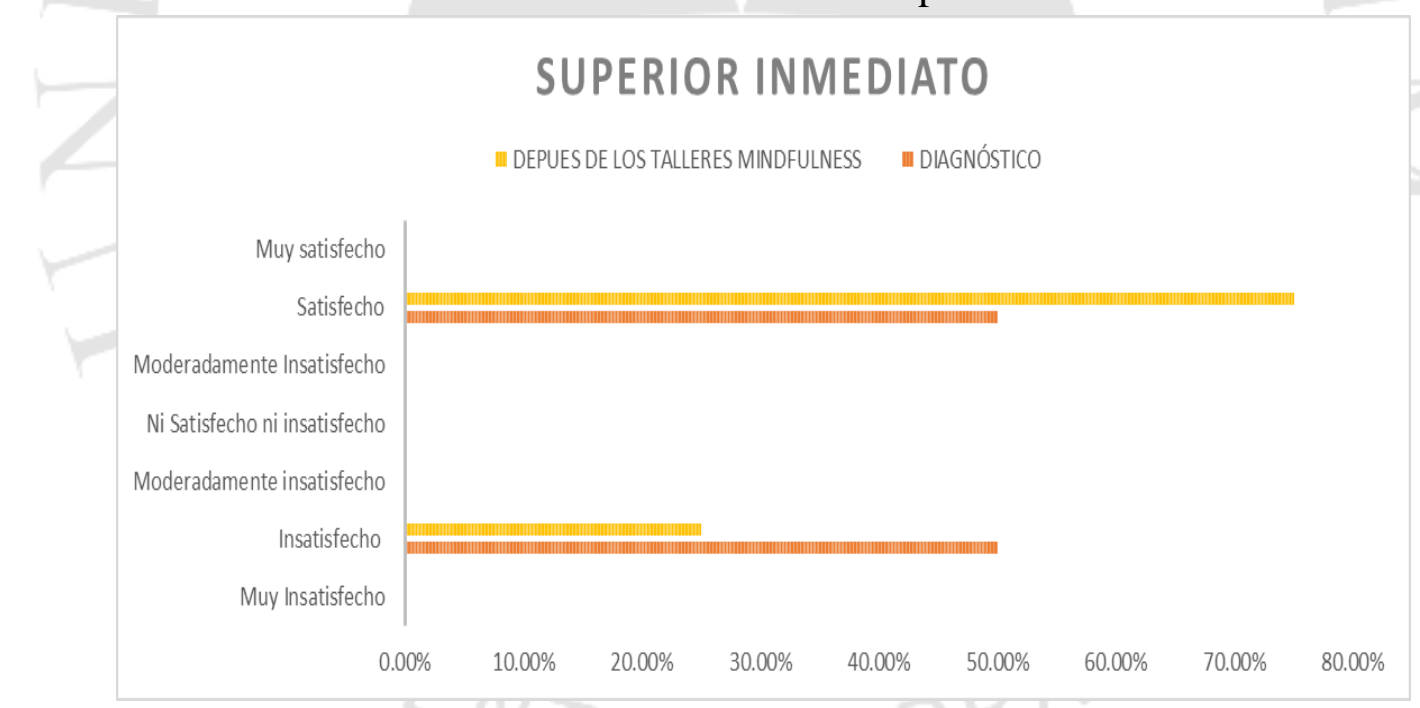

Elaboración propia

Interpretación: En la encuesta de diagnóstico, el 50\% de los empleados de Renta 4, se encontraban satisfechos con el superior inmediato, y el 50\%, insatisfechos. Después de la implementación de los talleres mindfulness, el 75\% de los empleados se encontraban satisfechos, y el 25\%, insatisfechos. 
PREGUNTA 6. Responsabilidad asignada.

Tabla 4.11

Resultados de la encuesta de Satisfacción General: Responsabilidad asignada.

\begin{tabular}{|l|c|c|c|c|}
\hline \multicolumn{1}{|c|}{ RESPUESTAS } & PERSONAS & $\begin{array}{c}\text { DIAGNÓSTICO } \\
(\%)\end{array}$ & PERSONAS & $\begin{array}{c}\text { DESPUÉS DE TALLERES } \\
\text { MINDFULNESS (\%) }\end{array}$ \\
\hline Muy Insatisfecho & 4 & $50.00 \%$ & 3 & $37.50 \%$ \\
\hline Insatisfecho & 0 & $0.00 \%$ & 0 & $0.00 \%$ \\
\hline Moderadamente insatisfecho & 0 & $0.00 \%$ & 0 & $0.00 \%$ \\
\hline Ni Satisfecho ni insatisfecho & 0 & $0.00 \%$ & 0 & $0.00 \%$ \\
\hline Moderadamente Insatisfecho & 0 & $0.00 \%$ & 0 & $0.00 \%$ \\
\hline Satisfecho & 4 & $50.00 \%$ & 5 & $62.50 \%$ \\
\hline Muy satisfecho & 0 & $0.00 \%$ & 0 & $0.00 \%$ \\
\hline$\quad$ Total & $\mathbf{8}$ & $100 \%$ & 8 & $100 \%$ \\
\hline
\end{tabular}

Elaboración propia.

Figura 4.9.

Resultados de la encuesta de Satisfacción General: Responsabilidad asignada.

\section{RESPONSABILIDAD ASIGNADA}

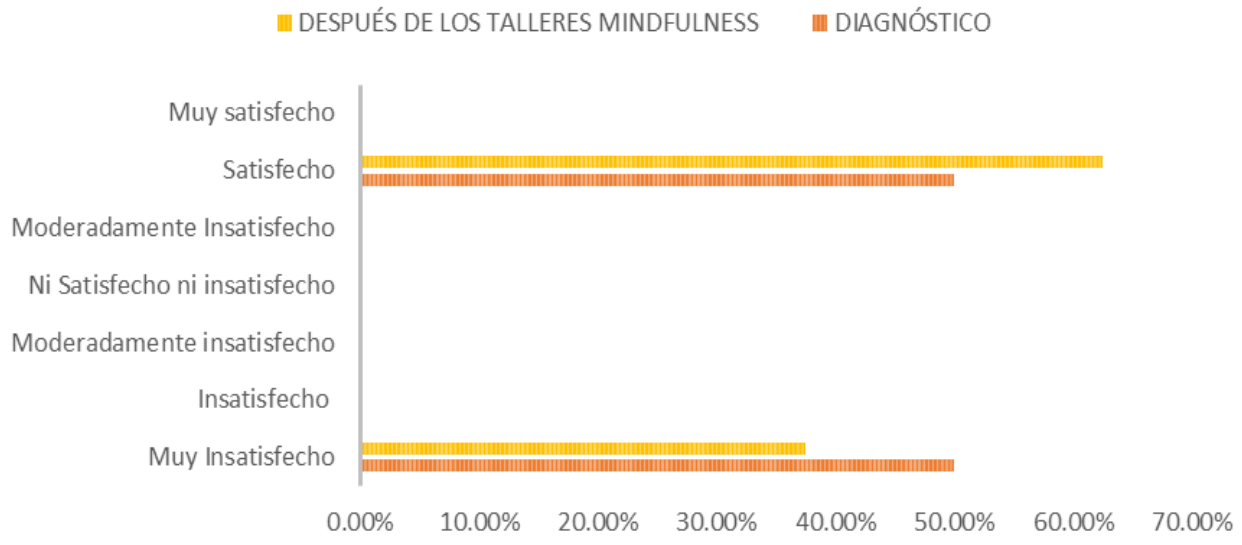

Elaboración propia.

Interpretación: En el diagnóstico de la encuesta, el 50\% de los empleados de Renta 4, se encontraban insatisfechos y el 50\%, satisfechos con la responsabilidad asignada. Después de la implementación de los talleres mindfulness, el 62.5\% de los empleados, se encontraban satisfechos, y el $37.50 \%$, insatisfechos. 
PREGUNTA 7. Salario

Tabla 4.12

Resultados de la encuesta de Satisfacción General: Salario

\begin{tabular}{|l|c|c|c|c|}
\hline \multicolumn{1}{|c|}{ RESPUESTAS } & PERSONAS & $\begin{array}{c}\text { DIAGNÓSTICO } \\
(\%)\end{array}$ & PERSONAS & $\begin{array}{c}\text { DESPUÉS DE TALLERS } \\
\text { MINDFULNESS (\%) }\end{array}$ \\
\hline Muy Insatisfecho & 5 & $62.50 \%$ & 5 & $62.50 \%$ \\
\hline Insatisfecho & 3 & $37.50 \%$ & 3 & $37.50 \%$ \\
\hline Moderadamente insatisfecho & 0 & $0.00 \%$ & 0 & $0.00 \%$ \\
\hline Ni Satisfecho ni insatisfecho & 0 & $0.00 \%$ & 0 & $0.00 \%$ \\
\hline Moderadamente Insatisfecho & 0 & $0.00 \%$ & 0 & $0.00 \%$ \\
\hline Satisfecho & 0 & $0.00 \%$ & 0 & $0.00 \%$ \\
\hline Muy satisfecho & 0 & $0.00 \%$ & 0 & $0.00 \%$ \\
\hline \multicolumn{1}{c|}{ Total } & $\mathbf{8}$ & $100 \%$ & $\mathbf{8}$ & $100 \%$ \\
\hline
\end{tabular}

Elaboración propia.

Figura 4.10.

Resultados de la encuesta de Satisfacción General: Salario
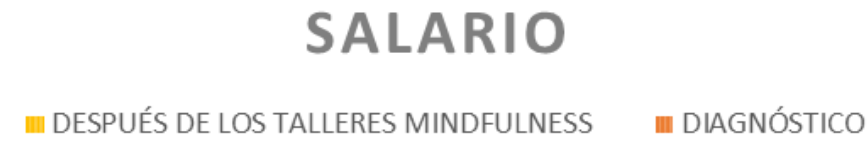

$$
\begin{array}{r}
\text { Muy satisfecho } \\
\text { Satisfecho }
\end{array}
$$

Moderadamente Insatisfecho

Ni Satisfecho ni insatisfecho

Moderadamente insatisfecho

Insatisfecho

Muy Insatisfecho

$0.00 \% \quad 10.00 \% \quad 20.00 \% \quad 30.00 \% \quad 40.00 \% \quad 50.00 \% \quad 60.00 \% \quad 70.00 \%$

Elaboración propia.

Interpretación: En la encuesta de diagnóstico, el 100\% de los empleados de Renta 4, se encuentran insatisfechos con el salario que reciben. Después de la implementación de los talleres mindfulness, el 100\% de los empleados permanecen insatisfechos. 
PREGUNTA 8. La posibilidad de utilizar sus capacidades.

Tabla 4.13

Resultados de la encuesta de Satisfacción General: La posibilidad de utilizar sus capacidades.

\begin{tabular}{|l|c|c|c|c|}
\hline \multicolumn{1}{|c|}{ RESPUESTAS } & PERSONAS & $\begin{array}{c}\text { DIAGNÓSTICO } \\
\text { (\%) }\end{array}$ & PERSONAS & $\begin{array}{c}\text { DESPUÉS DE TALLERES } \\
\text { MINDFULNESS (\%) }\end{array}$ \\
\hline Muy Insatisfecho & 0 & $0.00 \%$ & 0 & $0.00 \%$ \\
\hline Insatisfecho & 4 & $50.00 \%$ & 0 & $0.00 \%$ \\
\hline Moderadamente insatisfecho & 0 & $0.00 \%$ & 0 & $0.00 \%$ \\
\hline Ni Satisfecho ni insatisfecho & 0 & $0.00 \%$ & 0 & $0.00 \%$ \\
\hline Moderadamente Insatisfecho & 0 & $0.00 \%$ & 0 & $0.00 \%$ \\
\hline Satisfecho & 0 & $0.00 \%$ & 4 & $50.00 \%$ \\
\hline Muy satisfecho & 4 & $50.00 \%$ & 4 & $50.00 \%$ \\
\hline \multicolumn{1}{c}{ Total } & $\mathbf{8}$ & $\mathbf{1 0 0 \%}$ & $\mathbf{8}$ & $\mathbf{1 0 0 \%}$ \\
\hline
\end{tabular}

Elaboración propia.

Figura 4.11.

Resultados de la encuesta de Satisfacción General: La posibilidad de utilizar sus capacidades.

\section{POSIBILIDAD DE USAR SUS \\ CAPACIDADES}

III DESPUÉS DE LOS TALLERES MINDFULNESS ㅍ. DIAGNÓSTICO

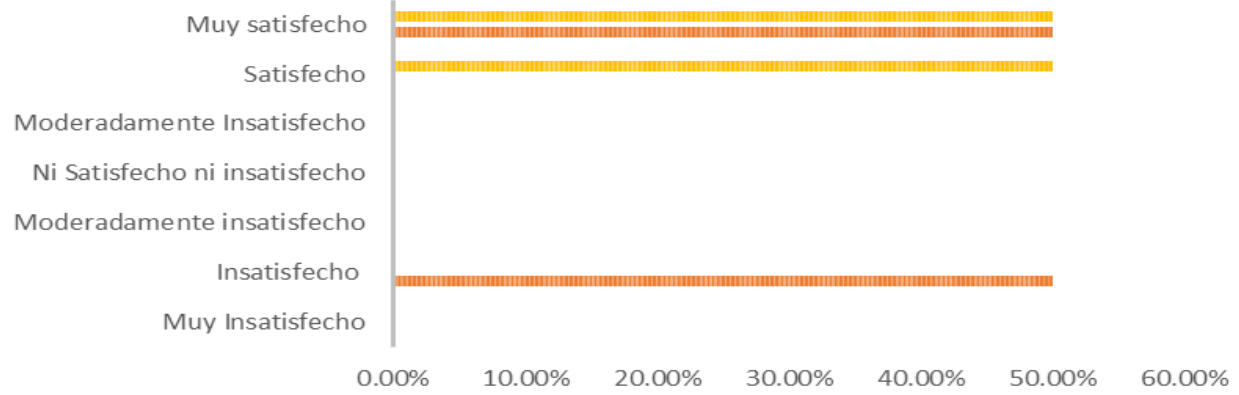

Elaboración propia (2018).

Interpretación: En el diagnóstico de la encuesta general de satisfacción laboral, el 50\% de los empleados de Renta 4, se encontraban insatisfechos con la posibilidad de utilizar sus capacidades; y el 50\%, satisfechos. Después de la implementación de los talleres mindfulness, el 100\% de los empleados se encontraban satisfechos. 
PREGUNTA 9. Relación entre la dirección y los trabajadores.

Tabla 4.14

Resultados de la encuesta de Satisfacción General: Relación entre la dirección y los trabajadores.

\begin{tabular}{|l|c|c|c|c|}
\hline \multicolumn{1}{|c|}{ RESPUESTAS } & PERSONAS & $\begin{array}{c}\text { DIAGNÓSTICO } \\
\text { (\%) }\end{array}$ & PERSONAS & $\begin{array}{c}\text { DESPUÉS DE TALLERES } \\
\text { MINDFULNESS (\%) }\end{array}$ \\
\hline Muy Insatisfecho & 2 & $25.00 \%$ & 2 & $25.00 \%$ \\
\hline Insatisfecho & 3 & $37.50 \%$ & 3 & $37.50 \%$ \\
\hline Moderadamente insatisfecho & 0 & $0.00 \%$ & 0 & $0.00 \%$ \\
\hline Ni Satisfecho ni insatisfecho & 0 & $0.00 \%$ & 0 & $0.00 \%$ \\
\hline Moderadamente Insatisfecho & 0 & $0.00 \%$ & 0 & $0.00 \%$ \\
\hline Satisfecho & 3 & $37.50 \%$ & 3 & $37.50 \%$ \\
\hline Muy satisfecho & 0 & $0.00 \%$ & 0 & $0.00 \%$ \\
\hline \multicolumn{1}{c|}{ Total } & $\mathbf{8}$ & $\mathbf{1 0 0 \%}$ & $\mathbf{8}$ & $\mathbf{1 0 0 \%}$ \\
\hline
\end{tabular}

Elaboración propia.

Figura 4.12.

Resultado de la encuesta de Satisfacción General: Relación entre la dirección y los trabajadores.

\section{RELACIÓN ENTRE LA DIRECCIÓN Y EMPLEADOS}

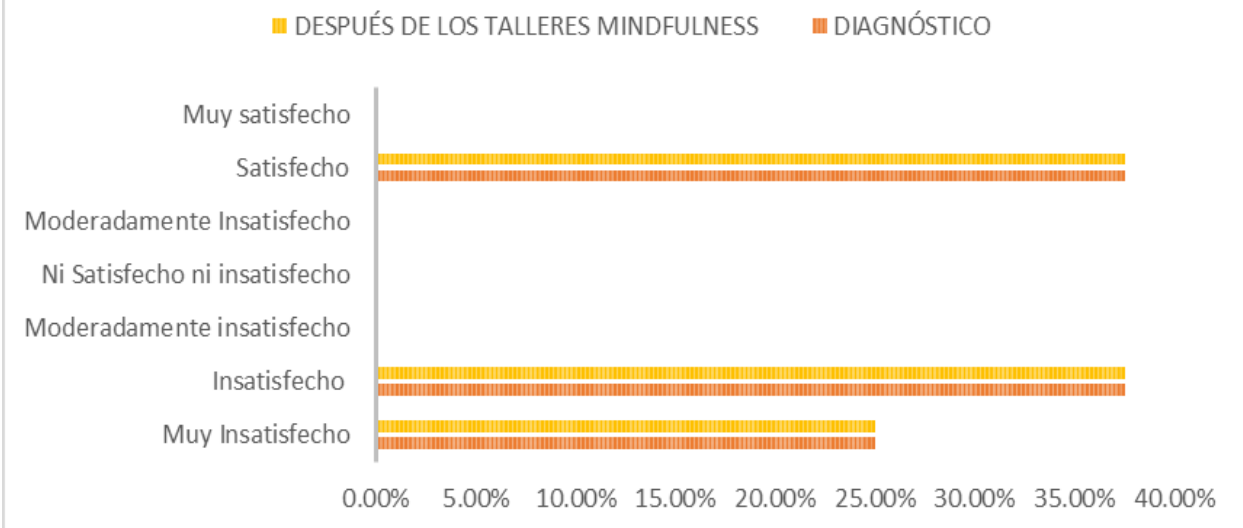

Elaboración propia.

Interpretación: En la encuesta de diagnóstico, el 62.5\% de los empleados de Renta 4, se encontraban insatisfechos con la relación que existe entre la directiva y los empleados; el 
$37.5 \%$ se encontraban satisfechos. Después de la implementación de los talleres mindfulness, los porcentajes se mantuvieron igual.

PREGUNTA 10. Posibilidades de promoción.

Tabla 4.15

Resultados de la encuesta de Satisfacción General: Posibilidad de promoción.

\begin{tabular}{|l|c|c|c|c|}
\hline \multicolumn{1}{|c|}{ RESPUESTAS } & PERSONAS & $\begin{array}{c}\text { DIAGNÓSTICO } \\
\text { (\%) }\end{array}$ & PERSONAS & $\begin{array}{c}\text { DESPUÉS DE TALLERES } \\
\text { MINDFULNESS (\%) }\end{array}$ \\
\hline Muy Insatisfecho & 2 & $25.00 \%$ & 2 & $25.00 \%$ \\
\hline Insatisfecho & 5 & $62.50 \%$ & 5 & $62.50 \%$ \\
\hline Moderadamente insatisfecho & 0 & $0.00 \%$ & 0 & $0.00 \%$ \\
\hline Ni Satisfecho ni insatisfecho & 0 & $0.00 \%$ & 0 & $0.00 \%$ \\
\hline Moderadamente Insatisfecho & 0 & $0.00 \%$ & 0 & $0.00 \%$ \\
\hline Satisfecho & 1 & $12.50 \%$ & 1 & $12.50 \%$ \\
\hline Muy satisfecho & 0 & $0.00 \%$ & 0 & $0.00 \%$ \\
\hline \multicolumn{1}{|c|}{ Total } & $\mathbf{8}$ & $\mathbf{1 0 0 \%}$ & $\mathbf{8}$ & $\mathbf{1 0 0 \%}$ \\
\hline
\end{tabular}

Elaboración propia

Figura 4.13.

Resultados de la encuesta de Satisfacción General: Posibilidad de promoción.

\section{POSIBILIDAD DE PROMOCIÓN}

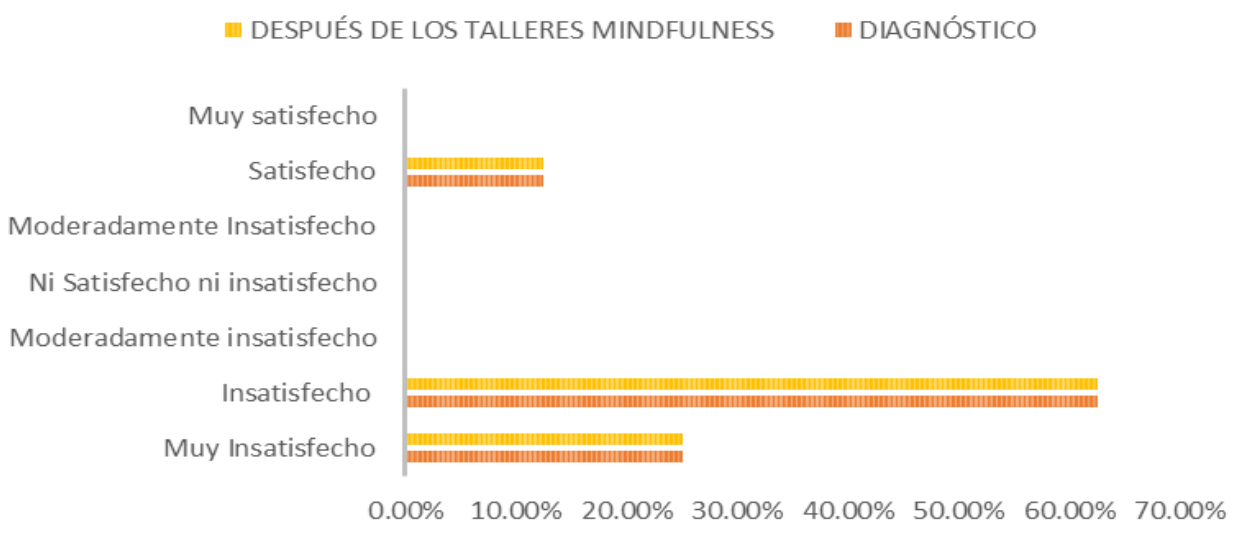

Elaboración propia.

Interpretación: En la encuesta de diagnóstico, el 87.5\% de los empleados de Renta 4, se encuentran insatisfechos con la posibilidad de promocionar en la empresa, y el $12.5 \%$ se encuentran satisfechos. Después de la implementación de los talleres mindfulness, los porcentajes se mantuvieron igual, sin ninguna variación. 
PREGUNTA 11. El modo en que la empresa está gestionada.

Tabla 4.16

Resultados de la encuesta de Satisfacción General: Modo de gestión de la empresa.

\begin{tabular}{|l|c|c|c|c|}
\hline \multicolumn{1}{|c|}{ RESPUESTAS } & PERSONAS & $\begin{array}{c}\text { DIAGNÓSTICO } \\
\text { (\%) }\end{array}$ & PERSONAS & $\begin{array}{c}\text { DESPUÉS DE TALLERES } \\
\text { MINDFULNESS (\%) }\end{array}$ \\
\hline Muy Insatisfecho & 4 & $50.00 \%$ & 4 & $50.00 \%$ \\
\hline Insatisfecho & 4 & $50.00 \%$ & 4 & $50.00 \%$ \\
\hline Moderadamente insatisfecho & 0 & $0.00 \%$ & 0 & $0.00 \%$ \\
\hline Ni Satisfecho ni insatisfecho & 0 & $0.00 \%$ & 0 & $0.00 \%$ \\
\hline Moderadamente Insatisfecho & 0 & $0.00 \%$ & 0 & $0.00 \%$ \\
\hline Satisfecho & 0 & $0.00 \%$ & 0 & $0.00 \%$ \\
\hline Muy satisfecho & 0 & $0.00 \%$ & 0 & $0.00 \%$ \\
\hline Total & $\mathbf{8}$ & $100 \%$ & $\mathbf{8}$ & $100 \%$ \\
\hline
\end{tabular}

Elaboración propia.

Figura 4.14.

Resultado de la encuesta de Satisfacción General: Modo de gestión de la empresa.

\section{MODELO DE GESTIÓN DE LA EMPRESA}

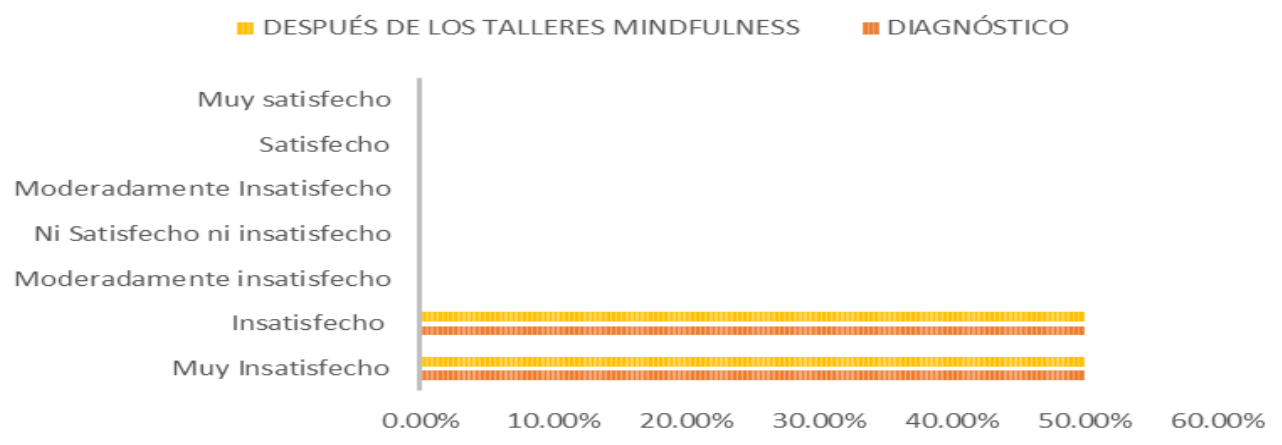

Elaboración propia.

Interpretación: En la encuesta de diagnóstico, el 100\% de los empleados de Renta 4, se encuentran insatisfechos con el modelo de gestión de la empresa. Después de la implementación de los talleres, los resultados obtenidos en el diagnóstico no han tenido ninguna variación. 
PREGUNTA 12. La atención que se presta a las sugerencias que hace.

Tabla 4.17

Resultados de la encuesta de Satisfacción General: La atención que se presta a las sugerencias que hace.

\begin{tabular}{|l|c|c|c|c|}
\hline \multicolumn{1}{|c|}{ RESPUESTAS } & PERSONAS & $\begin{array}{c}\text { DIAGNÓSTICO } \\
\text { (\%) }\end{array}$ & PERSONAS & $\begin{array}{c}\text { DESPUÉS DE TALLERES } \\
\text { MINDFULNESS (\%) }\end{array}$ \\
\hline Muy Insatisfecho & 0 & $0.00 \%$ & 0 & $0.00 \%$ \\
\hline Insatisfecho & 4 & $50.00 \%$ & 4 & $50.00 \%$ \\
\hline Moderadamente insatisfecho & 0 & $0.00 \%$ & 0 & $0.00 \%$ \\
\hline Ni Satisfecho ni insatisfecho & 0 & $0.00 \%$ & 0 & $0.00 \%$ \\
\hline Moderadamente Insatisfecho & 0 & $0.00 \%$ & 0 & $0.00 \%$ \\
\hline Satisfecho & 4 & $50.00 \%$ & 4 & $50.00 \%$ \\
\hline Muy satisfecho & 0 & $0.00 \%$ & 0 & $0.00 \%$ \\
\hline Total & $\mathbf{8}$ & $100 \%$ & $\mathbf{8}$ & $100 \%$ \\
\hline
\end{tabular}

Elaboración propia.

Figura 4.15.

Resultado de la encuesta de Satisfacción General: La atención que se le presta a las sugerencias que hace.

\section{LA EMPRESA TOMA EN CUENTA LOS APORTES QUE HACE}

iㅣ DESPUÉS DE LOS TALLERES MINDFULNESS In DIAGNÓSTICO

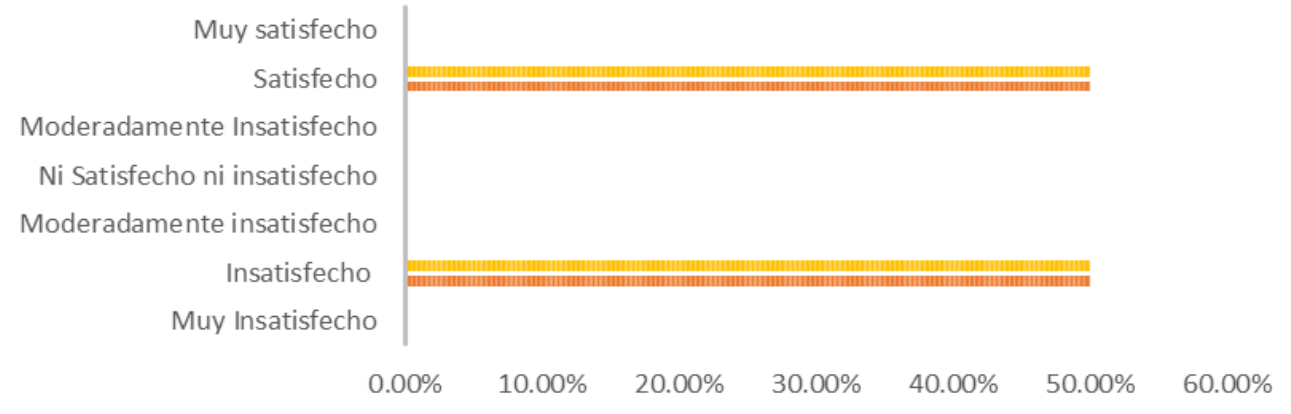

Elaboración propia.

Interpretación: En la encuesta de diagnóstico de satisfacción laboral general, el 50\% de los empleados de Renta 4, se encontraban insatisfechos con las sugerencias aportadas y que no eran consideradas en la empresa; mientras que el $50 \%$, se encontraban satisfechos. 
Después de la implementación de los talleres de mindfulness, no ocurrió ninguna variación.

PREGUNTA 13. Horario de trabajo

Tabla 4.18

Resultados de la encuesta de Satisfacción General: Horario de trabajo.

\begin{tabular}{|l|c|c|c|c|}
\hline \multicolumn{1}{|c|}{ RESPUESTAS } & PERSONAS & $\begin{array}{c}\text { DIAGNÓSTICO } \\
\text { (\%) }\end{array}$ & PERSONAS & $\begin{array}{c}\text { DESPUÉS DE TALLRES } \\
\text { MINDFULNESS (\%) }\end{array}$ \\
\hline Muy Insatisfecho & 0 & $0.00 \%$ & 0 & $0.00 \%$ \\
\hline Insatisfecho & 0 & $0.00 \%$ & 0 & $0.00 \%$ \\
\hline Moderadamente insatisfecho & 0 & $0.00 \%$ & 0 & $0.00 \%$ \\
\hline Ni Satisfecho ni insatisfecho & 0 & $0.00 \%$ & 0 & $0.00 \%$ \\
\hline Moderadamente Insatisfecho & 0 & $0.00 \%$ & 0 & $0.00 \%$ \\
\hline Satisfecho & 4 & $50.00 \%$ & 4 & $50.00 \%$ \\
\hline Muy satisfecho & 4 & $50.00 \%$ & 4 & $50.00 \%$ \\
\hline \multicolumn{1}{|c|}{ Total } & $\mathbf{8}$ & $\mathbf{1 0 0 \%}$ & $\mathbf{8}$ & $\mathbf{1 0 0 \%}$ \\
\hline
\end{tabular}

Elaboración propia.

Figura 4.16.

Resultados de la encuesta de Satisfacción General: Horario de trabajo.

\section{HORARIO DE TRABAJO}

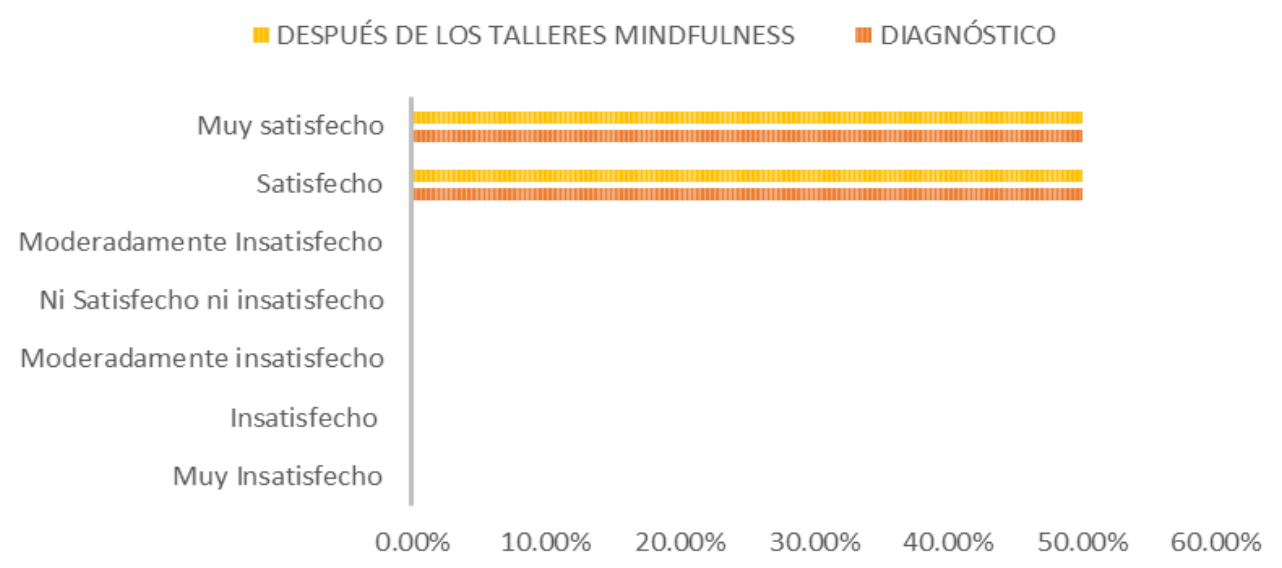

Elaboración propia.

Interpretación: En el diagnóstico de la encuesta general de satisfacción laboral, el 100\% de los empleados de la empresa Renta 4, se encuentran satisfecho con el horario de trabajo. Así mismo, luego de la implementación de los talleres mindfulness, los porcentajes no tuvieron ninguna variación. 
PREGUNTA 14. Variedad de tareas asignadas.

Tabla 4.19

Resultados de la encuesta de Satisfacción General: Variedad de tareas asignadas.

\begin{tabular}{|l|c|c|c|c|}
\hline \multicolumn{1}{|c|}{ RESPUESTAS } & PERSONAS & $\begin{array}{c}\text { DIAGNÓSTICO } \\
\text { (\%) }\end{array}$ & PERSONAS & $\begin{array}{c}\text { DESPUÉS DE TALLERES } \\
\text { MINDFULNESS (\%) }\end{array}$ \\
\hline Muy Insatisfecho & 0 & $0.00 \%$ & 0 & $0.00 \%$ \\
\hline Insatisfecho & 2 & $25.00 \%$ & 2 & $25.00 \%$ \\
\hline Moderadamente insatisfecho & 0 & $0.00 \%$ & 0 & $0.00 \%$ \\
\hline Ni Satisfecho ni insatisfecho & 0 & $0.00 \%$ & 0 & $0.00 \%$ \\
\hline Moderadamente Insatisfecho & 0 & $0.00 \%$ & 0 & $0.00 \%$ \\
\hline Satisfecho & 5 & $62.50 \%$ & 5 & $62.50 \%$ \\
\hline Muy satisfecho & 1 & $12.50 \%$ & 1 & $12.50 \%$ \\
\hline \multicolumn{1}{|c|}{ Total } & $\mathbf{8}$ & $100 \%$ & $\mathbf{8}$ & $100 \%$ \\
\hline
\end{tabular}

Elaboración propia.

Figura 4.17.

Resultados de la encuesta de Satisfacción General: Variedad de tareas asignadas.

\section{VARIEDAD DE TAREAS ASIGNADAS}

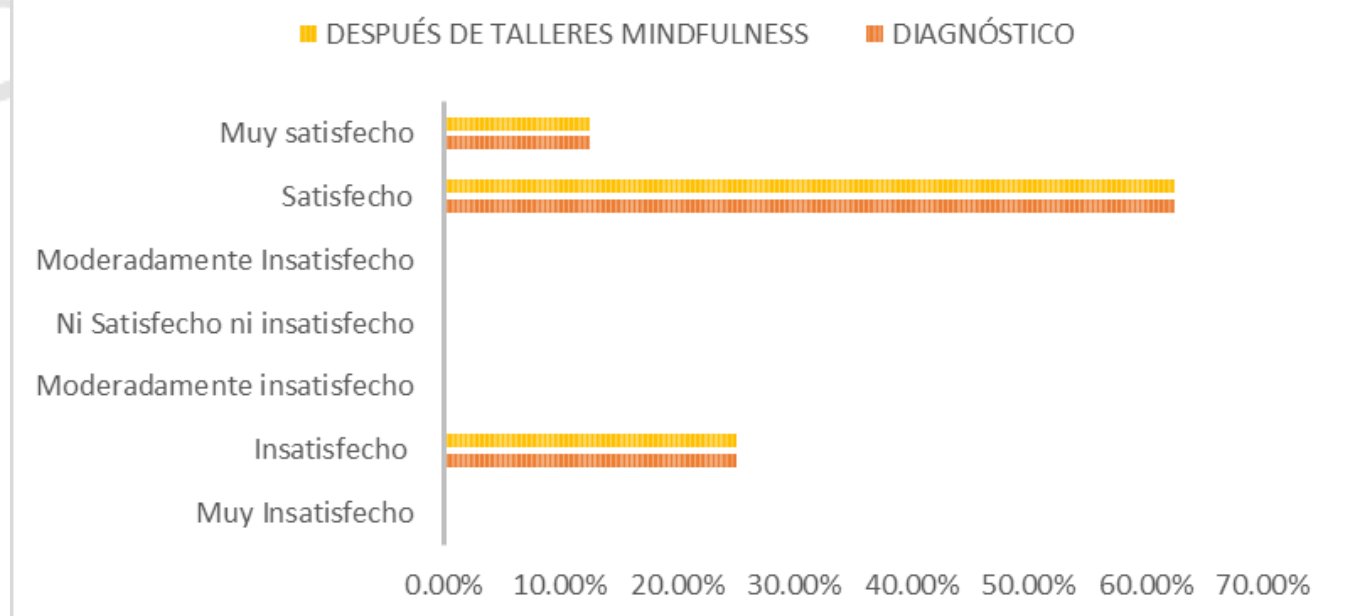

Elaboración propia

Interpretación: En el diagnóstico de la encuesta general de satisfacción laboral, el 25\% de los empleados de Renta 4, se encuentran insatisfechos con la variedad de tareas asignadas en su puesto de trabajo; y el $75 \%$, satisfechos. Después de la implementación de los talleres, no ocurrió ninguna variación. 
PREGUNTA 15. Estabilidad en el empleo.

Tabla 4.20

Resultados de la encuesta de Satisfacción General: Estabilidad en el empleo.

\begin{tabular}{|l|c|c|c|c|}
\hline \multicolumn{1}{|c|}{ RESPUESTAS } & PERSONAS & $\begin{array}{c}\text { DIAGNÓSTICO } \\
(\%)\end{array}$ & PERSONAS & $\begin{array}{c}\text { DESPUÉS DE TALLERS } \\
\text { MINDFULNESS (\%) }\end{array}$ \\
\hline Muy Insatisfecho & 0 & $0.00 \%$ & 0 & $0.00 \%$ \\
\hline Insatisfecho & 1 & $12.50 \%$ & 1 & $12.50 \%$ \\
\hline Moderadamente insatisfecho & 0 & $0.00 \%$ & 0 & $0.00 \%$ \\
\hline Ni Satisfecho ni insatisfecho & 0 & $0.00 \%$ & 0 & $0.00 \%$ \\
\hline Moderadamente Insatisfecho & 0 & $0.00 \%$ & 0 & $0.00 \%$ \\
\hline Satisfecho & 4 & $50.00 \%$ & 4 & $50.00 \%$ \\
\hline Muy satisfecho & 3 & $37.50 \%$ & 3 & $37.50 \%$ \\
\hline Total & $\mathbf{8}$ & $100 \%$ & 8 & $100 \%$ \\
\hline
\end{tabular}

Elaboración propia.

Figura 4.18.

Resultados de la encuesta de Satisfacción General: Estabilidad en el empleo.

\section{ESTABILIDAD EN EL EMPLEO}

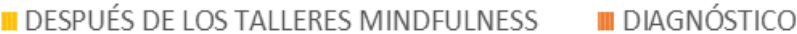

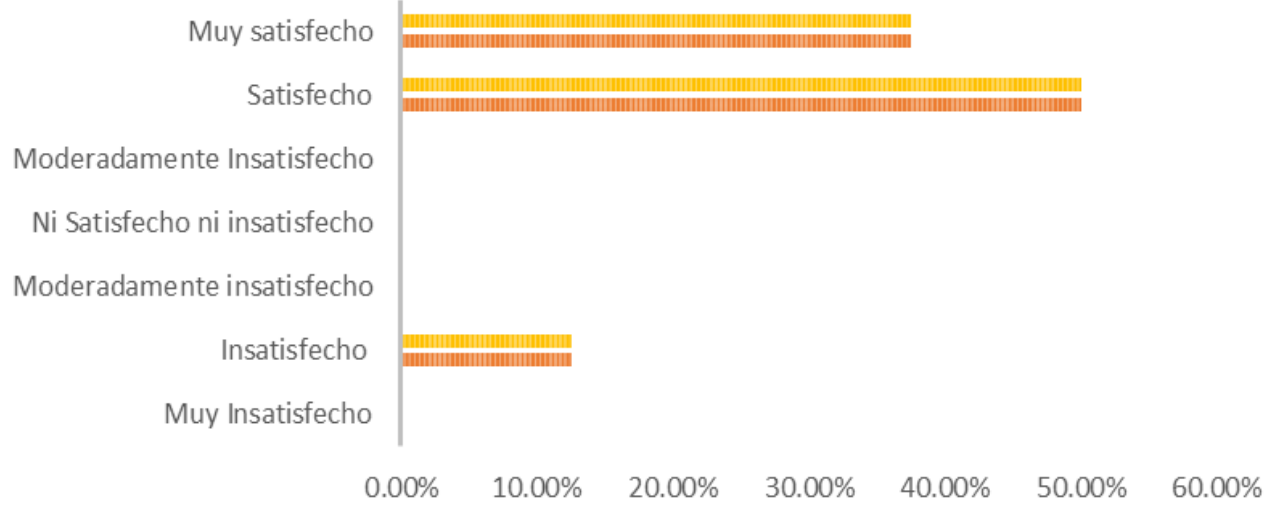

Elaboración propia.

Interpretación: En el diagnóstico de la encuesta general de satisfacción labora, el 12.5 $\%$ de los empleados de Renta 4, se encuentran insatisfechos con la estabilidad de su empleo; y el $87.5 \%$, satisfechos. Después de la implementación de los talleres mindfulness, no se mostró ninguna variación en los resultados. 


\subsection{Mindfulness - Satisfacción laboral}

\section{Análisis de fiabilidad del cuestionario operativo}

Se hizo el análisis de fiabilidad utilizando el coeficiente "alfa de Cronbach" para las preguntas utilizadas en el cuestionario propuesto.

Tabla 4.21

Análisis del Coeficiente de Cronbach

ESTADISTICA DE FIABILIDAD

\begin{tabular}{|c|c|}
\hline Alfa de Crombach & $\mathrm{N}^{\circ}$ de elementos \\
\hline 0,861 & 10 \\
\hline
\end{tabular}

Elaboración propia.

Interpretación: El coeficiente de fiabilidad es 0,861 lo cual indica que las preguntas son aceptadas para medir la relación entre las variables de análisis, los talleres mindfulness y la satisfacción laboral.

\section{Resultados del cuestionario Operativo}

Este cuestionario se aplicó después de 4 semanas, finalizando la implementación de los talleres mindfulness en la empresa Renta 4.

Pregunta 1. ¿Considera usted que el estrés tiene impacto directo en la satisfacción laboral?

Tabla 4.22

Resultados del cuestionario operativo: pregunta 1.

\begin{tabular}{|c|c|c|}
\hline Alternativa & $\mathbf{N}^{\circ}$ & $\%$ \\
\hline $\begin{array}{c}\text { Muy en } \\
\text { desacuerdo }\end{array}$ & 0 & $0,00 \%$ \\
\hline En desacuerdo & 0 & $0,00 \%$ \\
\hline Indiferente & 4 & $50,0 \%$ \\
\hline De acuerdo & 4 & $50,0 \%$ \\
\hline Muy de acuerdo & 0 & $0,00 \%$ \\
\hline TOTAL & 8 & $100 \%$ \\
\hline
\end{tabular}

Elaboración propia. 
Figura 4.19.

Resultados del cuestionario operativo: pregunta 1.

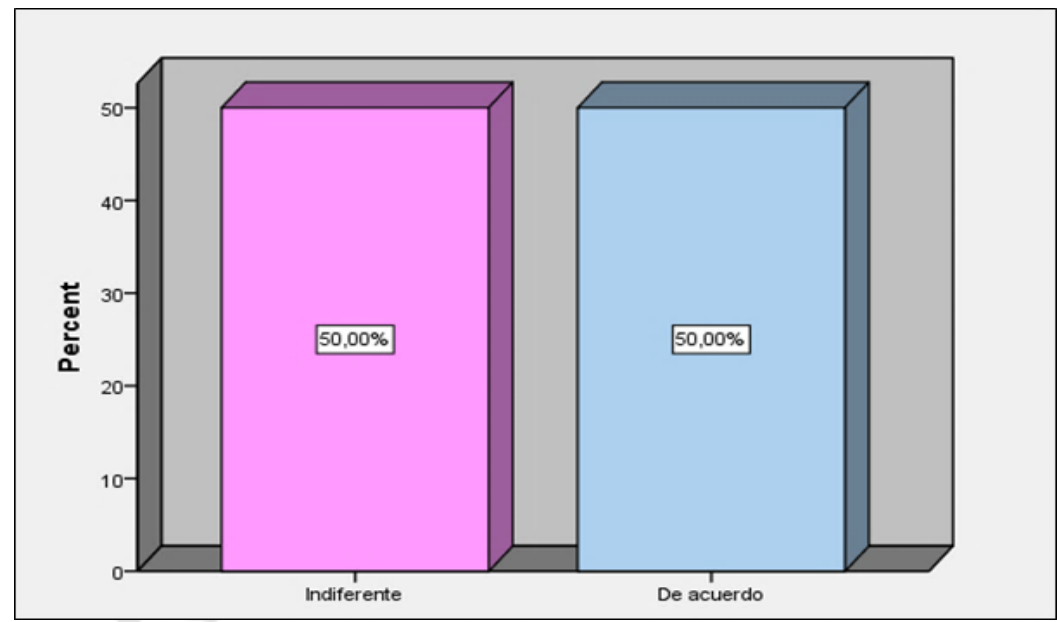

Fuente: Spss vs 23 (2018).

Interpretación: El resultado favorece la investigación; el 50.00\% de los encuestados están de acuerdo en que el estrés afecta la satisfacción laboral, y el 50.00\% respondieron que el estrés es indiferente para la satisfacción laboral en la empresa Renta 4.

Pregunta 2. ¿Cree usted que el programa de Reducción del Estrés y de Relajación (MBSR) mejora la satisfacción laboral?

Tabla 4.23

Resultados del cuestionario operativo: pregunta 2.

\begin{tabular}{|c|c|c|}
\hline Alternativa & $\mathbf{N}^{\mathbf{2}}$ & $\%$ \\
\hline $\begin{array}{c}\text { Muy en } \\
\text { desacuerdo }\end{array}$ & 0 & $0,00 \%$ \\
\hline En desacuerdo & 0 & $0.00 \%$ \\
\hline Indiferente & 2 & $25,00 \%$ \\
\hline De acuerdo & 5 & $62,50 \%$ \\
\hline Muy de acuerdo & 1 & $12,50 \%$ \\
\hline TOTAL & 8 & $100 \%$ \\
\hline
\end{tabular}

Elaboración propia. 
Figura 4.20.

Resultados del cuestionario operativo: pregunta 2.

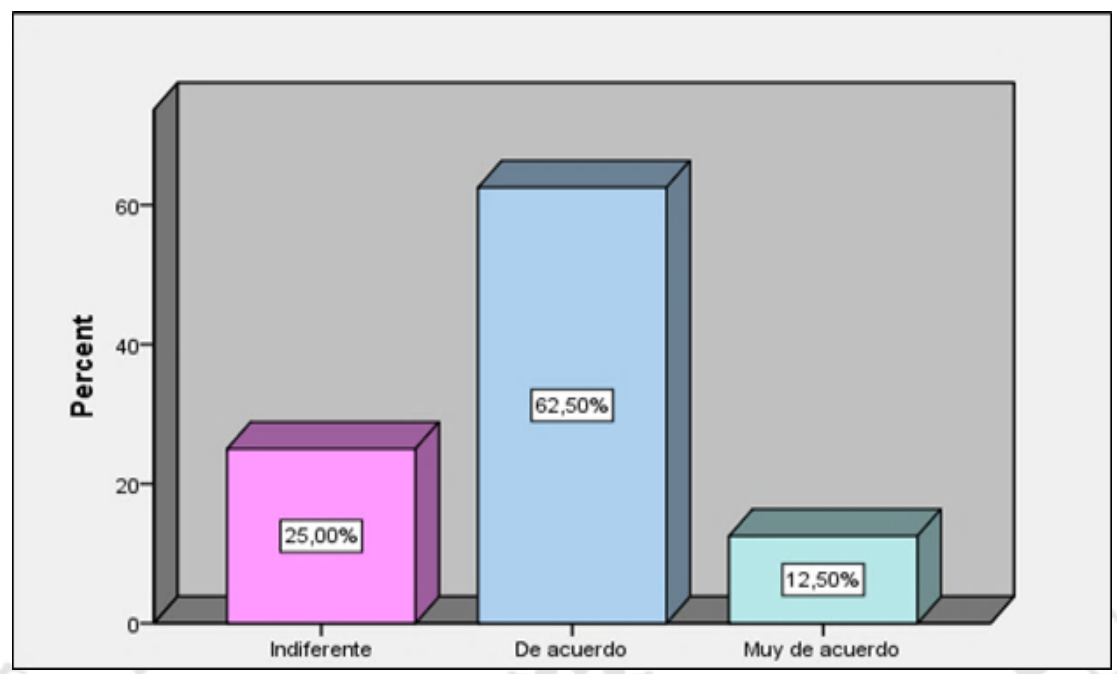

Fuente: Spss vs 23 (2018).

Interpretación: El resultado favorece a la investigación; el 12.50\% de los encuestados están muy de acuerdo, el $62.50 \%$ respondieron de acuerdo, y $25.00 \%$ se muestran indiferente, al considerar que el Programa de Reducción del Estrés y de Relajación (MBSR) es importante para la satisfacción laboral.

Pregunta 3. ¿Considera usted que los talleres de mindfulness son una solución para el estrés laboral?

Tabla 4.24

Resultados del cuestionario operativo: pregunta 3.

\begin{tabular}{|c|c|c|}
\hline Alternativa & $\mathbf{N}^{\mathbf{2}}$ & $\%$ \\
\hline $\begin{array}{c}\text { Muy en } \\
\text { desacuerdo }\end{array}$ & 0 & $0,00 \%$ \\
\hline En desacuerdo & 0 & $0,00 \%$ \\
\hline Indiferente & 2 & $25,0 \%$ \\
\hline De acuerdo & 5 & $62,5 \%$ \\
\hline Muy de acuerdo & 1 & $12,5 \%$ \\
\hline TOTAL & 8 & $100 \%$ \\
\hline
\end{tabular}

Elaboración propia. 
Figura 4.21.

Resultados del cuestionario operativo: pregunta 3.

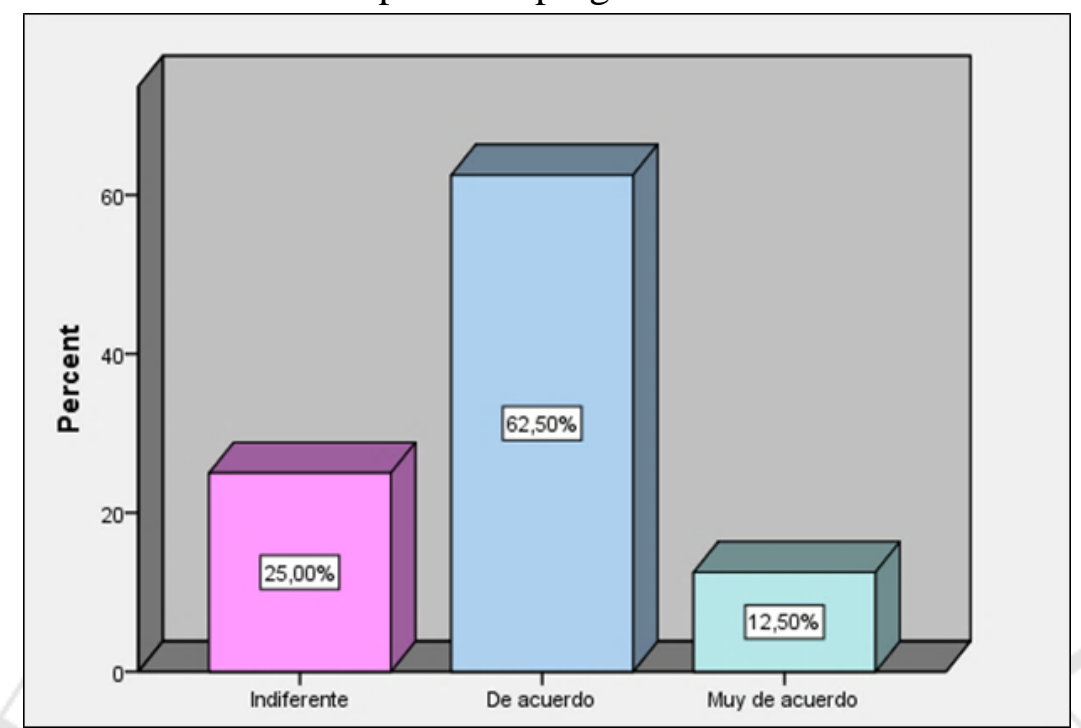

Fuente: Spss vs 23 (2018).

Interpretación: El resultado favorece la investigación; el $12.50 \%$ de los encuestados están muy de acuerdo, el $62.50 \%$ respondieron de acuerdo y $25.00 \%$ se muestran indiferente, al considerar que los talleres mindfulness son una solución para el estrés.

Pregunta 4. ¿Considera usted que la mejora del estado psicológico y calidad de vida impactan de manera positiva en la satisfacción laboral?

\section{Tabla 4.25}

Resultados del cuestionario operativo: pregunta 4.

\begin{tabular}{|c|c|c|}
\hline Alternativa & $\mathbf{N}^{\circ}$ & $\%$ \\
\hline $\begin{array}{c}\text { Muy en } \\
\text { desacuerdo }\end{array}$ & 0 & $0,00 \%$ \\
\hline En desacuerdo & 0 & $0,00 \%$ \\
\hline Indiferente & 2 & $25,0 \%$ \\
\hline De acuerdo & 5 & $62,5 \%$ \\
\hline Muy de acuerdo & 1 & $12,5 \%$ \\
\hline TOTAL & 8 & $100 \%$ \\
\hline
\end{tabular}

Elaboración propia 
Figura 4.22.

Resultados del cuestionario operativo: pregunta 4.

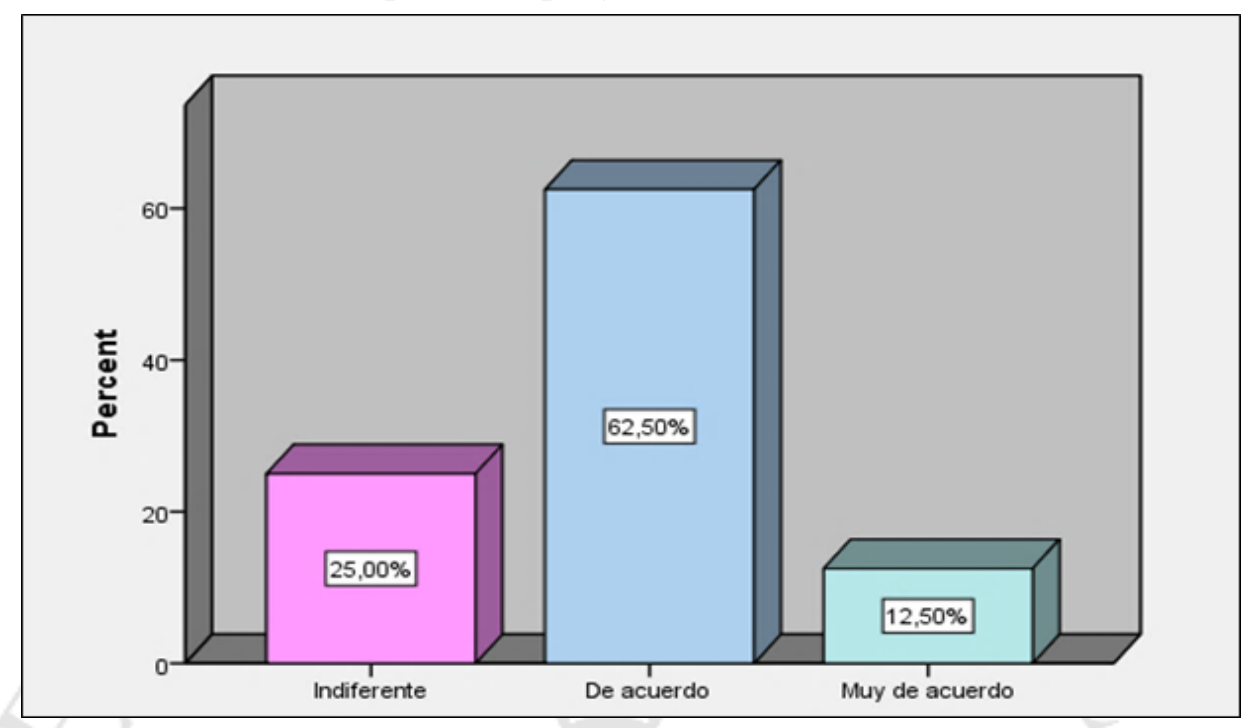

Fuente: Spss vs 23 (2018).

Interpretación: El resultado favorece la investigación; el $12.50 \%$ de los encuestados están muy de acuerdo, el $62.50 \%$ respondieron de acuerdo y $25.00 \%$ se muestran indiferente, al considerar que la mejora del estado psicológico y calidad de vida impactan de manera positiva en la satisfacción laboral.

Pregunta 5. ¿Considera usted que la productividad impacta directamente en la satisfacción laboral?

Tabla 4.26

Resultados del cuestionario operativo: pregunta 5.

\begin{tabular}{|c|c|c|}
\hline Alternativa & $\mathbf{N}^{\circ}$ & $\%$ \\
\hline $\begin{array}{c}\text { Muy en } \\
\text { desacuerdo }\end{array}$ & 0 & $0,00 \%$ \\
\hline En desacuerdo & 0 & $0,00 \%$ \\
\hline Indiferente & 2 & $25,0 \%$ \\
\hline De acuerdo & 5 & $62,5 \%$ \\
\hline Muy de acuerdo & 1 & $12,5 \%$ \\
\hline TOTAL & 8 & $100 \%$ \\
\hline
\end{tabular}

Elaboración propia. 
Figura 4.23.

Resultados del cuestionario operativo: pregunta 5.

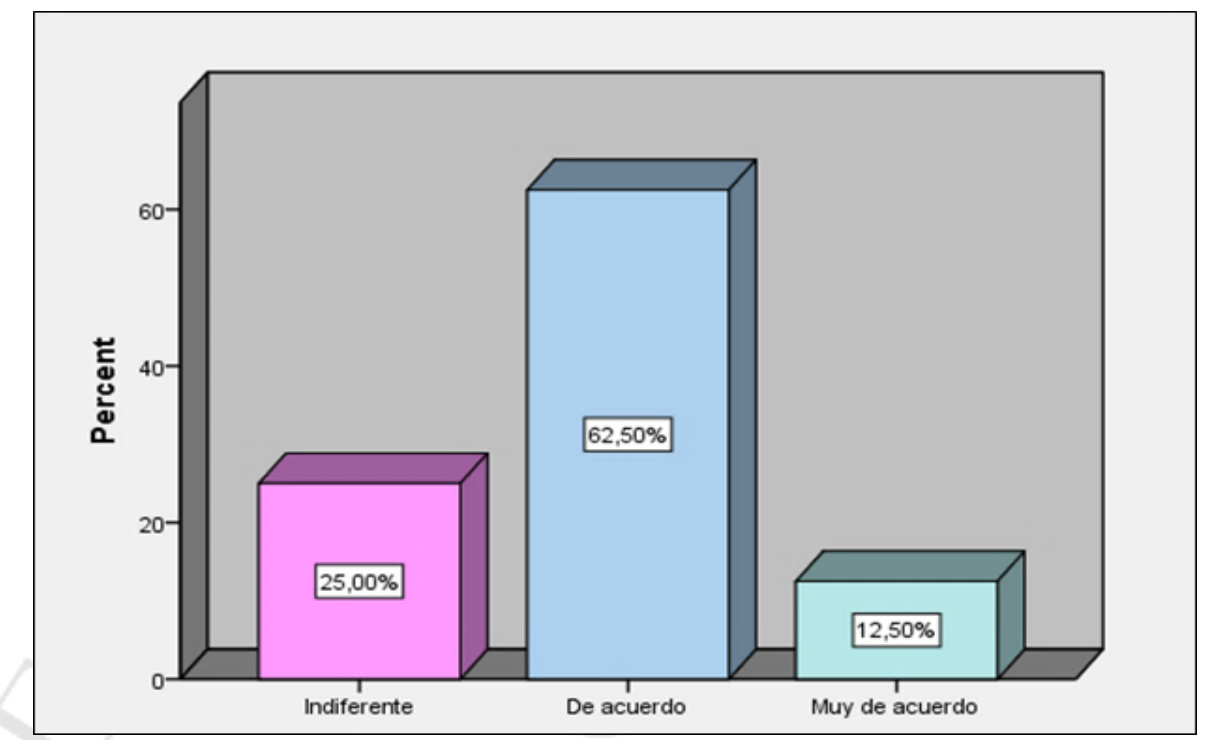

Fuente: Spss vs 23 (2018).

Interpretación: El resultado favorece la investigación; el $12.50 \%$ de los encuestados están muy de acuerdo, el $62.50 \%$ respondieron de acuerdo y $25.00 \%$ se muestran indiferente, al considerar que la productividad impacta directamente en la satisfacción laboral.

Pregunta 6. ¿Cree usted que el desempeño laboral impacta directamente en la satisfacción laboral?

Tabla 4.27

Resultados del cuestionario operativo: pregunta 6.

\begin{tabular}{|c|c|c|}
\hline Alternativa & $\mathbf{N}^{\circ}$ & $\%$ \\
\hline $\begin{array}{c}\text { Muy en } \\
\text { desacuerdo }\end{array}$ & 0 & $0,00 \%$ \\
\hline En desacuerdo & 0 & $0,00 \%$ \\
\hline Indiferente & 1 & $12,5 \%$ \\
\hline De acuerdo & 3 & $37,5 \%$ \\
\hline Muy de acuerdo & 4 & $50,0 \%$ \\
\hline TOTAL & 8 & $100 \%$ \\
\hline
\end{tabular}

Elaboración propia. 
Figura 4.24.

Resultados del cuestionario operativo: pregunta 6 .

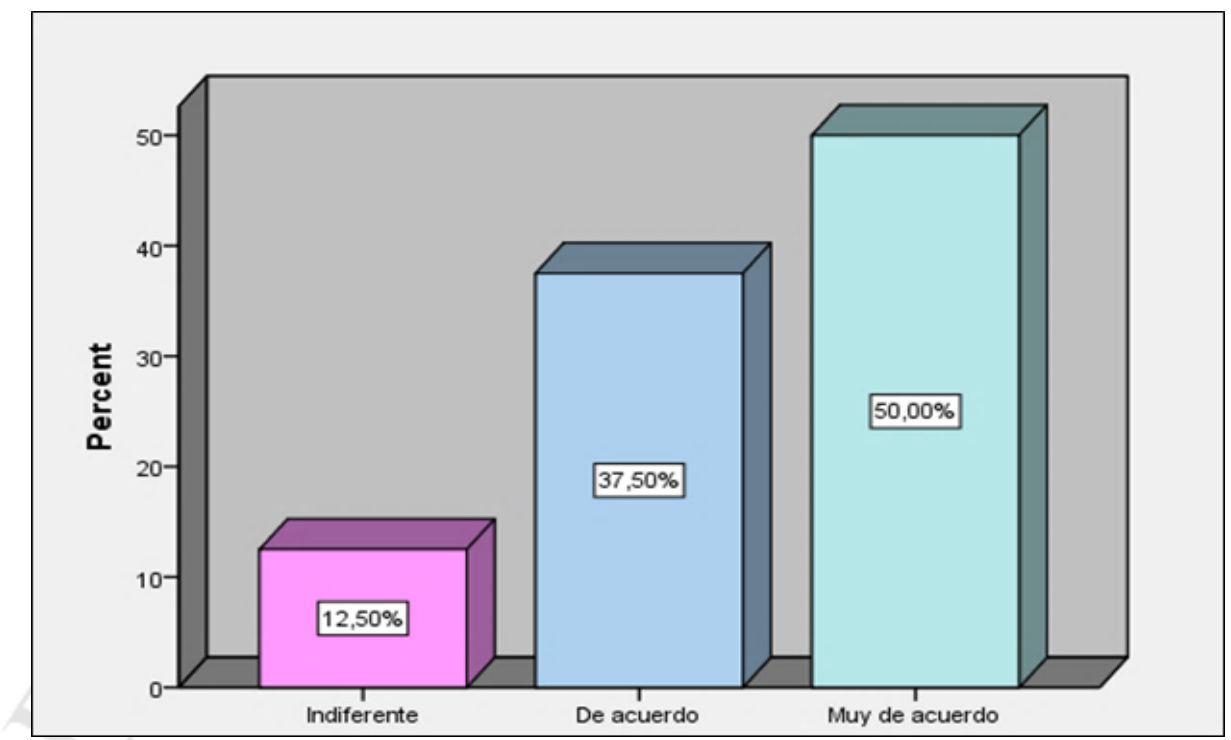

Fuente: Spss vs 23 (2018).

Interpretación: El resultado favorece la investigación; el 50.00\% de los encuestados están muy de acuerdo, el $37.50 \%$ respondieron de acuerdo y $12.50 \%$ se muestran indiferente, al considerar que el desempeño laboral impacta directamente en la satisfacción laboral.

Pregunta 7. ¿Considera usted que la mejora del desempeño laboral influye positivamente en la satisfacción laboral?

Tabla 4.28

Resultados del cuestionario operativo: pregunta 7.

\begin{tabular}{|c|c|c|}
\hline Alternativa & $\mathbf{N}^{\circ}$ & $\%$ \\
\hline $\begin{array}{c}\text { Muy en } \\
\text { desacuerdo }\end{array}$ & 0 & $0,00 \%$ \\
\hline En desacuerdo & 0 & $0,00 \%$ \\
\hline Indiferente & 0 & $0,00 \%$ \\
\hline De acuerdo & 5 & $62,5 \%$ \\
\hline Muy de acuerdo & 3 & $37,5 \%$ \\
\hline TOTAL & 8 & $100 \%$ \\
\hline
\end{tabular}

Elaboración propia. 
Figura 4.25.

Resultados del cuestionario operativo: pregunta 7.

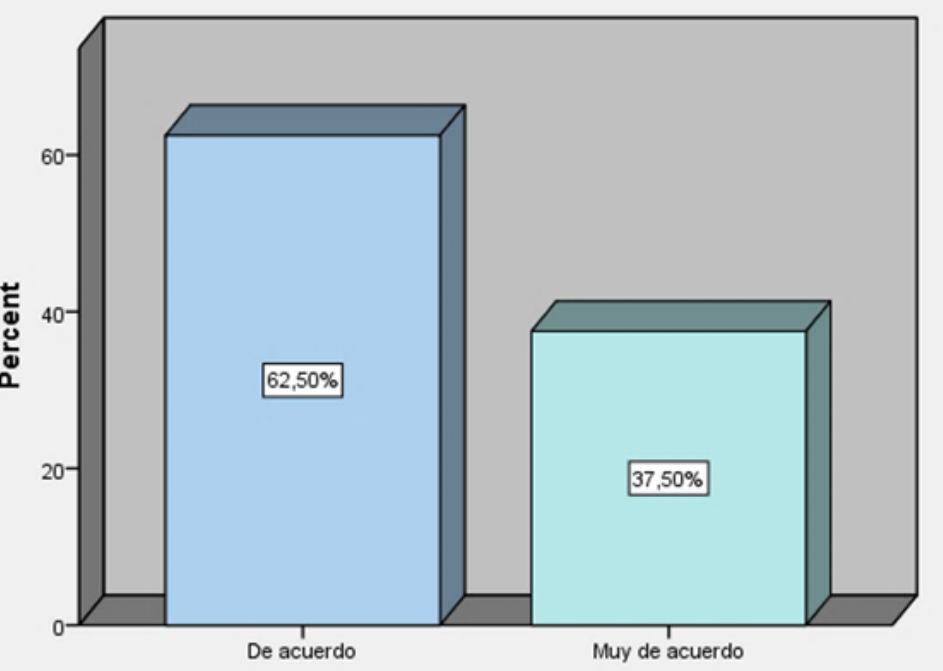

Fuente: Spss vs 23 (2018).

Interpretación: El resultado favorece la investigación; el 37.50\% de los encuestados están muy de acuerdo y el $62.50 \%$ respondieron de acuerdo, al considerar que la mejora del desempeño laboral influye positivamente en la satisfacción laboral.

Pregunta 8. ¿Cree usted que las actitudes positivas y/o negativas de las personas, en el entorno de trabajo, influyen en la satisfacción laboral?

Tabla 4.29

Resultados del cuestionario operativo: pregunta 8.

\begin{tabular}{|c|c|c|}
\hline Alternativa & $\mathbf{N}^{\circ}$ & $\%$ \\
\hline $\begin{array}{c}\text { Muy en } \\
\text { desacuerdo }\end{array}$ & 0 & $0,00 \%$ \\
\hline En desacuerdo & 0 & $0,00 \%$ \\
\hline Indiferente & 0 & $0,00 \%$ \\
\hline De acuerdo & 7 & $87,5 \%$ \\
\hline Muy de acuerdo & 1 & $12,5 \%$ \\
\hline TOTAL & 8 & $100 \%$ \\
\hline
\end{tabular}

Elaboración propia. 
Figura 4.26.

Resultados del cuestionario operativo: pregunta 8.

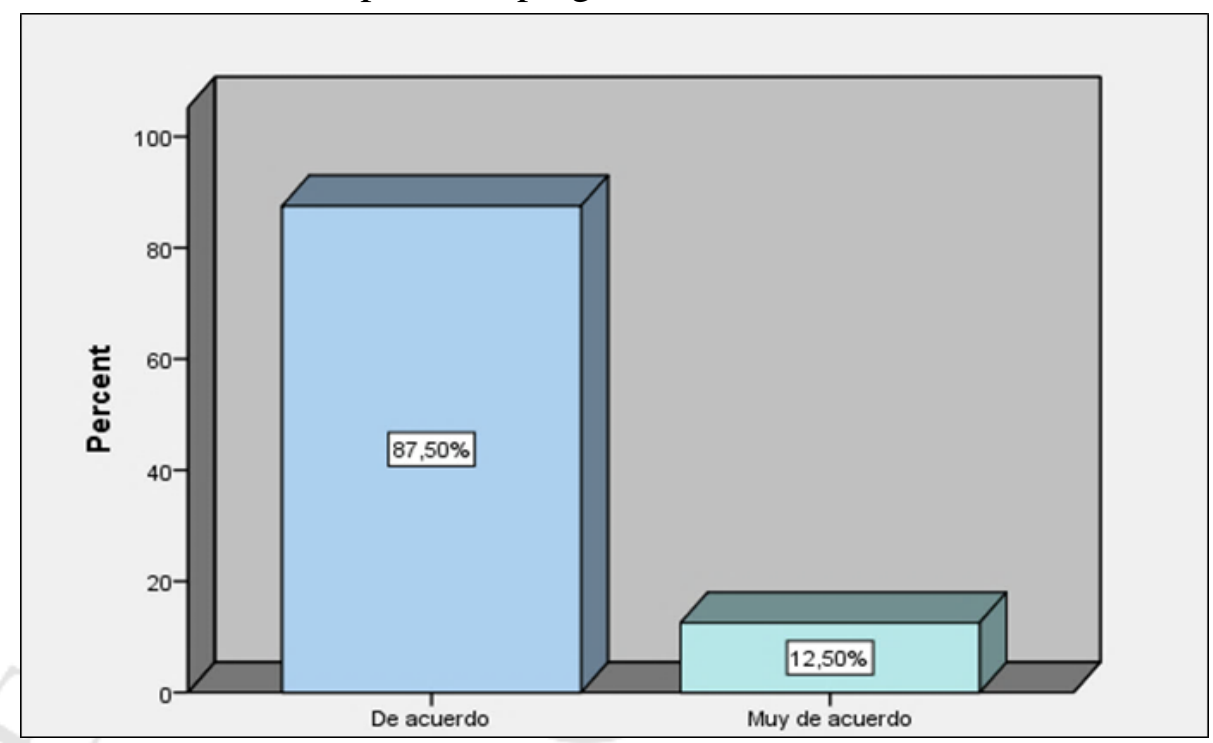

Fuente: Spss vs 23 (2018).

Interpretación: El resultado favorece la investigación; el $12.50 \%$ de los encuestados están muy de acuerdo y el $87.50 \%$ respondieron de acuerdo, al considerar que las actitudes positivas y/o negativas de las personas, en el entorno de trabajo, influyen en la satisfacción laboral.

Pregunta 9. ¿Considera usted que los talleres mindfulness impactan directamente en la satisfacción laboral?

Tabla 4.30

Resultados del cuestionario operativo: pregunta 9.

\begin{tabular}{|c|c|c|}
\hline Alternativa & $\mathbf{N}^{\circ}$ & $\%$ \\
\hline $\begin{array}{c}\text { Muy en } \\
\text { desacuerdo }\end{array}$ & 0 & $0,00 \%$ \\
\hline En desacuerdo & 0 & $0,00 \%$ \\
\hline Indiferente & 0 & $0,00 \%$ \\
\hline De acuerdo & 4 & $50,00 \%$ \\
\hline Muy de acuerdo & 4 & $50,00 \%$ \\
\hline TOTAL & 8 & $100 \%$ \\
\hline
\end{tabular}

Elaboración propia. 
Figura 4.27 .

Resultados del cuestionario operativo: pregunta 9.

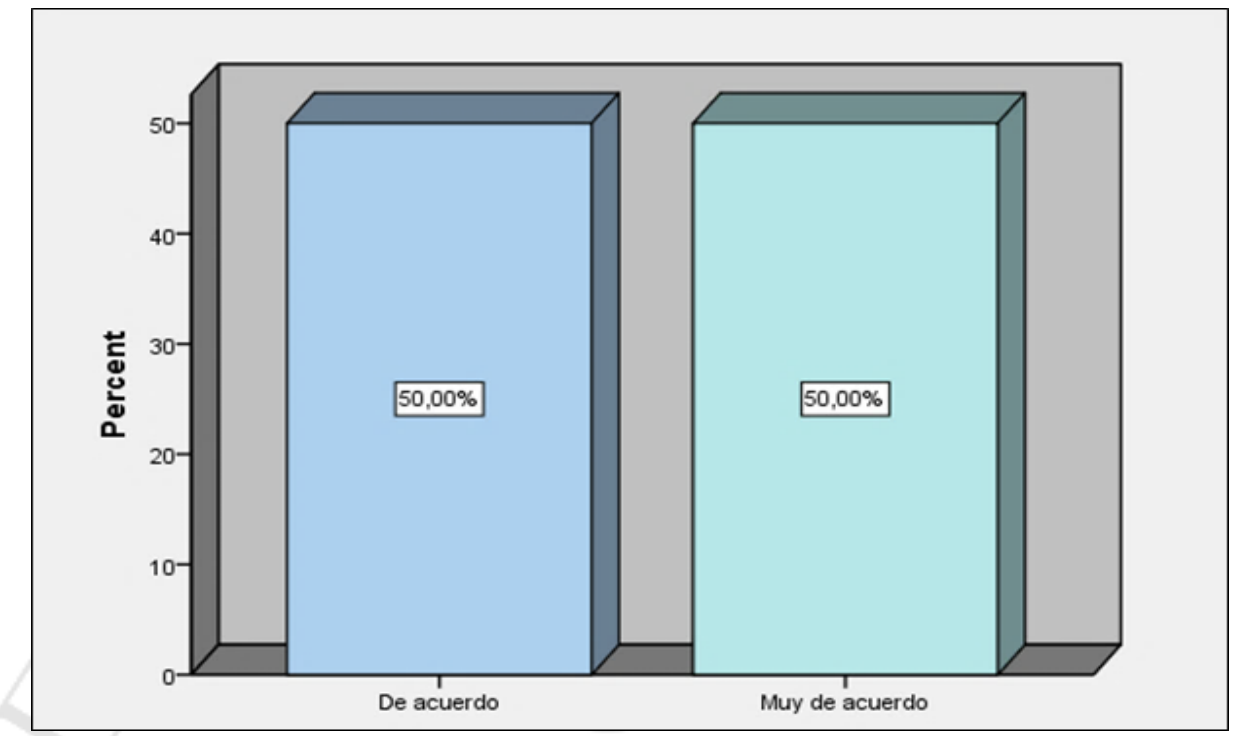

Fuente: Spss vs 23 (2018).

Interpretación: El resultado favorece la investigación; el 50.00\% de los encuestados están completamente de acuerdo y el $50.00 \%$ se muestran en de muy acuerdo, al considerar que los talleres mindfulness impactan directamente en la Satisfacción Laboral.

Pregunta 10. ¿Considera usted que la aplicación de talleres mindfulness, en las empresas, ayuda a mejorar la satisfacción laboral?

Tabla 4.31

Resultados del cuestionario operativo: pregunta 10.

\begin{tabular}{|c|c|c|}
\hline Alternativa & $\mathbf{N}^{\circ}$ & $\%$ \\
\hline $\begin{array}{c}\text { Muy en } \\
\text { desacuerdo }\end{array}$ & 0 & $0,00 \%$ \\
\hline En desacuerdo & 0 & $0,00 \%$ \\
\hline Indiferente & 0 & $0,00 \%$ \\
\hline De acuerdo & 5 & $62,5 \%$ \\
\hline Muy de acuerdo & 3 & $37,5 \%$ \\
\hline TOTAL & 8 & $100 \%$ \\
\hline
\end{tabular}

Elaboración propia. 
Figura 4.28.

Resultados del cuestionario operativo: pregunta 10.

Fuente: Spss vs 23 (2018).

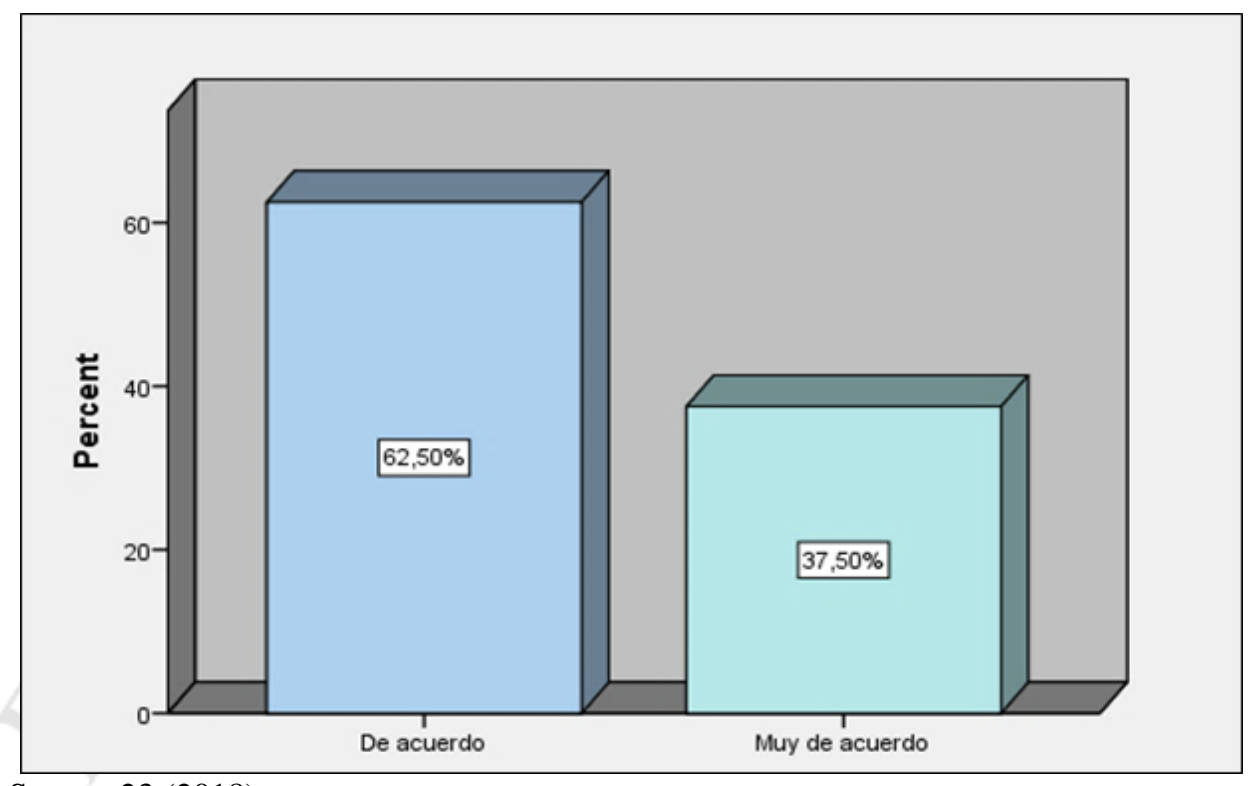

Interpretación: El resultado favorece la investigación; el 37.50\% de los encuestados están muy de acuerdo y el $62.50 \%$ respondieron de acuerdo, al considerar que la aplicación de talleres mindfulness, en las empresas, ayuda a mejorar la satisfacción laboral.

\subsection{Análisis de discusión de resultados}

\subsubsection{Contrastación de Hipótesis}

Para el análisis de todas las hipótesis, se aplicará una prueba de Correlación de Rho de Spearman y Pearson que nos indicará el nivel de correlación entre los talleres de mindfulness y la satisfacción laboral. Para un nivel de significancia con un valor de probabilidad menor que 0.05 para aceptar $\mathrm{H} 1$ y rechazar Ho 
Tabla 4.32

Rangos de correlación Pearson.

\begin{tabular}{|c|l|}
\hline $\begin{array}{c}\text { Valor del coeficiente de } \\
\text { correlación de Pearson }(\boldsymbol{r})\end{array}$ & \multicolumn{1}{|c|}{ Interpretación } \\
\hline$r=0$ & Ausencia de correlación lineal \\
\hline $0.10<r<0.19$ & Correlación lineal insignificante \\
\hline $0.20<r<0.39$ & Correlación lineal baja - leve \\
\hline $0.40<r<0.69$ & Correlación lineal moderada \\
\hline $0.70<r<0.99$ & Correlación alta muy alta \\
\hline$r=1$ & Función lineal perfecta \\
\hline
\end{tabular}

Elaboración propia.

\subsubsection{Hipótesis General}

H0: Los tallares de mindfulness no impactan positivamente en la satisfacción laboral de los empleados de la empresa Renta 4.

H1: Los tallares de mindfulness impactan positivamente en la satisfacción laboral de los empleados de la empresa Renta 4.

Tabla 4.33

Resultados de la correlación de talleres mindfulness y la satisfacción laboral.

\begin{tabular}{|l|l|r|r|}
\hline \multicolumn{5}{|c|}{ Correlations } \\
\hline \multirow{4}{*}{ Talleres Mindfulness } & $\begin{array}{c}\text { Talleres } \\
\text { Mindfulness }\end{array}$ & $\begin{array}{c}\text { Satisfacción } \\
\text { Laboral }\end{array}$ \\
\hline & $\begin{array}{l}\text { Pearson } \\
\text { Correlation }\end{array}$ & 1 &, $775^{*}$ \\
\cline { 2 - 5 } & Sig. (2-tailed) & &, 024 \\
\cline { 2 - 4 } & $\mathrm{N}$ & 8 & 8 \\
\hline \multirow{5}{*}{ Satisfacción Laboral } & $\begin{array}{l}\text { Pearson } \\
\text { Correlation }\end{array}$ &, $775^{*}$ & 1 \\
\cline { 2 - 5 } & Sig. (2-tailed) &, 024 & \\
\cline { 2 - 5 } & $\mathrm{N}$ & 8 & 8 \\
\hline
\end{tabular}

Nota: La correlación significativa es 0.05 .

Fuente: Spss vs 23 (2018).

Interpretación: La correlación encontrada es positiva con un coeficiente de correlación de Pearson $r=0.775$, lo cual nos indica que tiene una correlación muy alta; con un nivel 
de significancia bilateral de 0.05 que es igual a la significación máxima de 0.05 , por lo tanto, se acepta la hipótesis (H1) de la investigación y, de paso se rechaza la hipótesis nula (H0).

\subsubsection{Primera hipótesis específica}

H0: El Programa de Reducción del Estrés y Relajación (MBSR) no impacta positivamente en la satisfacción laboral en los empleados de la empresa Renta 4.

H1: El Programa de Reducción del Estrés y Relajación (MBSR) influye positivamente en la satisfacción laboral en los empleados de la empresa Renta 4.

Tabla 4.34

Resultados de la correlación entre el MBSR y la Satisfacción laboral.

\begin{tabular}{|c|c|c|c|}
\hline \multicolumn{4}{|c|}{ Correlations } \\
\hline & & MBSR & $\begin{array}{c}\text { Satisfacción } \\
\text { Laboral }\end{array}$ \\
\hline \multirow{3}{*}{ MBSR } & $\begin{array}{l}\text { Pearson } \\
\text { Correlation } \\
\end{array}$ & 1 &, $851^{\star *}$ \\
\hline & Sig. (2-tailed) & &, 007 \\
\hline & $\mathrm{N}$ & 8 & 8 \\
\hline \multirow{3}{*}{ Satisfacción Laboral } & \begin{tabular}{|l} 
Pearson \\
Correlation \\
\end{tabular} &, $851^{* \star}$ & 1 \\
\hline & Sig. (2-tailed) &, 007 & + \\
\hline & $\mathrm{N}$ & 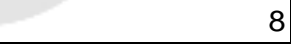 & 8 \\
\hline
\end{tabular}

Nota: La correlación significativa es de 0.01 .

Fuente: Spss vs 23 (2018).

Interpretación: La correlación encontrada es positiva con un coeficiente de correlación de Pearson $\mathrm{r}=0.851$, el cual indica una correlación alta muy alta; con un nivel de significancia bilateral de 0.007 que es menor a la significación máxima de 0.05 , por lo tanto, se acepta la hipótesis (H1) de la investigación y se rechaza la hipótesis nula (Ho). 


\subsubsection{Segunda hipótesis específica}

H0: La práctica de la atención plena no influye significativamente en la satisfacción laboral en los trabajadores de la empresa Renta 4.

H1: La práctica de la atención plena influye significativamente en la satisfacción laboral en los trabajadores de la empresa Renta 4.

Tabla 4.35

Resultados de correlación entre las técnicas mindfulness y la satisfacción laboral.

\begin{tabular}{|l|l|r|r|}
\hline \multicolumn{2}{|c|}{ Correlations } & Atención Plena & $\begin{array}{c}\text { Satisfacción } \\
\text { Laboral }\end{array}$ \\
\hline \multirow{2}{*}{ Atención Plena } & $\begin{array}{l}\text { Pearson } \\
\text { Correlation }\end{array}$ & 1 &, $573^{*}$ \\
\cline { 2 - 5 } & Sig. (2-tailed) & 8 &, 138 \\
\cline { 2 - 5 } & $\mathrm{N}$ &, $573^{*}$ & 8 \\
\hline \multirow{3}{*}{ Satisfacción Laboral } & $\begin{array}{l}\text { Pearson } \\
\text { Correlation }\end{array}$ &, 138 & 1 \\
\cline { 2 - 5 } & Sig. (2-tailed) & 8 & 8 \\
\cline { 2 - 5 } & $\mathrm{N}$ & & 8 \\
\hline
\end{tabular}

Nota: La correlación significativa es de 0.05 .

Fuente: Spss vs 23 (2018).

Interpretación: La correlación encontrada es positiva con un coeficiente de correlación de Pearson $r=0.573$, que indica una correlación lineal moderada; con un nivel de significancia bilateral de 0.05 que es no menor a la significación máxima de 0.05 , por lo tanto, se Acepta la hipótesis (H2) de la investigación y se rechaza la hipótesis nula (Ho).

\subsubsection{Tercera hipótesis específica}

H0: Los beneficios de las técnicas mindfulness no mejora el desempeño laboral en los trabajadores de la empresa Renta 4.

H1: Los beneficios de las técnicas mindfulness mejora la satisfacción laboral en los trabajadores de la empresa Renta 4. 
Tabla 4.36

Resultados de la correlación entre los talleres mindfulness y la satisfacción laboral.

\begin{tabular}{|l|l|r|r|}
\hline \multicolumn{2}{|c|}{ Correlations } \\
\hline \multicolumn{5}{|c|}{} & \multicolumn{1}{|c|}{$\begin{array}{c}\text { Técnicas } \\
\text { Mindfulnesss }\end{array}$} & $\begin{array}{c}\text { Satisfacción } \\
\text { Laboral }\end{array}$ \\
\hline \multirow{5}{*}{ Técnicas Mindfulnesss } & $\begin{array}{l}\text { Pearson } \\
\text { Correlation }\end{array}$ & 1 &, $783^{*}$ \\
\cline { 2 - 5 } & Sig. (2-tailed) & 8 &, 022 \\
\cline { 2 - 5 } & $\mathrm{N}$ &, $783^{*}$ & 8 \\
\hline \multirow{5}{*}{ Satisfacción Laboral } & $\begin{array}{l}\text { Pearson } \\
\text { Correlation }\end{array}$ &, 022 & 8 \\
\cline { 2 - 5 } & Sig. (2-tailed) & 8 & \\
\cline { 2 - 5 } & $\mathrm{N}$ & & \\
\hline
\end{tabular}

Nota: La correlación significativa es de 0.05 .

Fuente: Spss vs 23 (2018).

Interpretación: La correlación encontrada es positiva con un coeficiente de correlación de Pearson $r=0.783$ indica una correlación alta muy alta; con un nivel de significancia bilateral de 0.05 que es menor a la significación máxima de 0.05 , por lo tanto, se Acepta la hipótesis (H1) de la investigación y se rechaza la hipótesis nula (Ho). 


\section{CONCLUSIONES}

El propósito de esta investigación fue demostrar que los talleres mindfulness tienen impacto en la satisfacción laboral, y para esto se implementó los talleres en la empresa Renta 4. A continuación se mostrará las conclusiones obtenidas de la investigación:

1) En el marco teórico de esta investigación muestra los beneficios e impactos positivos que tiene la práctica del mindfulness en las personas y sus puestos de trabajo, mejorando su satisfacción laboral. Así mismo, diversos estudios de Universidades, la universidad de Massachussets comprobó que la práctica del mindfulness minimiza el estrés de las personas mejorando la disposición en el trabajo. Así mismo, una empresa como Google, muestra el impacto positivo de la implementación de los talleres mindfulness en los empleados, posicionándose desde el 2014 a la actualidad como una de las mejores empresas para trabajar. Teóricamente esta investigación sustenta que el mindfulness impacta positivamente en la satisfacción laboral.

2) La encuesta de Satisfacción General de diagnóstico mostró que el 12\% de los empleados de Renta 4, sentían satisfacción laboral, y el 88\%, insatisfacción laboral. Después de la implementación de los talleres mindfulness, se dio una variación en estos resultados, el 62\% sentía satisfacción laboral y el 38\%, insatisfacción laboral. Mostrando el impacto positivo de las técnicas de mindfulness, con una variación de 50\%, en la satisfacción laboral de los empleados de Renta 4. Así mismo, fue interesante ver este cambio basado en un enfoque diferente y positivo del entorno laboral, que se aprendió en los talleres mindfulness; porque nos muestra que las personas actuamos y/o pensamos por influencia de los factores de nuestro entorno, si estamos rodeados de actitudes negativas, nuestro enfoque del entorno será negativo, por el contrario, si nos rodeamos de actitudes positivas, nuestro enfoque también se tornará positivo, reforzados por competencias de tolerancia y compresión, y esto también se desarrolla en los talleres mindfulness.

3) Los factores intrínsecos, de la encuesta general de satisfacción, se basa en reconocimientos, responsabilidad, y demás aspectos relativos a las tareas 
desempeñadas por el empleado, que van más allá de las cosas establecidas en la oferta económica inicial del puesto. Durante la implementación de los talleres de mindfulness se identificó que los factores intrínsecos son una "recompensa o beneficio" que el empleado puede tener en base a su propio esfuerzo, basándose en actitudes, aptitudes y productividad en sus tareas. Los talleres mindfulness, ayudaron a los empleados a enfocarse en sus objetivos, tareas y aprendieron a ser conscientes de sus actitudes y acciones con sus compañeros, y todos los que influyen en su entorno laboral. Es así, que se alinearon los beneficios propios de la práctica de mindfulness con factores que influyen en la satisfacción laboral. Como resultado de ello, en la encuesta final, después de la implementación de los talleres mindfulness, se obtuvo una satisfacción intrínseca, en los empleados de Renta 4, de $75 \%$, siendo inicialmente $38 \%$, con una variación importante de $37 \%$.

4) Los factores extrínsecos, de la encuesta de satisfacción general, se refiere a el diseño pre establecido por los directivos de la empresa, remuneración, horario de trabajo, y otros factores que son parte del diseño y estructura organizacional. Durante los talleres mindfulness, se llegó a la conclusión que los factores extrínsecos son cosas que los empleados no pueden cambiar. En la práctica de los talleres, a través de las técnicas, se buscó desarrollar la competencia de tolerancia, respeto y aceptación, por parte de los empleados, de la estructura y políticas organizacionales, los factores extrínsecos, con el objetivo de mejorar la insatisfacción general. En la encuesta de diagnóstico de satisfacción general, se obtuvo que $12 \%$ de los empleados de Renta 4, sentían satisfacción extrínseca, y el $88 \%$, insatisfacción extrínseca. Luego de la implementación de los talleres mindfulness se obtuvo que el $25 \%$ de los empleados estaban satisfechos, y el $75 \%$ insatisfechos, obteniendo una variación positiva de $13 \%$. Se concluye que los talleres de mindfulness impactan favorablemente en la satisfacción extrínseca, por ende, en la satisfacción general de los empleados de Renta 4.

5) Uno de los beneficios del mindfulness, mostrados en el marco teórico, es la reducción y manejo del estrés laboral. Los empleados de Renta 4, luego de la implementación de los talleres mindfulness, en la encuesta operacional, el $62.5 \%$ estuvieron de acuerdo, y el $12.5 \%$, muy de acuerdo, en que los talleres mindfulness reducen el estrés laboral. Así mismo, en la misma encuesta, el 50\% de los empleados, estuvieron de acuerdo en que el estrés afecta la satisfacción laboral. Durante el desarrollo de los talleres se busca minimizar el estrés para un mejor 
enfoque en las actividades y tareas diarias. Por lo tanto, se concluye que los talleres de mindfulness reducen y maneja el estrés laboral, impactando positivamente en la satisfacción laboral.

6) El marco teórico señala a la productividad como uno de los beneficios importantes de la práctica del mindfulness. Luego de la aplicación de los talleres mindfulness en Renta 4, se les explicó a los participantes, mostrándoles resultados y el impacto de la aplicación de estos en otras empresas. Un ejemplo, Aetna, empresa americana, que ahorró 2 mil dólares por empleado y generó 3 mil dólares, por empleado, de utilidad anual. En base al conocimiento y experiencia de los talleres mindfulness, en la encuesta operativa, se obtuvo que el $75 \%$ de los empleados, estuvieron de acuerdo en que la productividad impacta en la satisfacción laboral, ya que en los talleres aprendieron a enfocarse y organizar sus tareas. Por ello, se pude concluir que la implementación de los talleres, impacta en la satisfacción laboral.

7) La práctica del mindfulness mejora la actitud y mentalidad positiva con un impacto directo en la satisfacción laboral. Luego de la implementación de los talleres mindfulness en Renta 4, se concluyó, mediante la encuesta operacional, que el $100 \%$ de los empleados están de acuerdo que las actitudes positivas de las personas de su entorno impactan en la satisfacción laboral. Así mismo, el 75\% de los empleados, están de acuerdo que mejorar el estado psicológico también favorece a la satisfacción laboral que perciben en Renta 4. Esta afirmación, también se ve reforzada por el resultado final, de la encuesta general de satisfacción, en donde se obtuvo que $100 \%$ de los empleados estaban satisfechos con sus compañeros de trabajo, siendo el resultado inicial, $75 \%$ empleados insatisfechos y $25 \%$, satisfechos. Esto concluye el impacto positivo que tiene la práctica el mindfulness en la satisfacción laboral, mediante el enfoque positivo que aporta en las personas.

8) Finalmente, de la encuesta operacional, se obtuvo que el $50 \%$ de los empleados de Renta 4, están de acuerdo y el 50\% muy de acuerdo, en que los talleres mindfulness impactan directamente en la satisfacción laboral. Así mismo, el 62.5\% de los empleados está de acuerdo y el 37.5\% muy de acuerdo, en que la implementación de los talleres mindfulness en las empresas, mejoran la satisfacción laboral. Al finalizar los talleres mindfulness en Renta 4, los resultados refuerzan y favorecen la afirmación de la hipótesis establecida en este trabajo de investigación. 


\section{RECOMENDACIONES}

1) La encuesta de diagnóstico de Satisfacción General mostró que los empleados de Renta 4 se sentían insatisfechos laboralmente. Después de la aplicación de los talleres mindfulness los resultados mejoraron significativamente. Por ello, se recomienda a la empresa, realizar actividades o talleres que ayuden a seguir mejorando la satisfacción laboral que los empleados perciben, ya que finalmente, la insatisfacción se basa en varios componentes, como las oportunidades laborales, buena relación con sus compañeros jefes, entre otros; estos pueden impactar en indicadores importantes, como la rentabilidad de la empresa, ya que empleados insatisfechos no dan lo mejor de sí mismos en una organización.

2) Los empleados de Renta 4, afirmaron que la implementación de los talleres mindfulness son beneficiosos para la satisfacción laboral en una empresa. Por tal motivo, se sugiere la implementación de los talleres mindfulness en empresas con indicadores por mejorar en temas de gestión humana, ya que según los resultados obtenidos en esta investigación, los talleres mindfulness son una herramienta importante para mejorar resultados en la gestión humana.

3) Los beneficios del mindfulness tienen un impacto de largo plazo, debido a que estas técnicas mejoran a un empleado con un enfoque 360 grados. Esto podría ayudar a mejorar indicadores organizacionales, ya que la base de todo resultado organizacional son los empleados, sus habilidades y competencias.

4) Un importante beneficio de la práctica del mindfulness es ayudar a los empleados a enfocarse en los objetivos y resultados a nivel personal y organizacional, motivándolos a tener predisposición para adaptarse y aceptar cambios de forma positiva. Por lo tanto, se recomienda la implementación de los talleres, en las empresas, en escenarios de cambios organizacionales, que precisen cambios actitudinales, aptitudinales y/o nuevos métodos de trabajo por parte de los empleados y directivos.

5) Una eficiente gestión humana, basada en el clima y cultura organizacional, es una tendencia global en las organizaciones, por lo cual, se recomienda el uso de las técnicas mindfulness como una herramienta para lograr objetivos organizacionales. 
Esta investigación se puede tomar como referencia para investigaciones futuras, ya que nos muestra resultados positivos e importantes al implementarlos.

6) Se recomienda invitar a los directivos y altos mandos de la organización ah asistir a talleres de mindfulness, ya que está comprobado que estos talleres desarrollan y mejoran la competencia de liderazgo. Impactando positivamente en las personas a cargo y mejorando la competencia de manejo de escenarios complejos a los cuales estos tipos de cargos suelen enfrentar.

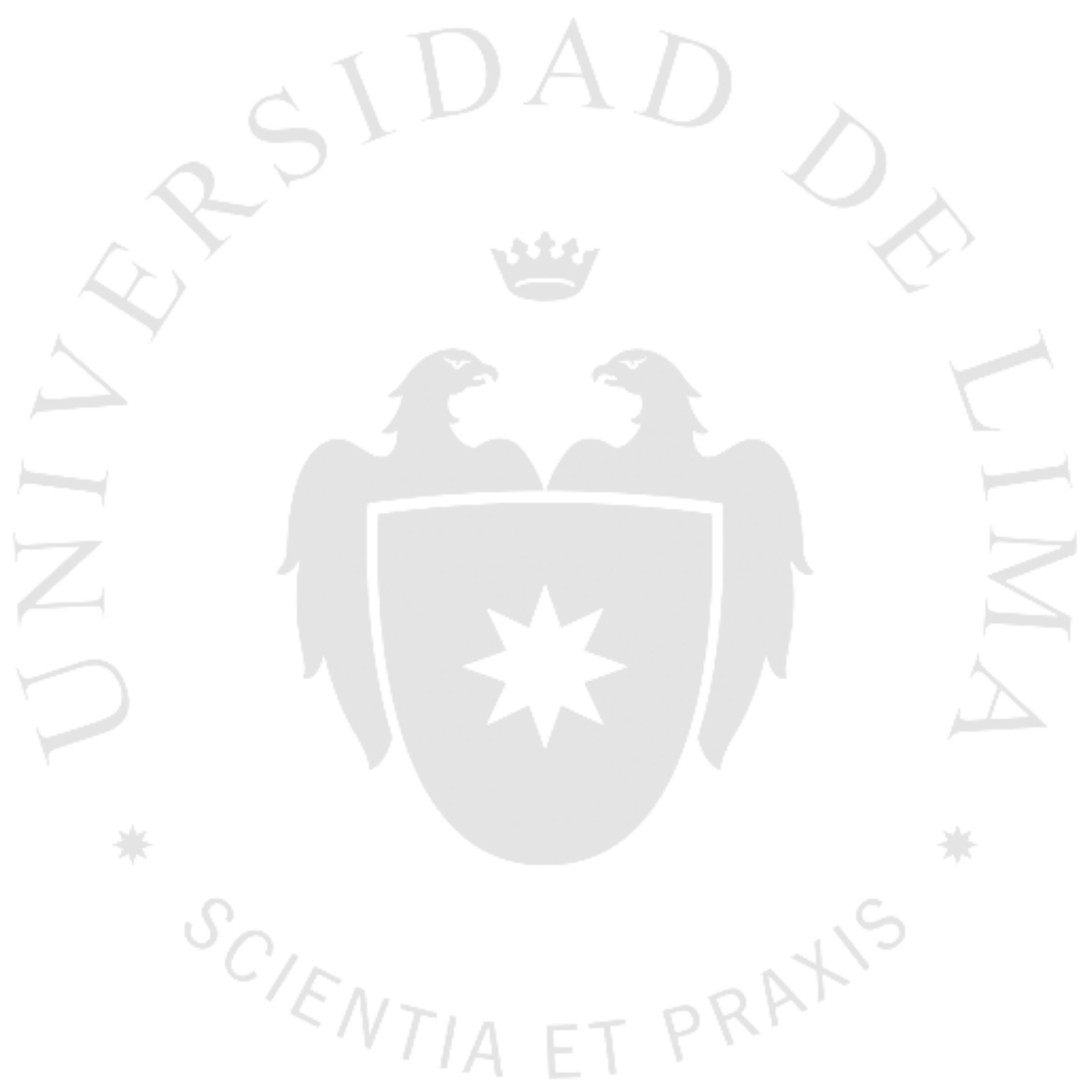




\section{BIBLIOGRAFIA}

Alberts, H. \& Hülsheger, U. (2015). Applying mindfulness in the context of work: mindfulness-based interventions. In J. Reb \& P. Atkins (Eds.), Mindfulness in Organizations: Foundations, Research, and Applications (pp. 100-132). Cambridge, USA: Cambridge University Press. doi:10.1017/CBO9781107587793.007

Baer R., Carmody J. y Hunsinger M. (2012). Weekly Change in mindfulness and Perceived Stress in a mindfulness-Based Stress Reduction Program. Journal of Clinical Psychology, 68, 755 - 765. doi: 10.1002/jclp.21865

Chopra, D. (2012). El alma del liderazgo. España: Aguilar.

Fernández, E. (2017). Mindfulness, liderazgo y empresa. Harvard Deusto Business Review, 81(267), 44 - 52.

Issacson, W. (2011). Steve Jobs. España: Vintage Español.

Kabat-Zinn, J. (2016). Mindfulness for beginners: Reclaiming the present moment and your life. USA: Sounds true.

Kotter, J. (2008). Developing a change-culture friendly. Leader to leader, 2008, 33-38. doi:10.1002/lt1.278

Martín Rodríguez, R. (2015). Perfil socioemocional de los que más se benefician de un programa mindfulness (tesis de doctorado). Universidad De Las Palmas De La Gran Canaria.

Mercer. (2017). Tendencias de gestión humana. Lima: Mercer. 
Ministerio de salud (24 de Junio del 2017). Día Internacional del Yoga. Recuperado de https://www.gob.pe/institucion/minsa/noticias/13638-ministra-de-saludparticipo-en-celebracion-por-el-dia-internacional-del-yoga

Ortiz Olaechea, C. (2017). Relación del feedback laboral con la satisfacción en el trabajo del personal en una Regional de Agricultura Del Perú (tesis para optar el título profesional de Licenciada en Administración). Universidad de Lima.

Pérez-Bilbao J, Fidalgo M. (1995) Job satisfaction: Overall job satisfaction scale. Barcelona: Centro Nacional de Condiciones de Trabajo.

Salessi, S. (2014). Satisfacción laboral: acerca de su conceptualización, medición y estado actual del arte. Revista de Psicología, 10(19), 68-83. Recuperado de http://bibliotecadigital.uca.edu.ar/repositorio/revistas/satisfaccion-laboralacerca-conceptualizacion.pdf

Sánchez Gutiérrez, G. (2011). Meditación, mindfulness y sus efectos psicosociales. Revista Electrónica de Psicología Iztacala, (2), 223 - 254. Recuperado de www.revistas.unam.mx/index.php/repi

Shimon, D. (2007). La gestión de los recursos humanos. Madrid: Mcgraw-Hill. 


\section{REFERENCIAS}

Asociación Respira Vida Breathworks: mindfulness y compasión en la salud y la educación. (2018). Respira vida breathworks. Recuperado de https://www.respiravida.net/

Bishop R., Lau, M., Shapiro, S. y Carlson L., (2004) Mindfulness: a proposed operational definition. Clinical psychology: Science and practice, 11, 230-241.

Chan, A. S., Han, Y.M.Y. y Cheung, M. (2008). Electroencephalographic (EEG) Measurements of Mindfulness-based Triarchic Body-pathway Relaxation Technique: A Pilot Study. Applied Psychophysiological Biofeedback, 33, 39-47.

Dalal, R. S., Baysinger, M., Brummel, B. \& LeBreton, J. (2012). The relative importance of employee engagement, other job attitudes, and trait affect as predictors of job performance. Journal of Applied Social Psychology, 42, 295325.

Dalal, R. S., Bashshur, M. R. \& Credé, M. (2011). The forgotten facet: Employee satisfaction with management above the level of immediate supervision. Applied Psychology: An International Review, 60, 183-209.

Fadiman y Frager, 1976. Teorías de la personalidad. México: Harla.

Foundation for a Mindful Society. (2018). Mindful, healthy mind, healthy life. Recuperado de https://www.mindful.org/

Gonzáles P., Llinares L. y Zurriaga R. (2012). Gestión positiva del conflicto organizacional. España: Síntesis.

Guzman, CP., Pontes, P. y Szuflita, M. (2015). Empowerment y satisfacción laboral. ReiDoCrea, 4, 66-73. 
Instituto Mexicano de Mindfulnes. (2018). Descubre Mindfulness. Recuperado de https://www.mindfulness.org.mx/

Jah, Bernal, Elizondo, A. Y Montoya, M. S. R. (2010). Desarrollo de habilidades cognitivas con aprendizaje móvil: un estudio de casos. Comunicar: Revista científica iberoamericana de comunicación y educación, (34), 201-209.

Koch, C. (2014). Efectos cerebrales de la meditación. Mente y Cerebro, 68, 44 - 47.

Labrador, F. (2008) Técnicas de modificación de Conducta. Madrid: Pirámide.

Langer, E. y Moldoveanu, M. (2000). The Construct of mindfulness. Journal of Social Issues, 56 (1), 1-9.

Lazar, S. (2011). Mindfulness practice leads to increases in regional brain gray matter density. Psychiartry Pesearch: Neuroimaging, 191, 36 - 43.

López, J. (2014). Entiende tu estrés. Jaén: Formación Alcalá.

Mason, O. y Heargreaves, I. (2001). A qualitative study of mindfulness-based cognitive therapy for depression. British Journal of Medical Psychology,74, 197-212.

McIntosh, W. (1997). East Meets West: Parallels Between Zen Buddhism and Social Psychology. The International Journal for The Psychology Of Religion, 7 (1), $37-52$.

Mindfulness Empresas. (2018). Programas de Mindfulness para empresas. Recuperado de https://www.mindfulness-salud.org/

Mindful Academy Solterreno. (2018). Mindfullness teacher training. Recuperado de https://mbsr.website/ 
Morris, M. G. \& Venkatesh, V. (2010). Job characteristics and job satisfaction: Understanding the role of enterprise resource planning system implementation. MIS Quarterly, 34, 143-161.

Moore, A. Y Malinowski, P. (2009). Meditation, mindfulness and cognitive flexibillity. Conscious Cogn, 18, 176 - 186.

Mrazek, M., Franklin, M., Tarchin, D., Baird, B. Y Scooler, J. (2012). Mindfulness Training Improves Working Memory Capacity and GRE Performance While Reducing Mind Wandering. Psychological Science, 24, 776 - 781.

Positive Psychology Program. (2018). Positive Psychology Program - Your One-Stop PP Resource! Recuperado de https://positivepsychologyprogram.com/

Proulx, K. (2003). Integrating mindfulness-Based Stress Reduction. Holistic Nursing Practice, 17 (4), 201-208.

Reviewed by Martin Lumpkin (2010) Siegel, D. (2010). The Mindful Therapist: A Clinician's Guide to Mindsight and Neural Integration. The Humanistic Psychologist, 38:3, 244-248, DOI: 10.1080/08873267.2010.512253

Robbins, S. \& Judge, T. (2013). Essentials of organizational behaviour. Mount Zion rd, Lebanon, IN, EE.UU.: Pearson College.

Rogelberg, S. G., Allen, J. A., Shanock, L., Scott, C. \& Shuffler, M. (2010). Employee satisfaction with meetings: a contemporary facet of job satisfaction. Human Resource Management, 49, 149-172.

Ruth A. Baer. (2014). Mindfulness - Based Treatment Approaches. USA: Academic Press.

Sociedad Mindfullness Y Salud. (2018). Cursos de meditación. Recuperado de https://www.mindfulness-salud.org/ 
Wachs y Cordova (2007). Consciente Relativa: Explorando mindfulness y repertorios Emoción en las relaciones íntimas. Diario de civil y Terapia Familiar, 33, 464 481.

Warr P, Cook J y Wall T. (1979). Scales for the measurement of some work attitudes and aspects of psychological well-being. Journal of Occupational Psychology, $52,129-48$.

Yukl, G. (2008). Leadership in organizations. Upper Saddle River, NJ, EE.UU.: Prentice Hall.

Zeidan, F., Martucci, K., Keaft, R., McHaffie, J. y Coghill, R. (2011). Neural correlates of mindfulness meditation-related anxiety relief. Social cognitive and affective neuroscience, 41 , recuperado de http://scan.oxfordjournals.org. 


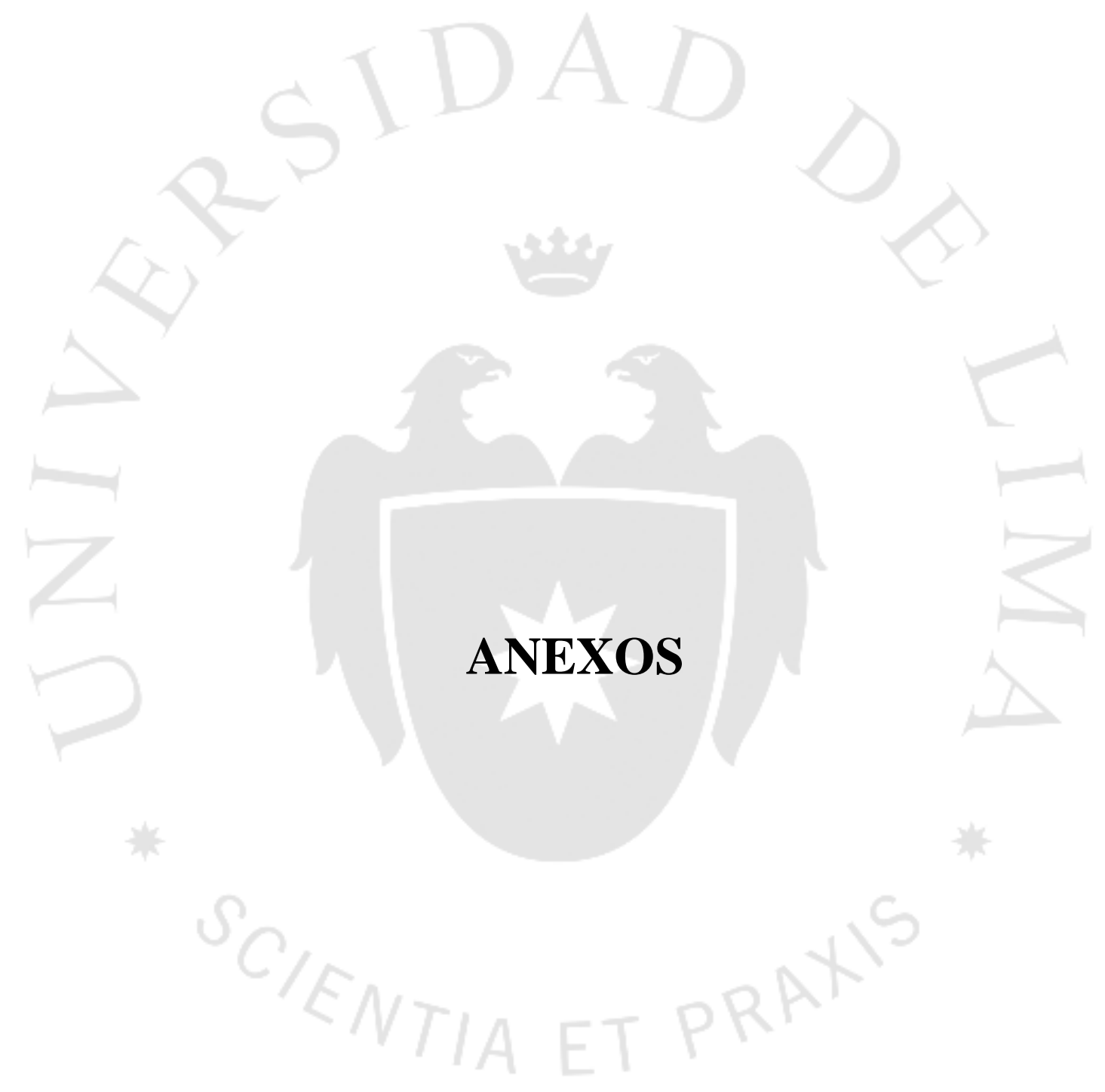


ANEXO 1: Encuesta de Satisfacción General - Adaptación de la “Overall Job Satisfaction Scale" de Warr, Cook y Wall (1979).

\begin{tabular}{|c|c|c|c|c|c|c|c|c|}
\hline \multirow[b]{2}{*}{$\mathrm{N}^{\circ}$} & \multirow[b]{2}{*}{ PREGUNTA } & \multicolumn{7}{|c|}{ RESPUESTAS } \\
\hline & & $\begin{array}{c}\text { Muy } \\
\text { Insatisfecho }\end{array}$ & Insatisfecho & $\begin{array}{c}\text { Moderadamente } \\
\text { insatisfecho }\end{array}$ & $\begin{array}{l}\text { Ni Satisfecho ni } \\
\text { insatisfecho }\end{array}$ & $\begin{array}{c}\text { Moderadamente } \\
\text { Insatisfecho }\end{array}$ & Satisfecho & $\begin{array}{l}\text { Muy } \\
\text { satisfecho }\end{array}$ \\
\hline 1 & Condiciones físicas de su trabajo. & & & & & & & \\
\hline 2 & $\begin{array}{l}\text { Libertad para elegir su propio método de } \\
\text { trabajo. }\end{array}$ & & & & & & & \\
\hline 3 & Sus compañeros de trabajo. & & & & & & & \\
\hline 4 & $\begin{array}{l}\text { Reconocimiento que obtiene por el } \\
\text { trabajo bien hecho. }\end{array}$ & & & & & & & \\
\hline 5 & Su superior inmediato. & & & & & & & \\
\hline 6 & Responsabilidad que usted tiene asignada. & & & & +2 & & & \\
\hline 7 & Su salario. & & & & & & & \\
\hline 8 & La posibilidad de utilizar sus capacidades. & & & & & & & \\
\hline 9 & $\begin{array}{l}\text { Relación entre dirección y trabajadores en } \\
\text { su empresa. }\end{array}$ & & & & & & & \\
\hline 10 & Sus posibilidades de promocionar. & & & & & - & & \\
\hline 11 & $\begin{array}{l}\text { El modo en que su empresa está } \\
\text { gestionada. }\end{array}$ & & & & & & & \\
\hline 12 & $\begin{array}{l}\text { La atención que se presta a las sugerencias } \\
\text { que usted hace. }\end{array}$ & & & & & & 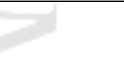 & \\
\hline 13 & Su horario de trabajo. & & & & & & & \\
\hline 14 & $\begin{array}{l}\text { La variedad de tareas que realiza en su } \\
\text { trabajo. }\end{array}$ & & & & & & & \\
\hline 15 & Su estabilidad en el empleo. & & & & & & & \\
\hline
\end{tabular}




\section{ANEXO 2: Encuesta Operacional: mindfulness - Satisfacción Laboral}

ENCUESTA OPERACIONAL: MINDFULNESS - SATISFACCIÓN LABORAL

\begin{tabular}{|c|c|c|c|c|c|c|}
\hline \multirow{2}{*}{$\mathrm{N}^{\circ}$} & \multirow{2}{*}{ PREGUNTAS } & \multicolumn{5}{|c|}{ RESPUESTAS - Marcar con $(\mathrm{x})$} \\
\hline & & Muy en desacuerdo & En desacuerdo & Indiferente & De acuerdo & Muy de acuerdo \\
\hline 1 & $\begin{array}{l}\text { ¿Considera usted que el estrés tiene impacto directo en la } \\
\text { satifacción laboral ? }\end{array}$ & & & & & \\
\hline 2 & $\begin{array}{l}\text { ¿Considera usted que los talleres de Mindfulness son una solución } \\
\text { para el estrés? }\end{array}$ & & & & & \\
\hline 3 & $\begin{array}{l}\text { ¿Cree usted que el programa de Reducción del Estrés y de } \\
\text { Relajación (MBSR) mejora la satisfacción laboral ? }\end{array}$ & & & & & \\
\hline 4 & $\begin{array}{l}\text { ¿Considera usted que la mejora del estado psicologico y calidad de } \\
\text { vida impactan de manera positiva en la satisfacción laboral ? }\end{array}$ & & & & & \\
\hline 5 & $\begin{array}{l}\text { ¿Considera usted que la productividad impacta directamente en la } \\
\text { satisfacción laboral? }\end{array}$ & & & & & \\
\hline 6 & $\begin{array}{l}\text { ¿Cree usted que el desempeño laboral impacta directamente en la } \\
\text { satisfaccion laboral? }\end{array}$ & & & & & \\
\hline 7 & $\begin{array}{l}\text { ¿Considera usted que la mejora del desempeño laboral influye } \\
\text { positivamente en la satisfacción laboral? }\end{array}$ & & & & & \\
\hline 8 & $\begin{array}{l}\text { ¿Cree usted que las actitudes positivas y/o negativas de las } \\
\text { personas, en el entorno de trabajo, influyen en la satisfaccion } \\
\text { laboral? }\end{array}$ & & & & $0=0$ & \\
\hline 9 & $\begin{array}{l}\text { ¿Considera usted que los talleres Mindfulness impactan } \\
\text { directamente en la satisfacción laboral? }\end{array}$ & & & & & \\
\hline 10 & $\begin{array}{l}\text { ¿Cree usted que la aplicación de los Talleres de Mindfulness mejora } \\
\text { la satisfacción laboral? }\end{array}$ & & & & & \\
\hline 11 & $\begin{array}{l}\text { ¿Considera usted que la aplicación de talleres Mindfulness, en las } \\
\text { empresas, ayuda a mejorar la satisfacción laboral? }\end{array}$ & & & & & \\
\hline 12 & $\begin{array}{l}\text { ¿Considera usted que el cuestionarios de satisfacción general } \\
\text { ayuda a medir la satisfacción laboral? }\end{array}$ & & & & & \\
\hline
\end{tabular}


ANEXO 3: Contenido y herramientas de los talleres mindfulness.

\begin{tabular}{|c|c|c|c|c|}
\hline Talleres & Sesión & $\begin{array}{l}\text { Contenido - } \\
\text { Temas }\end{array}$ & Materiales & $\begin{array}{l}\text { Costo por } \\
\text { sesión }\end{array}$ \\
\hline \multirow{4}{*}{ YOGA } & Sesión 1 & $\begin{array}{l}\text { La respiración } \\
\text { (Teórico y } \\
\text { práctico) }\end{array}$ & \multirow{4}{*}{$\begin{array}{l}\text { - } \text { Colchonetas } \\
\text { Música de } \\
\text { relajación. } \\
\text { - } \text { Mantas } \\
\text { - } \text { Cojines } \\
\text { Cintas }\end{array}$} & s/. 200.00 \\
\hline & Sesión 2 & $\begin{array}{l}\text { Concentración } \\
\text { (Teórico y } \\
\text { práctico) }\end{array}$ & & s/. 200.00 \\
\hline & Sesión 3 & $\begin{array}{l}\text { Posiciones } \\
\text { claves (teórico } \\
\text { y práctico) }\end{array}$ & & s/. 200.00 \\
\hline & Sesión 4 & $\begin{array}{l}\text { Posiciones } \\
\text { claves (teórico } \\
\text { y práctico) }\end{array}$ & & s/. 200.00 \\
\hline \multirow{4}{*}{ MEDITACIÓN } & Sesión 1 & $\begin{array}{l}\text { Conocerme a } \\
\text { mí mismo } \\
\text { (teórico - } \\
\text { práctico) }\end{array}$ & \multirow{4}{*}{$\begin{array}{ll}\text { - } & \text { Velas } \\
\text { - } & \text { Colchonetas } \\
\text { - } & \text { Mantas } \\
\text { - } & \text { Cojines } \\
\text { - } & \text { Rosarzos } \\
\text { - } & \text { Aceites } \\
\text { - } & \text { Inciensos } \\
\text { - } & \text { Música } \\
& \text { relajante }\end{array}$} & s/. 200.00 \\
\hline & Sesión 2 & $\begin{array}{l}\text { Reconocer las } \\
\text { cosas que me } \\
\text { distraen (teórico } \\
\text { - práctico) }\end{array}$ & & s/. 200.00 \\
\hline & Sesión 3 & $\begin{array}{l}\text { Mi niño interior } \\
\text { (teórico - } \\
\text { práctico) }\end{array}$ & & s/. 200.00 \\
\hline & Sesión 4 & $\begin{array}{l}\text { Herramientas } \\
\text { para mejorar y } \\
\text { superar las } \\
\text { distracciones en } \\
\text { la vida (teórico } \\
\text { - práctico) }\end{array}$ & & s/. 200.00 \\
\hline \multirow{4}{*}{$\begin{array}{c}\text { PENSAMIENTO } \\
\text { POSITIVO }\end{array}$} & Sesión 1 & $\begin{array}{l}\text { Clasificación de } \\
\text { nuestros } \\
\text { pensamientos } \\
\text { (teórico - } \\
\text { práctico) }\end{array}$ & \multirow{4}{*}{$\begin{array}{l}\text { - Sillas } \\
\text { - } \quad \text { Proyector } \\
\text { - Computadora }\end{array}$} & s/. 200.00 \\
\hline & Sesión 2 & $\begin{array}{l}\text { El poder de los } \\
\text { pensamientos y } \\
\text { la palabra } \\
\text { (teórico - } \\
\text { práctico) }\end{array}$ & & s/. 200.00 \\
\hline & Sesión 3 & $\begin{array}{l}\text { Herramientas } \\
\text { para una } \\
\text { mentalidad } \\
\text { positiva (teórico } \\
\text { - práctico) }\end{array}$ & & s/. 200.00 \\
\hline & Sesión 4 & $\begin{array}{l}\text { Tu plan de vida } \\
\text { (teórico - } \\
\text { práctico) }\end{array}$ & & s/. 200.00 \\
\hline
\end{tabular}


ANEXO 4. Objetivos de los talleres mindfulness.

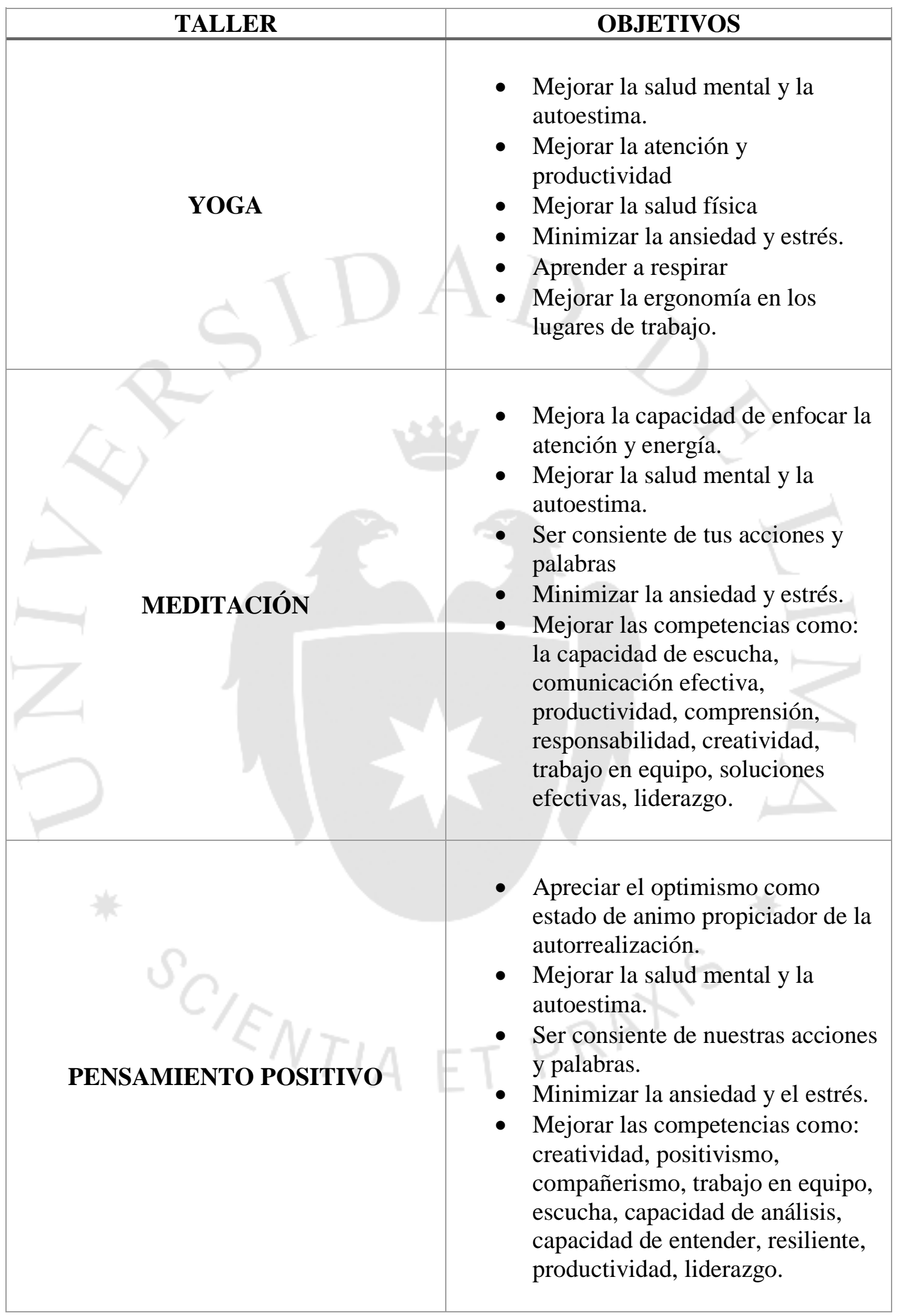

